\title{
Chironomidae (Insecta: Diptera) from the eastern Canadian Arctic and subarctic with descriptions of new life stages, a possible new genus, and new geographical records
}

\author{
A. Namayandeh, ${ }^{1,2}$ K.S. Heard, ${ }^{1,2}$ E.A. Luiker, ${ }^{1,2}$ J.M. Culp ${ }^{1-3}$ \\ ${ }^{1}$ Environment and Climate Change Canada; ${ }^{2}$ Department of Biology, University of New Brunswick; \\ ${ }^{3}$ Canadian Rivers Institute, Fredericton, NB, Canada
}

\begin{abstract}
Chironomidae larvae constituted the largest proportion of benthic invertebrates collected from 99 rivers stretching from northern Labrador (latitude $58^{\circ} \mathrm{N}$ ) to northern parts of Ellesmere Island
\end{abstract}

Correspondence: Armin Namayandeh, Environment and Climate Change Canada and Department of Biology, University of New Brunswick, 10 Bailey Drive, P0 Box 4400, E3B 5A3, Fredericton, NB, Canada.

E-mail: namayandeh@gmail.com

Key words: Chironomidae; International Polar Year; Environment Canada; taxonomy; diversity; benthic invertebrates; larva.

Acknowledgments: we would like to thank the field crew from Environment Canada, the Canadian Rivers Institute and the University of New Brunswick: Daryl Halliwell, Dave Hryn, Dr. Allen Curry, Mark Gautreau, Allison Ritcey, and Andrea Chute. We thank Parks Canada in the Torngat Mountains region including Angus Simpson, Tom Knight and Dave Cote. Craig Logan and Fonia Irvine aided with taxonomic identification. Our sincere thanks are extended to Mr. Bohdan Bilyj ofBIOTAX for taxonomic verifications and Dr. Bent Lauge Madsen for translation of German and Norwegian manuscripts. Many thanks to Dr. Bruno Rossaro of University of Milan and JEAR editorial staff. Our sincere thanks to our reviewers, including Dr. Wojciech Gilka of University of Gdansk, for their constructive comments and through examination of the paper.

Funding: this research was funded by the Canadian Government as part of an International Polar Year 2007-2009 grant to Dr. Joseph Culp.

Received for publication: 25 February 2016.

Revision received: 6 April 2016.

Accepted for publication: 6 April 2016.

(C) Copyright A. Namayandeh et al., 2016

Licensee PAGEPress, Italy

Journal of Entomological and Acarological Research 2016; $48: 5847$

doi:10.4081/jear.2016.5847

This article is distributed under the terms of the Creative Commons Attribution Noncommercial License (by-nc 4.0) which permits any noncommercial use, distribution, and reproduction in any medium, provided the original author(s) and source are credited. $\left(82^{\circ} \mathrm{N}\right)$. We describe 92 species of Chironomidae (mainly larval forms) providing new descriptions, a revision for the adult female of Parametriocnemus boreoalpinus Gowin et Thienemann, a possible new genus (larval form only), and 9 larval forms that may represent a new species. In addition, new geographical distribution records are specified for 1 Nearctic species, 6 species in Canada, 10 for Labrador, and 17 for Nunavut. This work contributes to Environment Canada's International Polar Year output (2007-2009).

\section{Introduction}

Chironomidae are a diverse group of aquatic organisms that generally make up a large proportion of aquatic insects in freshwaters, especially in Arctic regions (see Ferrington 2008). However, knowledge of the biogeography, taxonomy and ecology of this family remains poorly understood in Arctic freshwaters. It is beyond the scope of this paper to cover all the past Chironomidae research conducted in Arctic. In Arctic North America a portion of the past prominent investigations of Chironomidae are as follow: Hewitt's (1922), Oliver et al., (1978), Welch (1973, 1976), Butler's (1980, 1982a, b, 2000) Hershey's (1985a, b), Oliver and Dillon (1997), Kieffer's (1926), re-description of Kieffer's (1926) by Sæther et al., (1984), Edwards (1933, 1935a, 1935b) and Oliver (1964, 1968). Following these investigations taxonomic and ecological studies of Chironomidae in Arctic, especially in the eastern regions of Canada, have been in decline.

As part of an International Polar Year (IPY) project (2007-2009), we investigated macroinvertebrate communities in streams of the eastern Canadian Arctic to create a biodiversity database and to obtain environmental information from these Arctic rivers. Benthic invertebrates constituted a large portion of the biodiversity database, and Chironomidae larvae made up a large proportion of these benthos. Therefore, this collection presented an opportunity to examine the Chironomidae fauna from this region and to study the taxonomy, ecology and biogeography of the Chironomidae fauna of the eastern Arctic.

Here we describe 92 species of Chironomidae (mainly in larval form) from the IPY collections. Additionally, we re-describe the adult female of Parametriocnemus boreoalpinus Gowin et Thienemann, identify a possible new genus in the subfamily Orthocladiinae (larval stage only), and describe 9 larval forms that may represent a new species. This paper reports new records for 1 species in the Nearctic, 6 species in Canada, 10 species in Labrador, and 17 species in Nunavut, all of which may be of importance for the biogeographical studies of Chironomidae in the Holarctic region. 


\section{Study area, material and methods}

A total of 99 rivers and streams stretching from northern Labrador (latitude $\left.58^{\circ} \mathrm{N}\right)$ to Northern parts of Ellesmere Island $\left(82^{\circ} \mathrm{N}\right)$ were sampled from 2007 to 2009 (Figure 1). Regional sampling was undertaken in the Eastern sub-Arctic and Arctic Canada along a transect from latitudes $58^{\circ} \mathrm{N}, 59^{\circ} \mathrm{N}, 63^{\circ} \mathrm{N}, 72^{\circ} \mathrm{N}, 74^{\circ} \mathrm{N}, 81^{\circ} \mathrm{N}$ and $82^{\circ} \mathrm{N}$.

In terms of hydrology, streams were divided into 3 categories, nival, glacial and lake fed. For nival streams, hydrology is dominated by the spring melt, with high flows in late spring/summer, and then generally declining through the non-ice season. Watersheds with a significant portion of their area covered by glaciers had high flows at the height of summer, when glacial melt was at maximum. This glacial melt scenario was an important feature for Pond Inlet and Lake Hazen glacial rivers. Lake-fed streams had more constant flow throughout the open water period (Figures 2G-H). Table 1 provides the geographical location, type, and measured chemical and physical properties of the studied streams.

Benthic invertebrates were collected using a 3 min traveling kick net method following the Canadian Aquatic Biomonitoring Network (CABIN) standard (Reynoldson et al., 2007). The collection cups were then removed from the net and their contents emptied into one or more wide-mouth $500-\mathrm{mL}$ or $1-\mathrm{L}$ jars and preserved with $95 \%$ ethanol.

In addition to the Chironomidae larvae collected during the river benthic collection, we retrieved some pupae and adults in the samples to facilitate further taxonomical description and species level identification. Some of the pupal specimens retained their larval exuviae, which confirmed larvae identification. Other male or female pupae specimens were pharate and these aided in determination of mature stages. Initial chironomid taxonomic analysis was made using temporary, non-permanent slide preparation techniques. Therefore, many adult and pupae specimens in the collection were damaged or dried, making species level ta xonomic identification difficult. Considerable effort was made to repair and revive the mounted larval, pupae and adult specimens. Identifications were based on these revived and repaired specimens as best as possible; however, a complete description of some mature and immature specimens was not possible due to specimen condition. Nevertheless, taxonomic references are provided in the note sections for all species with the aim of facilitating future taxonomic investigations. Initial identifications of larvae were made based on Andersen et al. (2013) and Epler (2001). Additional, identifications were made based on various references including Bode (1983), Bolton (2007), Cranston (1982), Doughman (1983), Roback (1980, 1981), Oliver \& Dillon (1988), Makarchenko (1985), Moller Pillot (1984), Pankratova (1979), Sæther (1969, 1976), and Soponis (1977, 1990).

Repaired larvae and adult specimens were cleared and mounted based on methods described by Epler (2001) and Pinder (1978). Images were obtained by Nikon Digital Sight DS-Ril Camera mounted on Leica DM 2500 compound scope and Nikon SMZ 1500 stereoscope.

Geographical distribution records are taken from Ashe \& 0'Connor (2009, 2012), Hudson et al. (1990) and Oliver et al. (1990). We also cross checked the literature describing study species' taxonomy or ecology for corrections or additional geographical records which were not included in the references above. The produced subfamily key and generic diagnoses are only given for the larval stage. The number of specimens measured for larvae, pupae, and adults is indicated as (n). Unless otherwise indicated, all larval descriptions are $4^{\text {th }}$ instars. Table 2 contains additional diagnosis, measurements and ratios for the larvae. Numbers in the Table 2 represent the average value for the $4^{\text {th }}$ and, in some cases, younger instars of a given species. Voucher specimens were taken for all species collected and have been submitted to the Canadian National Collection of Insects, Arachnids and Nematodes in Ottawa, Canada.

\section{Results}

Report on new larval forms and the geographic distributional records are provided in Table 3 .

\section{Abbreviations}

Abbreviations for adult male, pupa and larva morphological characters are based on Sæther (1980). Exceptions are: a, b, c $1, c_{2}$, d from Fu \& Sæther (2012) referring to different measurments of hind tibia in adult male of Corynoneyra species; L setae in pupa, and L/W, $\mathrm{A}_{1-2}$ and $\mathrm{A}_{1} / \mathrm{M}$ of larva are taken from Roback (1976); DP and VP are taken from Andersen et al. (2013); HL and HW are head length and width. All abbreviations for adult female morphological characters are based on Sæther (1977a).

\section{Key to larvae of subfamilies and tribes of Chironomidae}

1a. Antenna long, retractile into head capsule. Ligula and MP well developed. Ligula toothed and MP with several stylets

Tanypodinae

1b. Antenna short, non-retractile into head capsule. Ligula and MP strongly reduced

2a. Procerci L/W at least 5. Premandible absent.............Podonominae

2b. Procerci LW rarely more than 4 . Premandible present 3

3a. VmP well-developed and with conspicuous striations, if without striations (i.e. in Stenochironomus) then plates raised laterally and fused to the maxillae throughout more than half their width.

..Chironominae (4)

3b. $\mathrm{VmP}$ vestigial to well-developed, if well-developed never with striations.

4a. Antenna subtended by distinct tubercles (pedestals). LO very large, conspicuous, or occurring at the apex of elongated stalks

Tanytarsini

4b. Antenna not subtended by distinct tubercles (pedestals). LO not large, not occurring at the apex of elongated stalks . ...5

5a. VmP straight, elongated, with more or less parallel-sided margins Pseudochironomini

5b. VmP usually fan-shaped, if elongate then anterior margins curved and tapering towards posterior margins . ..Chironomini

6a. Third antennal segment usually annulated Diamesinae

6b. Third antennal segment not annulated 7

7a. Antenna with 4 segments. VmP well-developed.....Prodiamesinae

7b. Antenna usually with 5 segments. VmP reduced if antenna 4-segmented. ..Orthocladiinae 


\section{Review of species}

\section{Subfamily Podonominae \\ Parochlus kiefferi (Garrett) \\ Larva $(n=1)$ \\ Figures 3A-F}

Description. Antenna 5 segmented, $4^{\text {th }}$ segment shorter than $3^{\text {rd }}$, the $3^{\text {rd }}$ segment annulated (Figure $3 \mathrm{~A}$ ), blade short and reaching the apex of $3^{\text {rd }}$ segment, $A R=1.9$. SI simple and strongly lamellate (Figure 3B), SII-SIII simple, SIII lamellate (Figure 3B). Pecten epipharyngis with 3 spine like scales. Mandible with 1 apical tooth and 5 inner teeth, $1^{\text {st }}$ inner teeth much larger than apical and other inner teeth (Figure 3C). Mentum with distinct trifid central tooth and 6 pairs of lateral teeth, $3^{\text {rd }}$ lateral teeth longer than $2^{\text {nd }}$ lateral (Figure 3D). Body with long single setae dorsally and laterally and bifid setae ventrally (Figure 3 E). Procercus small with 5-6 apical setae. Posterior parapods longer than wide each bearing group of claws and 1-2 simple long setae ( $\mathrm{L}=91.0 \mu \mathrm{m}$; Figure 3F).

Notes. Parochlus kiefferi is the only known Holarctic species within this genus. A single mounted specimen was found and repaired in this study. Many morphological features of the head overlap one another.

Sampling sites. McCormic Brook in Torngats Mountains National Park, N58 ${ }^{\circ} 59.1544^{\prime}$ W63 ${ }^{\circ} 47.8123$ '.

Ecology and habitats. Parochlus species were reported to inhabit cool spring and running waters (Brundin, 1983).

Nearctic distribution. CANADA: British Columbia, New Brunswick, Ontario, Quebec, Saskatchewan, and $1^{\text {st }}$ record for Labrador; GREENLAND; USA: Alaska, Arizona, California, Colorado, Maine, Massachusetts, Michigan, Minnesota, New Hampshire, New Mexico, New York, Oregon, Utah, Washington, and Wyoming.

\section{Trichotanypus posticalis (Lundbeck)}

Pupa $(n=1)$

Figures 4A-C

Description. Pupae small, $\mathrm{L}=3.0 \mathrm{~mm}$. Frontal setae small, $\mathrm{L}=34.0$ $\mu \mathrm{m}$. Thoracic horn long and cylindrical $\sim 4 \mathrm{X}$ as long as wide, stalk of horn with scattered spines and small plastron on top, respiratory atrium slender and cocoon like (Figure 4A). Wing sheath without nose, $\mathrm{L}=683.0 \mu \mathrm{m}, \mathrm{W}=233.0 \mu \mathrm{m}$. Abdomen appears flattened with weakly developed microsculptures (Figure 4B). Tergites I-VIII with 5 D setae, segment VIII with 5 long setae on apical lobe, segment IX with 2 long setae in mid-section and 1 short setae on apical portion. Anal lobes with outer surface serrated and 2 small setae on apical tips $(\mathrm{L}=156.0$ $\mu \mathrm{m}$; Figure $4 \mathrm{C})$. Genitalia sacs almost reaching the tip of anal lobes (Figure 4C).

Notes. Pupa is described by Makarchenko (1985).

\section{Larva $(n=1)$}

\section{Figures 5A-G}

Description. Antenna 5 segmented, $3^{\text {rd }}$ segment annulated (Figure 5B), blade shorter than flagellum reaching mid-point of segment 3 , accessory blade shorter than blade (Figure $5 \mathrm{~B}$ ), $\mathrm{R} 0$ at the base, $\mathrm{AR}=1.5$. SI and SII simple and prominent ( $\mathrm{Ls}=52.0 \mu \mathrm{m}$ and $61.0 \mu \mathrm{m})$ sit on tubercles ( $\mathrm{Ls}=26.0 \mu \mathrm{m}$ and $25.0 \mu \mathrm{m}$; Figure $5 \mathrm{C}$ ). Pecten epipharyngis with 4 short spines. Maxillary bisensilum located posteriorly. Mandible with 1 apical tooth and 5 inner teeth, apical tooth darker than inner teeth and shorter than the $1^{\text {st }}$ inner (Figure5D), seta interna branched (with 35-36 spines) and prominent (Figure 5D). Mentum with distinct retracted trifid median tooth and 12 pairs of lateral teeth (Figure $5 \mathrm{E}$ ), SSm long and well posterior to the mentum, SSm reaches above the apex of the mentum. Long prominent body setae (Figure 5G).
Procercus distinctly long, darker on anterior margins with 6 long apical setae (Figures 5F-G). Anterior margin of posterior parapods with several spines, blades of posterior parapods simple, elongate and hooklike. 4 anal tubules present, dorsal tubules sub-equal to posterior parapods and ventral shorter (Figure 5G).

Notes. Larva described by Makarchenko (1985). The specimen obtained is probably $3^{\text {rd }}$ instar larva and was not associated with the pupa described above, although it was collected from the same stream.

Sampling sites. Tributary of Ruggles River in Lake Hazen area, N81 ${ }^{\circ} 43.14199^{\prime}$ W69 ${ }^{\circ} 25.512$ '.

Ecology and habitats. Larvae of Trichotanypus species occur in moss and in lotic and lentic environment (Sæther \& Andersen, 2013).

Nearctic distribution. CANADA: Nunavut; GREENLAND; USA: New York.

Notes. According to Sæther \& Andersen (2013) T. posticalis is the only species of this genus and has its widest distribution in the Holarctic.

\section{Subfamily Tanypodinae \\ Procladius (Holotanypus) sp. \\ Larva $(n=1)$ \\ Figures 6A-I}

Description. Head capsule yellowish-brown and even colored (Figure 6A), HL/HW=1.06. DP, S7 and S8 in less an angle and more of a straight line to each other (Figure 6B). Antenna retractile, 4 segmented antennal blade sub-equal to flagellum (Figure 6C), antennal pedestals with large spine (Figure $6 \mathrm{C}$ ) $\mathrm{AR}=6.9$. MP is short and stout with its setae longer than $B$ sensillum, ring organ close to the center (Figure 6D). Mentum and m-appendage well- developed with 8 dorsomental teeth on each side (Figure 6E). Pseudoradula straight with lines parallel. Ligula dark (brownish-black) with 5 teeth increasing in size from centre (Figure 6E), paraligula pinnate with 5-6 small blades and a central blade of longer and larger size (Figure 6E). Mandible curved, with long apical tooth that is darkened at the tip and cone shaped mola (Figure 6F). Body with fringe of setae more prominent in segments 2-5. Procercus long with 19-20 long apical setae, darker in ventral side (Figures 6G-H). Posterior parapods 2.3X longer than anal tubules (Figure $6 \mathrm{H}$ ), posterior parapods bear 2 long setae $(\mathrm{L}=236.0$ $\mu \mathrm{m})$ posteriorly, smallest claws of posterior parapods hook-like, larger claws with hair-like inner extensions (Figure 6I).

Notes. Larvae of Procladius (Holotanypus) were described as Procladius (Psilotanypus) by Roback (1980). The combination of a larger central blade of the paraligula, angulated S7, S8 and DP, and hair-like inner extensions of the posterior parapods' longer blades separate this subgenus from others.

Sampling sites. Salor Creek in Lake Hazen area, N81 ${ }^{\circ} 54.156$ W68 54.457 '.

Ecology and habitats. Larvae of this subgenus are found in lakes, ponds and streams. According to Roback (1980), larvae of this subgenus occur in running waters with $\mathrm{pH}$ of 4.1-8.0, hardness of 50-260 $\mathrm{ppm}$, conductivity $100-500 \mathrm{~s} / \mathrm{cm}$, and water temperature of $8-28^{\circ} \mathrm{C}$.

Nearctic distribution. CANADA: Nunavut.

\section{Thienemannimyia group}

Group description. Ventral hypostomal groove present. MP with 7 stylets, sensillum b 2-3 segments (Figures 7C, 8D). R0 in distal third of the $1^{\text {st }}$ antennal segment, antenna with blade sub-equal to slightly longer than flagellum, $A R=3-6$. Mandible with curved and small to weak inner tooth (Figures 7G, 8G). M-appendage with pseudoradula more or less straight with prominent granulation, dorsomentum with two pointed teeth. Ligula with 5 teeth, inner laterals teeth out-turned (Figures 7I, 8F). Abdomen with simple hairs. Procercus L/W 3-4, with 7 apical 
hairs. Anal tubules elongate and conical (Figures 7J-K). Posterior parapod with 15 regular sized claws.

Notes. Fourth instar larvae are required for species diagnosis in this group. Detailed examination of the group is given by Roback (1981), and by Fittkau \& Roback (1983). In this study we present descriptions for two species within this group; Conchapelopia and Thienemannimyia. Conchapelopia was originally a subgenus of Thienemannimyia (Roback, 1981) and is distinguished from Thienemannimyia by having a 3-segmented b-sensillum. Larvae of both species described in this study have larger AR (i.e., >5.2) than species described for this group.

\section{Conchapelopia sp. A}

Larva $(n=2)$

Figures 7A-K

Description. Larva is large, $\mathrm{L}=8-10 \mathrm{~mm}$ (Figure $7 \mathrm{~A}$ ). $\mathrm{HL}=817.2 \mu \mathrm{m}$ (Figure 7B). S9 and S10 are very close forming a triangle with VP, S9 and S10 in straight line with SSm (Figure 7C). Antenna 4 segmented, $1^{\text {st }}$ segment very long, $3^{\text {rd }}$ segment slightly longer than $4^{\text {th }}$, blade shorter than flagellum reaching the basal $1 / 3^{\text {rd }}$ of the $3^{\text {rd }}$ segment (Figure 7DE), R0 located on anterior $2 / 3^{\text {rd }}$ of the basal segment, $A R=5.3$. MP with b-sensillum 3 segmented (Figure 7F), basal MPL $=63.0 \mu \mathrm{m}$, MPL/MP at $\mathrm{RO}=4.7$. Mandible with 1 long apical tooth, small inner tooth and large MF (Figure 7G), apical tooth darkens at the tip, mola appears small. Pseudoradula straight, slightly broadens at the base with granules parallel-sided and increase in size closer to ligula (Figure $7 \mathrm{H}$ ), Mappendages and mentum (Figure 7I). Ligula with 5 dark brown teeth, inner teeth out-turned, paraligula bifid (Figure 7I). Body with scattered large setae ( $\mathrm{L}=370.0 \mu \mathrm{m}$; Figures 7A-J). Anterior parapods with simple claws. Posterior parapods longer than anal tubules $(\sim 2 \mathrm{x})$ each bearing simple claws (Figures 7J-K), spines located posteriorly on posterior parapods and extend to claws (Figure 7K). Procercus long, sclerotized dorsally each bearing 6 long $(\mathrm{L}=930.0 \mu \mathrm{m})$ apical setae.

Notes. Larvae examined in this study are longer than the described Nearctic species of Conchapelopia (see Roback, 1981) and resemble Helopelopia. Larvae of the Conchapelopia species are very similar to Helopelopia. Cranston \& Epler (2013) suggested that Helopelopia could be placed into Conchapelopia as a subgenus. The combination of broad pseudoradula, A1 $<375 \mu \mathrm{m}$, basal MP $<70 \mu \mathrm{m}$ places the larvae in Conchapelopia. The larvae in this study may represent a new species.

Study site. Burton River in Baffin Island, N63 ${ }^{\circ} 52.800384^{\prime}$ W68 ${ }^{\circ}$ 18.894168'. Nearctic distribution. CANADA: Nunavut.

\section{Thienemannimyia sp.}

Larva $(n=1)$

\section{Figures 8A-G}

Description. Larva medium size, $\mathrm{L}=6.5 \mathrm{~mm}$. $\mathrm{HL}=720 \mu \mathrm{m}$. $\mathrm{S} 9$ and S10 are close forming a triangle with VP, S9 and S10 not in an exact straight line with SSm (Figure 8A). S7 and S8 close together, S8 parallel with DP forming an almost right-angled triangle with S7, S5 anterior to DP (Figure $8 \mathrm{~B}$ ). Antenna 4 segmented, $1^{\text {st }}$ segment long, $3^{\text {rd }}$ segment longer than $4^{\text {th }}$, blade shorter than flagellum reaching the base of the $3^{\text {rd }}$ segment (Figure $8 \mathrm{C}$ ), R0 located on anterior $2 / 3^{\text {rd }}$ of the basal segment, AR=5.7. MP with b-sensillum 2 segmented (Figure 8D), basal MP $50.6 \mu \mathrm{m}, \mathrm{MPL} / \mathrm{MPW}$ at $\mathrm{R} 0=5.3$. Pseudoradula straight with granules parallel-sided and increase in size closer to ligula (Figure 8E). Ligula with 5 dark brown teeth, inner teeth out-turned, paraligula bifid (Figure 8F). Mandible with 1 long apical tooth, small inner tooth (Figure 8G), apical tooth darkens at the tip, mola appears small. Body with scattered setae $(\mathrm{L} \sim 211 \mu \mathrm{m})$. Anterior parapods with simple claws. Posterior parapods longer than anal tubules each bearing simple claws (Figure 8G). Procercus longer than wide, sclerotized dorsally each bearing 7 long $(\mathrm{L} \sim 796 \mu \mathrm{m})$ setae.
Notes. Larva could be Thienemannimyia fusciceps (Edwards) based on the geographical records (Ashe \& 0'Connor, 2009).

Study sites. Nakvak River in Saglek, N58 $39.449^{\prime}$ W63 $35.944^{\prime}$; unnamed creek near Iqaluit airport in Baffin Island, N63 ${ }^{\circ} 75.0866^{\prime}$ W68 ${ }^{\circ}$ 53.172 '.

Nearctic distribution. CANADA: Nunavut, Labrador.

\section{Subfamily Diamesinae \\ Diamesa Meigen}

Generic description. Five segmented antenna, antennal segment 5 is longer than $4^{\text {th }}$, antennal segment 3 annulated (Figures 9B, 15B). 5 segmented pecten epipharyngis (Figure 9C), SI simple, SIII simple, bifid or bifid-branched. Mentum with single or double median tooth and 7-11 pairs of lateral teeth (Figures 9E, 11F, 15D). Mandible with 1 apical tooth and 4 inner teeth. Premandible with 5-7 teeth and branched spine (Figure 11C). Reduced to absent procercus.

Notes. All 3 described larvae in this study have simple SIII. The characteristic of mentum and AR can partially separate the 3 Diamesa larvae described in this study. Diamesa amplexivirilia Hansen has a mentum with notched to bifid median tooth with 20 lateral teeth and $\mathrm{AR}=1.3$. Diamesa arctica (Boheman) has a mentum with small single median teeth, 19 lateral teeth, and AR=1.8. Diamesa spinacies Sæther has a large median tooth with 20 lateral teeth and $A R=2.2$.

\section{Diamesa amplexivirilia Hansen}

Larva $(n=5)$

\section{Figures 9A-H}

Description. Larva $\mathrm{L}=3.6 \mathrm{~mm}$ (Figure $9 \mathrm{~A}$ ). Antenna 5 segmented, $3^{\text {rd }}$ segment longer than $4^{\text {th }}$ and annulated (Figure 9B), blade shorter than flagellum, AR=1.3. Pecten epipharyngis with 5 scales (Figure 9C). Premandible with 6-7 teeth. Mandible with 1 short apical tooth (same size as inner teeth) and 4 inner teeth, seta interna with 27-28 long serrated branches (Figure 9D). Mentum with bifid median tooth and 11 pairs of lateral teeth (Figure 9E), VmP small but visible (Figure 9E), SSm posterior to mentum and long. Abdominal setae are present, setae are about $1 / 10^{\text {th }}$ of the segments which bearing them. Procercus well reduced each bearing 5 apical setae and 1 sub-apical setae (Figure 9F). Anal tubules small and tubular (Figure 9G). Posterior parapods longer than wide each bearing group of claws (Figures 9G-H).

Notes. Larva is described by Makarchenko (1985).

Sampling sites. Tributary of Marla River in Borden Peninsula, N72 ${ }^{\circ}$ $57.408^{\prime} \mathrm{W} 81^{\circ} 12.207$ '.

Ecology and habitats. D. amplexivirilia is a circumpolar species with a range from the low Arctic to mountain regions of the northern Holarctic. Larvae live in cold, small bodies of flowing water including streams originating from glaciers (Oliver \& Dillon, 1997). Mating of the adults occurs on the ground or other exposed substrate.

Nearctic distribution. CANADA: Alberta, British Columbia, and $1^{\text {st }}$ record for Nunavut; USA: Montana and Washington.

\section{Diamesa arctica (Boheman)}

Pupa $(n=1)$

\section{Figures 10A-F}

Description. Pupa medium size, $\mathrm{L}=3.5 \mathrm{~mm}$. Frontal apotome with frontal setae $141 \mu \mathrm{m}$ (Figure 10A). Thoracic horn long ( $\mathrm{L}=79.0 \mu \mathrm{m}$ $\mathrm{W}=19.0 \mu \mathrm{m}$ ), gradually becoming slender with the tip flat (Figure 10B). Abdomen with segment I without shagreens, segments II with patches of shagreens on median and laterals, segments III-VIII with median and lateral shagreens continuous on anterior half and lateromedially on the posteriors (Figure 10C), segment IX with shagreen on anterior half. Tergite II without spine, Tergite III-VIII with large spines gradually 
increasing in size (Figure $10 \mathrm{D}$ ). Tergite I-VII with 5 D setae, VIII with 2D setae and $4 \mathrm{~L}$ setae (Figure $10 \mathrm{E}$ ). Anal lobes with 3 apical setae of equal size (Figure 10F).

Notes. Pupa is described by Makarchenko (1985). A puparium specimen of this species was obtained which is smaller than the description given by Makarchenko (1985) (i.e. $\mathrm{L}=6.5-7 \mathrm{~mm}$ ). The frontal setae is also longer than the description given by Makarchenko (1985) (i.e. $\mathrm{L}=92.0-96.0 \mu \mathrm{m})$. However, other characters (e.g., thoracic horn) match the description.

\section{Larva $(n=2)$}

\section{Figures 11A-G}

Description. Larva L=3.9mm (Figure 11A). Antenna 5 segmented, $3^{\text {rd }}$ segment longer than $4^{\text {th }}$ and annulated, blade longer than flagellum (Figure 11B), AR=1.8. SI simple and lamellate, SII simple, SIII with multiple branches. Pecten epipharyngis with 5 scales. Premandible with 6 teeth and its lateral spine with 9-10 branches with at least two of the branches bifid (Figure 11C). Mandible with 1 small apical tooth and 4 inner teeth (Figure 11D), apical tooth almost the same size as $1^{\text {st }}$ inner teeth, SSd small, setae interna with 27-28 serrated branches. Maxilla (Figure 11E). Mentum with 1 median tooth and 19 lateral teeth (Figure $11 F)$, median tooth and $1^{\text {st }}$ three pair of the laterals appear in same plane giving the mentum a truncated appearance, $\mathrm{VmP}$ small and visible (Figure 11F), SSm posterior to mentum. Abdominal setae present, about $1 / 20^{\text {th }}$ of the segment which bearing them. Procercus reduced each bearing 4 apical setae (Figures 11G-H). Anal tubules small and tubular. Posterior parapods long each bearing group of claws (Figures 11G-H).

Notes. Makarchenko (1985) described the larvae of this species.

Sampling sites. Utuk River tributary in Pond Inlet area, N72 $2^{\circ} 36.988^{\prime}$ W78 7.878'; an unnamed stream in Resolute Bay, N74 ${ }^{\circ} 44.809^{\prime}$ W94 ${ }^{\circ}$ 47.688'; Blister Creek in Lake Hazen area, N81 ${ }^{\circ} 49.1470^{\prime}$ W71 ${ }^{\circ} 31.741^{\prime}$.

Ecology and habitats. Kurek (1966) indicated that this species has a diurnal periodicity in its emergence with peak emergence in the afternoon when species can experience higher light intensity and warmest temperatures.

Nearctic distribution. CANADA: Nunavut; USA: Alaska.

\section{Diamesa bertrami Edwards}

Pharate male $(n=6)$

\section{Figures 12A-K}

Description. Pharate male $\mathrm{TL}=3.6 \mathrm{~mm}$. Head and thorax brown, lighter in abdomen. Antenna plumose with 13 flagellomeres (Figure $12 \mathrm{~A})$, ultimate flagellomere with short sub-apical setae $(\mathrm{L}=55.0 \mu \mathrm{m}$; Figure 12B), shaft starts at $4^{\text {th }}$ segment. $A R=1.35$. Eyes pubescent, microtrichia longer than ommatidium (Figure 12C), dorsomedial portion of the eyes short (Figures 12A, 12C). Cornua of cibarial pump pointed (Figure 12D). Palpomere 5 segmented $\left(\mathrm{L}_{1-5}=33 \mu \mathrm{m}, 29 \mu \mathrm{m}, 60\right.$ $\mu \mathrm{m}, 69 \mu \mathrm{m}, 87 \mu \mathrm{m})$. Acrostichals absent, dosrocentrals in 1 row regularly spaced, scutellars in 3 rows and scattered (Figure 12E). Hind tibia with large comb and 2 spine (Figure 12F), combs in mid and fore legs reduced to few hair like structures, $4^{\text {th }}$ tarsomere cordiform (Figure 12G), pulvillus as in Figure 12H, pseudospurs are present on $\mathrm{t}_{1-2}$ of all legs. Well-developed median field with protruded ventromedial portion appearing triangular (Figure 12I), setae of median field are short and even-sized. Gonostyle club shaped about $0.5 \mathrm{X}$ length of gonocoxite (Figures 12J-K). HR=1.5, HV=2.7.

Legs lengths $(\mu \mathrm{m})$ and proportions:

\begin{tabular}{lccccccccccc} 
& $\mathbf{f e}$ & $\mathbf{t i}$ & $\mathbf{t a}_{\mathbf{1}}$ & $\mathbf{t a}_{\mathbf{2}}$ & $\mathbf{t a}_{\mathbf{3}}$ & $\mathbf{t a}_{\mathbf{4}}$ & $\mathbf{t a}_{\mathbf{5}}$ & $\mathbf{L R}$ & $\mathbf{B V}$ & $\mathbf{S V}$ & $\mathbf{B R}$ \\
\hline P1 & 488 & 519 & 359 & 184 & 140 & 84 & 116 & 0.7 & 2.6 & 2.8 & 1.5 \\
P2 & 494 & 494 & 268 & 163 & 111 & 73 & 94 & 0.5 & 2.9 & 3.7 & 2.0 \\
P3 & 525 & 723 & 407 & 253 & 157 & 80 & 125 & 0.6 & 2.7 & 3.1 & 2.3
\end{tabular}

Notes. Adult male is described by Hansen \& Cook (1976). Hypopygium of this species is similar to Diamesa chorea Lundbeck. Adult males from the two species are only distinguished by the presence of microtrichia on the eyes of the $D$. bertrami.

\section{Pharate female $(n=2)$}

\section{Figures 13A-H}

Description. Pharate female TL=3.7 $\mathrm{mm}$. Antenna 8 segmented, ultimate segment with 2 apical setae $\mathrm{L}=42 \mu \mathrm{m}$ (Figure $13 \mathrm{~A}$ ), $\mathrm{AR}=0.55$. Eyes pubescent, microtrichia extending beyond ommatidium (Figure 13B). Palpomere 5 segmented (L1-5=30.0 $\mu \mathrm{m}, 30.0 \mu \mathrm{m}, 45.0 \mu \mathrm{m}, 62.0$ $\mu \mathrm{m}, 105.0 \mu \mathrm{m}$; Figure 13C). Cornua of cibarial pump pointed (Figure 13C). Acrostichals absent, dosrocentrals in 1 row regularly spaced, scutellars in 3 rows. Hind tibia with large comb and 2 spine (Figure 13D), combs in mid and fore legs short reduced to few hair like structures, $4^{\text {th }}$ tarsomere cordiform. GP VIII with large ventrolateral lobe covering smaller dorsomesal lobe and 8 spine like setae (Figure 13E). TIX with 32 setae. Ce pediform $\mathrm{L}=65.0 \mu \mathrm{m}$ and $\mathrm{W}=35.0 \mu \mathrm{m}$ (Figures $13 \mathrm{~F}-\mathrm{G}$ ). 2 semi-oval seminal capsules (Figure $13 \mathrm{H}$ ), $\mathrm{L}=38.0 \mu \mathrm{m}$ and $\mathrm{W}=25.0 \mu \mathrm{m}$.

Legs lengths $(\mu \mathrm{m})$ and proportions:

\begin{tabular}{lccccccccccc} 
& $\mathbf{f e}$ & $\mathbf{t i}$ & $\mathbf{t a}_{\mathbf{1}}$ & $\mathbf{t a}_{\mathbf{2}}$ & $\mathbf{t a}_{\mathbf{3}}$ & $\mathbf{t a}_{\mathbf{4}}$ & $\mathbf{t a}_{\mathbf{5}}$ & $\mathbf{L R}$ & $\mathbf{B V}$ & $\mathbf{S V}$ & $\mathbf{B R}$ \\
\hline P1 & 587 & 660 & 375 & 206 & 165 & 92 & 123 & 0.6 & 2.8 & 3.3 & 2.0 \\
P2 & 423 & 553 & 268 & 167 & 132 & 78 & 120 & 0.5 & 2.5 & 3.6 & 1.6 \\
P3 & 671 & 710 & 455 & 295 & 178 & 93 & 129 & 0.6 & 2.6 & 3.0 & 1.8
\end{tabular}

Notes. Female described by Serra-Tosio (1971).

\section{Pupae $(n=8)$}

\section{Figures 14A-F}

Description. Pupa medium size, $\mathrm{L}=3.6 \mathrm{~mm}$. Frontal setae $\mathrm{L}=144 \mu \mathrm{m}$ (Figure 14A). Thoracic horn with the tip pointed (Figure 14B). Abdomen with segment I without shagreens, segments II-VI with patches of shagreens on median and lateral sections, separated on posterior, shagreens not visible on anterior portion, segments VII-VIII with shagreens on both posterior and anterior portions, segment IX with shagreen on anterior half. Tergite III-VIII with large spines. Sternite II-III without spine. Segments III-VII with 5 D setae, segment VIII with 3D setae, segment II with 2 ventral L setae, segments III-VIII with 4 L setae (Figures 14C-D). Anal lobes with 3 apical setae of equal size $\mathrm{L}=260 \mu \mathrm{m}$, male genitalia sacs longer than anal lobes and females shorter (Figures 14E-F).

Notes. Pupa is described by Serra-Tosio (1971). Larva of this species is described by Rossaro \& Lencioni (2015a, b).

Study sites. Torr Bay Brook in Torngats Mountains National Park, N58 ${ }^{\circ} 27.944^{\prime}$ W62 ${ }^{\circ} 49.287$ '.

Ecology and habitat. Among cold stenothermic species of Diamesa, the $D$. bertrami is considered to be the most tolerant species (Rossaro, 1991a). Results of 40 years of Alpine glacier investigation by Rossaro \& Lencionni (2016) indicated that larvae prefers the kryal and krenal habitats of upper reaches of glacier streams and they may have a potential as indicator for glacier retreats. Larvae have temperature optima of $3.5 \pm 1.3^{\circ} \mathrm{C}$ and $\mathrm{pH}$ optima of $6.1 \pm 0.44$ (Rossaro et al., 2006).

Nearctic distribution. $1^{\text {st }}$ record for CANADA: Labrador; GREENLAND.

\section{Diamesa spinacies Sæther}

Larva $(n=3)$

\section{Figures 15A-F}

Description. HL/HW=1.3, head capsule as in Figure 15A. Antenna 5 segmented, $3^{\text {rd }}$ segment annulated (Figure 15B), blade shorter than flagellum, AR=2.2. SI-SIII simple. Pecten epipharyngis with 5 scale. Premandible with 6 teeth. Mandible with 1 apical tooth and 4 inner teeth (Figure 15C). Apical teeth sub-equal to $1^{\text {st }}$ inner but thinner, seta interna 
with 29-30 branches. Mentum with 1 large median tooth and 20 lateral teeth (Figure 15D), inner tooth and $1^{\text {st }}$ two lateral form a dome. Procercus vestigial each bearing 6-7 short apical setae (Figures 15E-F). Posterior parapods longer than anal tubules each bearing group of brown claws (Figure 15F).

Notes. Larva is described by Doughman (1983).

Study sites. Tributary of Ruggles River in Lake Hazen area, N81 ${ }^{\circ}$ $43.141^{\prime} \mathrm{W} 69^{\circ} 25.512$ '.

Nearctic distribution. CANADA: Alberta, and $1^{\text {st }}$ record Nunavut; USA: Alaska.

\section{Pagastia orthogonia Oliver \\ Larva $(n=2)$}

Figures 16A-G

Description. Head light yellow and without marking, head capsule elongated (Figure 16A). Antenna 5 segmented, $5^{\text {th }}$ segment longer than $4^{\text {th }}, 3^{\text {rd }}$ segment annulated (Figure $16 \mathrm{~B}$ ) AR=0.92, LO as long as $3^{\text {rd }}$ segment, RO at the base. SI and SIII simple, Pecten epipharyngis with 3 narrow scales. Premandible with 5 teeth and small spine (Figure 16C). Mandible with elongated apical tooth and 4 inner teeth. Apical tooth slightly longer than combined length of inner teeth, SSd small (Figure 16D), seta interna with 5 branches. Mentum with no median teeth, 4-6 projections and 6-7 lateral teeth (Figures 16E-F), VmP well developed covering the lateral teeth (Figures 16E-F). Procercus present with 7-8 apical setae and 2 sub-apical setae (Figure 16G).

Notes. The teeth of the mentum are often difficult to detect. This is because of the dark and over bearing ventromental plates. Epler (2001) notes that mandible of $P$. orthogonia is similar to that of the western Nearctic species Pagastia sequax (Garrett). Lack of markings on the head capsule separates the larvae of this species from $P$. sequax. $P$. orthogonia AR is $<1.2$ which separates it from other known Holarctic species (Makarchenko \& Makarchenko, 2000).

Sampling sites. Unnamed creek in Iqaluit, Baffin Island $\mathrm{N}^{\circ}{ }^{\circ}$ 45.096' W78 31.340'.

Ecology and habitats. Larvae of Pagastia inhabit small streams.

Nearctic distribution. CANADA: $1^{\text {st }}$ record for Nunavut, Prince Edward Island; USA: Alaska, Georgia, Michigan, North Carolina, North Dakota, Ohio, and Tennessee.

\section{Pseudodiamesa (Pseudodiamesa) branicki (Nowicki) \\ Pharate male $(n=2)$ \\ Figure 17A-J}

Description. Pharate male TL=7.5 mm. Eyes bear with parallel-sided dorsomedial extension (Figure 17A). Antenna 14 segmented, AR=2.5. Clypeus with $48-50$ bristle (Ls=66.0-76.0 $\mu \mathrm{m}$. 17B). Palpomere 5 segmented, $5^{\text {th }}$ segment longer than $4^{\text {th }},\left(\mathrm{L}_{1-5}=80.3 \mu \mathrm{m}, 110.8 \mu \mathrm{m}, 116.0 \mu \mathrm{m}\right.$, $162.3 \mu \mathrm{m}, 306.0 \mu \mathrm{m})$. Dorsocentrals present in multiple rows ( $42-44$ bristle in total). Fore tibia with 1 spur $(\mathrm{L}=119.4 \mu \mathrm{m})$, mid tibia with 2 spurs $\left(\mathrm{L}_{1-2}=94.0 \mu \mathrm{m}, 98.0 \mu \mathrm{m}\right)$, hind tibia with 2 spurs $\left(\mathrm{L}_{1-2=}=90.0 \mu \mathrm{m}, 128.0 \mu \mathrm{m}\right)$ and comb (Figures 17C-D), Pseudospurs present (detectable on ta $\mathrm{ta}_{1}$ and $\mathrm{ta}_{2}$ ). Segments I-VIII with multiple scattered setae (Figure 17E), tergite IX with 2 white patch containing around 25 long setae (Figure 17F). Sternapodeme tick and convex (Figure 17G) Anal point narrow and pointed, $\mathrm{L}=184.0 \mu \mathrm{m}$ (Figure 17H). Gonostyle racket shape widest at mid-point (Figures 17I-J), megasetae $\mathrm{L}=33.6 \mu \mathrm{m}$. HR=1.0, HV=1.1.

Notes. Adult male is described by Makarchenko (1985). Fore and mid tarsus are missing in both specimens.

Legs lengths $(\mu \mathrm{m})$ and proportions:

\begin{tabular}{lccccccccccc} 
& $\mathbf{f e}$ & $\mathbf{t i}$ & $\mathbf{t a}_{\mathbf{1}}$ & $\mathbf{t a}_{\mathbf{2}}$ & $\mathbf{t a}_{\mathbf{3}}$ & $\mathbf{t a}_{\mathbf{4}}$ & $\mathbf{t a}_{\mathbf{5}}$ & $\mathbf{L R}$ & $\mathbf{B V}$ & $\mathbf{S V}$ & $\mathbf{B R}$ \\
\hline P1 & 978 & 973 & 644 & - & - & - & - & 0.7 & - & 3.0 & - \\
P2 & 1088 & 930 & 492 & 279 & 212 & - & - & 0.5 & - & 4.1 & - \\
P3 & 1153 & 1909 & 962 & 515 & 331 & 199 & 228 & 0.5 & 3.2 & 3.2 & 1.8
\end{tabular}

\section{Pupae $(n=2)$}

Figures 18A-D

Description. Thoracic horn absent. Tergite I with posterior shagreen (Figure $18 \mathrm{~A}$ ), tergites II-VIII with median shagreens (Figures 18A-B), tergites I-VII with 5 D setae (Figure 18B), tergite VIII with 2 D setae $(\mathrm{L} \approx 73.0 \mu \mathrm{m})$. Segment I with $2 \mathrm{~L}$ setae, segments II-VIII with $4 \mathrm{~L}$ setae (L $\approx 170.0 \mu \mathrm{m}$; Figures 18B-C). Sternite 1 with $2 \mathrm{~V}$ setae, sternites II-VII with apparently $3 \mathrm{~V}$ setae, VIII with $2 \mathrm{~V}$ setae. Anal lobes with 3 equal macrosetae ( $\mathrm{L}=435.0 \mu \mathrm{m}$; Figures18C-D), male genitalia sacs not extending beyond the anal lobes (Figures 18C-D).

Notes. Pupa is described by Makarchenko (1985). Frontal setae and thorax regions are not discernible in the specimens. Therefore, the pupa diagnosis is only given for abdominal region. Pupae and pharate male were recovered from dried specimen.

\section{Larva ( $n=1)$}

\section{Figures 19A-K}

Description. Larva L=11.6mm (Figure 19A). Head capsule yellowish white (Figure 19B), HL/HW=1.3. Antenna 5 segmented, segment 5 longer than $4^{\text {th }}, 3^{\text {rd }}$ segment annulated (Figure 19C), AR=2.6. SI simple and lamellate (Figure 19D), SIII simple. Pecten epipharyngis with 7 scale. Maxilla palp as (Figure 19E), chaetula of palpiger spine-like and pointed. Premandible with 8 teeth, spine present on outer ridge (Figure 19F). Mandible with 1 apical tooth and 4 inner teeth and (Figure 19G) apical tooth smaller than combined inner teeth, SSd present and small, outer ridge of mandible with thick band. Mentum with single triangular median tooth and 7 pairs of lateral teeth (Figure 19H), median tooth shorter than $1^{\text {st }}$ laterals and lighter than laterals, $1^{\text {st }}$ and $2^{\text {nd }}$ laterals partially fused and appear bifid (Figure 19H), VmP well-developed covering $3^{\text {rd }} 7^{\text {th }}$ lateral teeth (Figure $\left.19 \mathrm{H}\right)$, SSm well posterior to mentum with long setae (Figure 19H). Small procercus present each bearing 7 apical setae and 2 sub-apical setae (Figure 19I). Anal tubules present reaching $3^{\text {rd }}$ of the posterior parapods (Figure 19J). Posterior parapods longer than wide with group of simple dark claws (Figures 19J-K).

Notes. Well-developed ventromental plates, and the lamellate and simple SI separates larva of this species from the other 3 known larvae in the Nearctic.

Sampling sites. Tributary of Apex River in Baffin Island, N63 ${ }^{\circ}$ 45.523' W68 27.493 '.

Ecology and habitats. Larvae of Pseudodiamesa are reported to inhabit springs, rivers and oligotrophic lakes (Sæther \& Andersen, 2013).

Nearctic distribution. CANADA: British Columbia, Alberta, and $1^{\text {st }}$ record for Nunavut; GREEANLAND; USA: California, Michigan and New Mexico.

\section{Pseudokiefferiella Zavřel}

Generic diagnosis. Antenna 5 segmented, $3^{\text {rd }}$ segment annulated (Figures 20A, 21A). SI and SIII are simples. Premandible with 5-6 teeth. Mandible with 1 apical 4 inner teeth. Mentum with 1 median and 5-7 pairs of lateral teeth (Figures 20C, 21D). Body with long setae (Figures 20D, 21E). Procercus longer than wide each bearing 6-8 apical and 2 sub-apical setae (Figure 20D).

Ecology and habitats. Larvae of Pseudokiefferiella inhabit small streams and springs.

\section{Pseudokiefferiella sp. 1 Doughman Larva $(n=1)$ \\ Figures 20A-E}

Description. Head capsule brown. Antenna 5 segmented, $3^{\text {rd }}$ segment annulated (Figure 20A) AR=2.5. SI and SIII simple. Premandible 
with 5 inner teeth. Mandible with 1 apical and 4 inner teeth, seta interna with 20-21 serrated branches (Figure 20B). Mentum with 3 median and 5 lateral teeth, median teeth and the $1^{\text {st }}$ two lateral teeth light, forming a separate plate, $2^{\text {nd }}-5^{\text {th }}$ lateral teeth darker (Figure 20C), SSm posteriad to mentum. Body with scattered long setae (Figure 20D). Procercus well-sclerotized each bearing 7 apical setae and 2 sub-apical setae (Figure 20E). Posterior parapods longer than anal tubules each bearing group of dark claws (Figure 20E).

Notes. Larva is described by Doughman (1983). Fourth instar larva obtained had a missing abdomen. Characteristic of posterior portion of the larva is based on a younger instar larva obtained in this study.

Study sites. Burton River in Baffin Island, N63 ${ }^{\circ} 52.800^{\prime}$ W68 ${ }^{\circ}$ 18.894'.

Nearctic distribution. CANADA: Nunavut; USA: Alaska.

Notes. This species has not been reported in Canada and represents a $1^{\text {st }}$ record for Canada and Nunavut.

\section{Pseudokeifferiella sp.}

Larva $(\mathrm{n}=1)$

\section{Figures 21 A-F}

Description. Head capsule brown. Antenna 5 segmented, $3^{\text {rd }}$ segment annulated (Figure 21A), blade as long as the flagellum, AR=1.94. SI and SIII simple. Pecten epipharyngis consist of 5 scales with median scale appearing to be smaller (Figure 21B). Labral lamella consist of 2 pectinate lobes (Figure 21B). Premandible with 5 inner teeth. Mandible with 1 apical and 4 inner teeth (Figure 21C). Mentum with 3 median teeth and 5 pairs of lateral teeth (Figure 21D), 3 median teeth and the $1^{\text {st }}$ two lateral teeth slightly lighter than remaining lateral teeth, SSm just below the mentum. Body with scattered long setae (Figure 21E). Procercus well-sclerotized each bearing 5-6 apical setae and no sub-apical setae (Figure 21F). Posterior parapods longer than anal tubules each bearing group of dark claws (Figure 21F).

Notes. The combination of lower AR (i.e. $<2$ ), darker mentum, and position of SSm to mentum separates this larva from Pseudokeifferiella sp. 1 Dougman.

Study sites. Unnamed river on the east side of Resolute Bay, N74 ${ }^{\circ}$ 44.809' W94 ${ }^{\circ} 47.688^{\prime}$.

Nearctic distribution. CANADA: Nunavut.

\section{Subfamily Orthocladiinae Chaetocladius Kieffer}

Generic diagnosis. Antenna 5 segmented with segment 3 shorter to sub-equal to $4^{\text {th }}$ (Figures 22B, 24A). SI simple, plumose, branched or serrated. Mentum with 1-2 median teeth and 5 pair of laterals (Figures $22 \mathrm{E}$ and $24 \mathrm{~F}$ ), $\mathrm{VmP}$ weak to well developed.

Notes. Larvae of Chaetocladius, Paraphaenocladius and Parametriocemus resemble each other. Chaetocladius can be separated from Paraphaenocladius and Parametriocemus based on SSms that are located near posterior of ventromental plates. In Paraphaenocladius and Parametriocemus SSms are located halfway down along the mentum. The combination of AR $<1$, a weakly sclerotized procerci, and short apical setae separates Paraphaenocladius larvae from that of Parametriocnemus.

\section{Chaetocladius (Chaetocladius) dentiforceps group Larva $(\mathrm{n}=2)$ \\ Figures 22A-F}

Description. Head capsule yellowish brown (Figure 22A), $\mathrm{HL} / \mathrm{HW}=1.1$. Antenna 5 segmented. segment 4 slightly longer than 3 (Figure 22B), blade short barely reaching middle of segment 4 (Figure 22B), L0 large and covering segment $3, \mathrm{AR}=1.8$. SI serrated, labral lamellae above SI. Maxilla pecten galearis vestigial, ALCh not distinct from other chaeta. Premandible bifid with accessory tooth (Figure 22C). Mandible with 1 apical and 4 inner teeth (Figure 22D), apical tooth slightly longer than inner teeth, SSd long and narrow, seta interna with 7-8 simple setae. Mentum with large median teeth and 5 pairs of laterals (Figure 22E), VmP is large and well-developed (Figure 22E). Procercus small as long as wide with each bearing 8 apical setae (Figure 22F). Anal tubules present and small. Posterior parapods are short with rows of claw (Figure 22F).

Sampling sites. Tributary of Turnabout River in Lake Hazen area, N82 ${ }^{\circ} 1.647^{\prime}$ W68 ${ }^{\circ} 43.978$ '. Muskox Creek in Lake Hazen area, N81 ${ }^{\circ}$ $50.332^{\prime}$ W71 ${ }^{\circ} 20.1820002$ '.

Nearctic distribution. CANADA: Nunavut.

\section{Chaetocladius (Chaetocladius) piger (Goetghebuer) \\ Male $(n=1)$ \\ Figures 23A-P}

Description. Male TL=3.9 mm. Eyes with short pubescence and short wedge-shaped dorsomedial extension (Figures 23A). Tentorium $\mathrm{L}=162$ $\mu \mathrm{m}$ (Figure 23B). Clypeus (Figures 23C-D) with 12 bristle (Ls=52-112 $\mu \mathrm{m})$. Palpomere 4 segmented $\left(\mathrm{L}_{1-4}=50 \mu \mathrm{m}, 97 \mu \mathrm{m}, 79 \mu \mathrm{m}, 144 \mu \mathrm{m}\right.$; Figure 23E). Thorax brown dorsally and ventrally, laterally light brown (Figures 23F-G), dorsocentrals present in single rows with 11-12 bristles (Figure 23G). Acrostichals with 5 short bristles, scutellum with white median portion and 5 bristles (Figure 23G). Wing L=2.4 mm (Figure 22H), $\mathrm{VR}=0.7$, Cul with slight sinuation (Figure $23 \mathrm{H}$ ), brachiolum with 1 bristle, $\mathrm{R}$ with 12 bristle. Mid and hind $\mathrm{t}_{1}$ with pseudospurs (Figure 23I), fore tibia with spur $\mathrm{L}=73 \mu \mathrm{m}$ (Figure $23 \mathrm{~J}$ ), comb absent on fore tibia, mid tibia with 2 spurs (Ls=30 $\mu \mathrm{m}$, and $15 \mu \mathrm{m}$; Figure $23 \mathrm{~K}$ ), comb absent on mid tibia, hind tibia with 2 spurs ( $(\mathrm{L}=66 \mu \mathrm{m}$ and $12 \mu \mathrm{m}$; Figure 23L), hind tibia with comb present. Tergites I-VIII with lateral and medial long setae (Figure 23M). Anal point $\mathrm{L}=92 \mu \mathrm{m}$ (Figure $23 \mathrm{~N}$ ), inferior volsella tongue shaped (Figure 230). Gonostyle club shaped with mega setae $\mathrm{L}=17 \mu \mathrm{m}$ (Figures 230-P). HR=2.0, HV=2.6.

Legs lengths $(\mu \mathrm{m})$ and proportions:

\begin{tabular}{lccccccccccc} 
& $\mathbf{f e}$ & $\mathbf{t i}$ & $\mathbf{t a}_{\mathbf{1}}$ & $\mathbf{t a}_{2}$ & $\mathbf{t a}_{3}$ & $\mathbf{t a}_{\mathbf{4}}$ & $\mathbf{t a}_{\mathbf{5}}$ & $\mathbf{L R}$ & $\mathbf{B V}$ & $\mathbf{S V}$ & $\mathbf{B R}$ \\
\hline P1 & 891 & 943 & 629 & 416 & 311 & 190 & 133 & 0.67 & 2.3 & 2.9 & 2.2 \\
P2 & 951 & 945 & 444 & 239 & 203 & 141 & 126 & 0.47 & 3.3 & 4.3 & 2.1 \\
P3 & 988 & 1067 & 566 & 333 & 268 & 158 & 127 & 0.53 & 3.0 & 3.6 & 3.1
\end{tabular}

Notes. Antennae are missing in this specimen. Male is described by Goetghebuer (1913) as Dactylocladius piger and by Sæther (1969) as Chaetocladius oliveri. Anal point of this specimen is longer than the described specimens by Sæther (1969).

\section{Larva $(n=5)$}

\section{Figures 24A-H}

Description. Antenna 5 segmented, segment 3 shorter than $4^{\text {th }}$ segment (Figure 24A), blade shorter than flagellum reaching end of $4^{\text {th }}$ segment, $A R=2.1$. SI serrate (Figure 24B), labral lamellae with apical teeth, located between SI. Premandible bifid (Figure 24C). MP as in Figure 24D, pecten galearis vestigial, ALCh distinct from other chaeta (Figure 24D). Mandible with 1 apical tooth and 4 inner teeth, apical tooth longer than $1^{\text {st }}$ inner, SSd large and appears hooked at the very tip (Figure 24E), seta interna with 8 branches. Mentum with broad double median teeth and 5 pairs of lateral (Figure 24F), VmP well-developed (Figure 24F), SSm posterior to mentum parallel to posterior edge of VmP. Procercus $2 \mathrm{X}$ as long as wide, each bearing 8 apical setae (Figure 24G). Anal tubules present about $1 / 2$ the parapods. Posterior parapods with group of claws (Figure $24 \mathrm{H}$ ).

Sampling sites. Tributary of Southwest Arm River, Saglek N58 ${ }^{\circ}$ 28.027' W63 ${ }^{\circ} 33.384$ '; Tributary of Borden River in Borden Peninsula 
N72 ${ }^{\circ} 44.098^{\prime}$ W80 23.135 ; Tributary of Salmon River in Pond Inlet area $\mathrm{N} 72^{\circ} 32.311^{\prime}$ W77 31.443 '; Unnamed stream in Resolute Bay area, N74 ${ }^{\circ} 44.809^{\prime}$ 'W94 ${ }^{\circ} 47.688$ '; Tributary of Very River in Lake Hazen area, N81 ${ }^{\circ} 32.950^{\prime} \mathrm{W}^{\circ}{ }^{\circ} 35.757^{\prime}$; Traverse River in Lake Hazen area, N81 ${ }^{\circ}$ $39.885^{\prime} \mathrm{W} 72^{\circ} 1.510^{\prime}$.

Ecology and habitats. Larvae of Chaetocladius are reported to occur in saturated soils, seep areas and in margins of small streams. In streams they occur among moss, algae, and detritus (Caldwell, 1997).

Nearctic distribution. CANADA: Ontario, Quebec, and $1^{\text {st }}$ record for Nunavut; USA: Connecticut, Georgia, Kansas, Kentucky, Michigan Minnesota, New York, North Carolina, North Dakota, Ohio, Pennsylvania, South Dakota, South Dakota, Tennessee, and Virginia.

Notes. The $C$. piger has a cosmopolitan geographical distribution in the Holarctic (Caldwell, 1997).

\section{Corynoneura Winnertz}

Generic description. Larva is small, $\mathrm{L}<4 \mathrm{~mm}$. Head capsule integuments smooth, weakly to strongly postulated or sculptured (Figure 25B). Antenna sub-equal to longer than head capsule, retractile, 4 segmented decreasing in size, $4^{\text {th }}$ segment minuscule (Figure 25B). Labral S setae are simple, SI and SII are weak, SIII well-developed. Premandible with multiple small teeth and brush (Figure 25D). Mandible with 1 apical tooth and 4 inner teeth. Mentum with 2-3 median teeth and 5 pairs of lateral, appearing triangular (Figures 25D, 25F, 26E). Abdomen with fused mesothoracic and metathoracic segments. Elongated anterior parapods. Procercus small each bearing 4-6 setae. Anal tubules small. Posterior parapods each bearing strong spiny setae of varying shapes.

Notes. Twenty-one known Nearctic species of Corynoneura are reviewed by Fu \& Sæther (2012). Fu \& Sæther (2012) provided keys and descriptions for 9 species and 6 designated larvae based on Bolton (2007) and Epler (2001). The combination of 4-segmented antenna and spined sub-basal setae of posterior parapods separate this larva from those of Thienemanniella Kieffer. Larvae described in this study do not match any of the described larvae by Fu \& Sæther (2012) in the Holarctic.

\section{Corynoneura sp. 1}

Larva $(n=2)$

\section{Figures 25A-H}

Description. Larvae $1.5 \mathrm{~mm}$ (Figure 25A). Head capsule is weakly sculptured (Figure 25B). Antenna slightly shorter than head capsule, $\mathrm{AL} / \mathrm{HL}=0.98$ (Figures $25 \mathrm{~B}-\mathrm{C}$ ), AR=0.72, $1^{\text {st }}$ segment yellow, 2-4 brown (Figure 25C). SII strong located on tubercles, SI and SIII weak. Premandible multi-toothed (Figure 25D). Mandible with 1 dorsal tooth, 1 apical tooth and 3 inner teeth (Figure 25E). Mentum with 3 median teeth and 5 pairs of laterals (Figure 25F). Sub-basal setae of posterior parapods with small spines arising only near their base (Figure 25G). Procercus small each bearing 4 long apical setae (Figure 25H). Anal tubules long and slender, ventral tubules longer than dorsal tubules (Figure 25H).

Sampling sites. Salor Creek in Lake Hazen area, N81 ${ }^{\circ} 54.156$ ' W68 $8^{\circ} 54.457^{\prime}$; Tributary of Turnbat River in Lake Hazen area, N82 $1.7170^{\prime} \mathrm{W} 68^{\circ} 43.939^{\prime}$.

Nearctic distribution. CANADA: Nunavut.

\section{Corynoneura sp. 2}

Larva $(n=1)$

\section{Figures 26A-G}

Description. Larvae $2.3 \mathrm{~mm}$ (Figure 26A). Head capsule with some sculpturing (Figure 26B). Antenna longer than head capsule, $\mathrm{AL} / \mathrm{HL}=1.23, \mathrm{AR}=0.78, \mathrm{R} 0$ located at $1 / 2$ of the $1^{\text {st }}$ segment, $1^{\text {st }}$ segment yellow, 2-4 brown (Figure 26C). SII strong located on tubercles, SI and SIII weak. Premandible multi toothed. Mandible with 1 dorsal tooth, 1 apical tooth and 3 inner teeth, apical tooth slightly shorter than $1^{\text {st }}$ inner teeth (Figure 26D). Mentum with 3 median teeth and 5 pairs of lateral teeth (Figure 26E). Sub-basal setae of posterior parapods with small spines arising only from their base (Figure 26F). Procercus with 4 apical setae (Figure 26G).

Notes. Larva of this species differs from the Corynoneura sp. 1 by these characteristics: head capsule of the $C$. sp. 2 is brown compared to pale yellow head capsule of $C$. sp.1, AL/HL $>1$ and sub-basal seta is longer.

Sampling sites. Salor Creek in Lake Hazen area, N81 ${ }^{\circ} 54.156^{\prime}$ W68 54.457 '.

Nearctic distribution. CANADA: Nunavut.

\section{Corynoneura lobata Edwards \\ Male $(n=3)$ \\ Figures 27A-L}

Description. Male is small, $\mathrm{TL}=1.7 \mathrm{~mm}$. Head and thorax brown, lighter dorsoventrally and in posterior portion of scutellum, abdomen brownish-white dorsally and white ventrally (Figures 27Aand G). Antenna 10 segmented, $A R=0.45-0.5$ (0.48), last segment with short setae on apex (Figures 27B-C), shaft starts from the apex of the $1^{\text {st }}$ segment. Eyes bare (Figure 27B). Tentorium long narrowing at the tip (Figure 27D). Clypeus wide (Figure 27E). Palpomere 5 segmented, $5^{\text {th }}$ segment longer than $4^{\text {th }}$ (Figure 27F), (L1-5=19.4 $\mu \mathrm{m}, 24.8 \mu \mathrm{m}, 17.6$ $\mu \mathrm{m}, 17.4 \mu \mathrm{m}, 35.5 \mu \mathrm{m})$. Antepronotal lobes developed, narrows before anteromedian portion of thorax, dorsocentrals in single rows (Figure 27G), acrostichals absent, scutellars light in middle (Figure 27G) with 2 single setae (Figures 27G). TL/wing $\mathrm{L}=1.3$. Wing $1.3 \mathrm{~mm}$ long, wing $\mathrm{W} /$ wing $\mathrm{L}=0.31$, clavus thin, $\mathrm{VR}=2.6, \mathrm{cu}=652.6 \mu \mathrm{m}, \mathrm{cu} /$ wing $\mathrm{L}=0.5$, costa with 11-13 setae, brachiolum bare (Figure 27H). Fore tibia $\mathrm{W}=19.6 \mu \mathrm{m}$, mid tibia $\mathrm{W}=20.5 \mu \mathrm{m}$, fore tibia with 2 spurs $\mathrm{Ls}=22 \mu \mathrm{m}$ and $12 \mu \mathrm{m}$, mid tibia spurs $=12.4 \mu \mathrm{m}$ and $10.3 \mu \mathrm{m}$, hind tibia spurs $=31.3 \mu \mathrm{m}$ and $10.7 \mu \mathrm{m}$, hind tibia spurs and comb (Figure 27I), hind tibia expanded at apex with $\mathrm{s}$ shaped setae at tip, hind tibia $\mathrm{W}=\mathrm{a}=44.2 \mu \mathrm{m}, \mathrm{b}=40$ $\mu \mathrm{m}, \mathrm{cl}=67.5 \mu \mathrm{m}, \mathrm{c} 2=90.1 \mu \mathrm{m}, \mathrm{d}=26.7 \mu \mathrm{m}, \mathrm{a} / \mathrm{d}=1.6, \mathrm{~b} / \mathrm{d}=1.5, \mathrm{cl} / \mathrm{d}=2.5$, c2/d=3.4. Tergite IX almost convex medially (Figure 27J). Sternapodeme narrows and triangular shape laterally and joins with phallapodeme caudally (Figure $27 \mathrm{~K}$ ), phallapodeme strongly curved (Figure 27K). Superior volsella not strongly projected, inferior volsella well developed and projecting medially and basally (Figure $27 \mathrm{~K}$ ). Gonocoxite large and wide, narrows at the base (Figures 27J-L), gonostyles long and curved anteromedially, strongly convex on anterior part starting mid-point and ends at mega setae (Figures 27J-L), mega setae long $6.25 \mu \mathrm{m}, \mathrm{HR}=2.1, \mathrm{HV}=5.0$.

Legs lengths $(\mu \mathrm{m})$ and proportions:

\begin{tabular}{lccccccccccc} 
& $\mathbf{f e}$ & $\mathbf{t i}$ & $\mathbf{t a}_{\mathbf{1}}$ & $\mathbf{t a}_{\mathbf{2}}$ & $\mathbf{t a}_{\mathbf{3}}$ & $\mathbf{t a}_{\mathbf{4}}$ & $\mathbf{t a}_{\mathbf{5}}$ & $\mathbf{L R}$ & $\mathbf{B V}$ & $\mathbf{S V}$ & $\mathbf{B R}$ \\
\hline P1 & 247 & 338 & 177 & 101 & 57 & 27 & 40 & 0.52 & 3.4 & 3.3 & 2.2 \\
P2 & 369 & 354 & 220 & 89 & 56 & 19 & 41 & 0.62 & 4.6 & 3.3 & 3.1 \\
P3 & 245 & 335 & 203 & 106 & 48 & 23 & 44 & 0.61 & 3.5 & 2.9 & 4.1
\end{tabular}

Notes. Male is described by Schlee (1968). The 3 adult males examined from the 3 localities in this study have an inferior volsella which is tapered. This character matches the Figure 27 in Schlee (1968).

Study sites. Nakvak Brook in Torngats Mountains National Park, N58 37.22196 ' W63 ${ }^{\circ} 23.28786$ '.

Ecology and habitat. Larvae of this species inhabit rivers, streams and springs (Fu \& Sæther, 2012). Adults have an early spring and fall emergence (Schlee, 1968).

Nearctic distribution. CANADA: Alberta, New Brunswick, $1^{\text {st }}$ record for Labrador, Northwest Territories, and Ontario; USA: Florida, Georgia, Michigan, Mississippi, New Jersey, New York, North Carolina, Ohio, South Carolina, and Virginia. 


\section{Cricotopus Hirvenoja}

Note on genus Cricotopus. Larvae of Cricotopus resemble some Orthocladius (Orthocladius) and Paratrichocladius species. There are no clear characteristics separating Cricotopus larvae from those of Orthocladius. The Paratrichocladius can be partially recognized by the constricted first lateral teeth of the mentum, presence of minuscule spines at the base of seta subdentalis and sclerotized area laterad to mentum from those of Cricotopus and Orthocladius. Diagnoses for 7 species are given in this study. Subgenus Cricotopus can be separated from Isocladius by having pecten epipharyngis with 3 scales that are sub-equal to equal in size (Figure 28D). However, species in subgenus Isocladius have pecten epipharyngis with a single scale and their lateral scales are fused and/or reduced (Figure 32C). The median scale may have a small notch on the side.

\section{Cricotopus (Cricotopus) bicinctus (Meigen) \\ Larva $(n=1)$ \\ Figures 28A-J}

Description. Head capsule yellowish-brown (Figure 28A). Antenna 5 segmented, $5^{\text {th }}$ segment slightly longer than $4^{\text {th }}$ (Figure 28B), LO prominent covering the $3^{\text {rd }}$ segment, blade shorter than flagellum, RO at the base of $1^{\text {st }}$ segment, AR=1.4. SI bifid, SII simple (Figure 28C). Pecten epipharyngis with 3 equal scales (Figure 28D). Premandible simples (Figure 28E). Mandible with 1 apical and 3 inner teeth, outer ridge crenulated (Figure 28F). Mentum with 1 wide dome shaped central tooth and 6 pairs of lateral teeth (Figure 28G), central tooth $4.2 \mathrm{x}$ of $1^{\text {st }}$ lateral tooth, $\mathrm{VmP}$ prominent reaching the $2^{\text {nd }}$ lateral teeth anteriorly and posteriorly parallel and just below the SSm location. Claws of anterior parapods serrated (Figure 28H). Body hair in bundles and long (Figure 28I). Anal tubules longer than posterior parapods. Procercus well sclerotized, each bearing 5 apical setae (Figure 28J).

Notes. C. bicinctus is similar to Cricotopus (Cricotopus) mackenziensis Oliver; however, head capsule width, antenna length, AR, mentum width, and mandible length separates the two larvae (See Oliver, 1977 and Table 2 in this study for further details). Additionally, the stronger contrast of color between the central and lateral portion of the mentum in $C$. mackenziensis separates it from C. bicinctus (Oliver, 1977).

Study sites: Utuk River in Pond Inlet area, N72 ${ }^{\circ} 39.742$ ' W78 ${ }^{\circ} 2.995$ '.

Ecology and habitats. This species is widespread in both the Palaearctic and Nearctic. Larvae are reported to tolerate high chromium, cyanide, copper and zinc toxicity in addition to low oxygen concentration (Surber, 1959; Winner et al., 1988). Rosenberg \& Wiens (1976) and Rosenberg et al. (1977a) reported the larvae to be abundant in areas with crude oil contamination. Larvae occur in almost all aquatic habitats, including rice fields, and usually are associated with masses of Spirogyra algae, which also form their diet along with desmids and diatoms (Darby, 1962). This species is multivoltine with peak emergence in June, July and August (Rosenberg et al., 1977b).

Nearctic distribution. CANADA: Alberta, Manitoba, New Brunswick, Labrador, Northwest territories, Nunavut, Ontario, Prince Edward Island, Saskatchewan, and Yukon Territory; MEXIC0: Mexico State; USA: Alabama, Alaska, Arkansas, California, Florida, Georgia, Louisiana, Maine, Michigan, Minnesota, New Mexico, New York, North Carolina, Ohio, Pennsylvania, South Carolina, South Dakota, and Tennessee.

\section{Cricotopus (Cricotopus) tibialis (Meigen) \\ Larva $(n=2)$}

Figure 29A-H

Description. Head capsule brown (Figure 29A). Antenna 5 segmented, sequentially decreasing in size (Figure 29B), LO large covering the $3^{\text {rd }}$ segment, blade nearly reaches the base of $5^{\text {th }}$ segment, $A R=1.7$. SI bifid, SII and SIII simple (Figure 29C). Pecten epipharyngis with 3 scales, median scale slightly longer (Figure 29C), chaetulae basalis and lateralis all simple and lamellate. Maxilla with ALCh similar to other chaeta, pecten galearis vestigial. Premandible bifid with small brush. Mandible with 1 apical tooth and 3 inner teeth, apical tooth slightly longer than $1^{\text {st }}$ lateral teeth (Figure 29D), outer ridge crenulated. Mentum with 1 median tooth and 6 pairs of lateral teeth appearing triangular (Figure 29E), median tooth $<1.5 \mathrm{X}$ wider than the $1^{\text {st }}$ laterals, $\mathrm{VmP}$ extending to the base of $2^{\text {nd }}$ lateral teeth, SSm anterior to the base of VmP. Claws of anterior parapods serrated (Figure 29F), body with long tuft of setae, however, not plumose (Figure 29G). Procercus small with 6 long apical setae (Figure 29H). Posterior parapods with group of simple claws. Anal tubules conical and sub-equal to posterior parapods (Figure $29 \mathrm{H}$ ).

Notes. Larva is described by Hirvenoja (1973). Larva of this species resembles larva of Cricotopus (Cricotopus) tremulus (Linnaeus). However, $C$. tremulus has a simple premandible, median tooth of its mentum is much larger, maxilla pecten galearis is well developed and setae on the body are simple.

Sampling sites. Tributary of Very River in Lake Hazen area, N81 ${ }^{\circ}$ $32.950^{\prime}$ W73 ${ }^{\circ} 35.757$ '; Salor Creek in Lake Hazen area, N81 ${ }^{\circ} 54.156^{\prime}$ $\mathrm{W} 68^{\circ} 54.457^{\prime}$.

Ecology and habitats. In the Arctic, larvae of this species have been reported only from permanent ponds; however, in Europe they were reported in variety of aquatic habitats (Oliver \& Dillon, 1997, 1988). Larvae are associated with filamentous algae in Carex stands (Oliver \& Dillon, 1988).

Nearctic distribution: CANADA: Manitoba, New Brunswick, Northwest Territories, Nunavut, Yukon Territory; GREENLAND; USA: Alaska, Minnesota.

\section{Cricotopus (Cricotopus) tremulus group}

Larva $(n=1)$

\section{Figures 30A-H}

Description. Head capsule light brown, $\mathrm{L}=421 \mu \mathrm{m}$. Antenna 5 segmented, $4^{\text {th }}$ segment smaller than $3^{\text {rd }}$ segment, LO large and covering $2 / 3^{\text {rd }}$ of $3^{\text {rd }}$ segment (Figure $30 \mathrm{~A}$ ), R0 at the basal $1 / 5^{\text {th }}$ of $1^{\text {st }}$ segment, blade reaching the base of $5^{\text {th }}$ segment, $A R=1.9$. SI bifid, SII and SIII simple and long (Figure 30B). Pecten epipharyngis with 3 scale of nearly equal size (Figure 30C). Premandible simple with small notch (Figure 30D), brush present. Maxilla with pecten galearis present, ALCh similar in size and shape to other chaeta. Prementum (Figure 30E). Mentum with 1 median tooth and 6 pairs of lateral teeth (Figure 30F), median teeth $1.4 \mathrm{x}$ of $1^{\text {st }}$ laterals, VmP prominent, the posterior tip parallel with the SSm, anteriorly reaching the $2^{\text {nd }}$ laterals (Figure 30F). Body yellowish green, setae are simple and long (Figure 30G). Procercus well-sclerotized each bearing 6 apical setae (Figure 30H). Posterior parapods with group of simple claws. Anal tubules shorter than posterior parapods (Figure 30H).

Notes. The specimen obtained in this study could be Cricotopus (Cricotopus) tremulus (Linnaeus). However, the mandible is light at the base which contradicts the description given for the larvae. Larvae keys out to Cricotopus (s.s.) luciae LeSage, based on couplet 26 (24') in section 7.58 of Epler (2001).

Study sites. Lower Torr Bay in Torngats Mountains National Park, N58 ${ }^{\circ} 26.635 '$ 'W62 ${ }^{\circ} 49.186$ '.

Nearctic distribution. CANADA: Nunavut.

\section{Cricotopus (Cricotopus) triannulatus (Macquart) Larva $(\mathrm{n}=3)$}

Figures 31A-J

Description. Larva L=4.4 mm (Figure 31A). Head capsule brown, $\mathrm{HL} / \mathrm{HW}=1.05$ (Figure $31 \mathrm{~A}-\mathrm{B}$ ). Antenna 5 segmented, sequentially decreasing in size (Figure 31B), LO large covering the $3^{\text {rd }}$ segment, 
blade sub-equal to flagellum, $A R=1.9$. SI bifid, SII simples SIII simple and small (Figure 31D). Pecten epipharyngis with 3 scale of equal size (Figure 31D). Premandible simple (Figure 31E). Maxilla pecten galearis present but weak. Mandible 1 apical tooth and 3 inner teeth, apical teeth longer than $1^{\text {st }}$ inner (Figure $31 \mathrm{~F}$ ), outer ridge crenulated. Mentum with 1 median tooth and 6 pairs of lateral teeth, median tooth $<1.5 \mathrm{X}$ of $1^{\text {st }}$ laterals (Figure $31 \mathrm{G}$ ), VmP this reaching the base of $2^{\text {nd }}$ laterals, SSm parallel with the base of $\mathrm{VmP}$. Claws of anterior parapods (Figure 31H). Procercus small with 6 long apical setae (Figures 31H-J). Posterior parapods with group of simple claws. Anal tubules present and conical sub-equal to posterior parapods (Figures $31 \mathrm{H}-\mathrm{J}$ ).

Sampling sites. Burton River in Baffin Island, N63 ${ }^{\circ} 52.800^{\prime}$ W68 ${ }^{\circ}$ 18.894'; Tributary of Mala River in Borden Peninsula, N72 ${ }^{\circ} 57.408^{\prime} \mathrm{W}^{\circ}{ }^{\circ}$ 12.207'; Pond Stream in Borden Peninsula, N72 ${ }^{\circ} 49.021^{\prime}$ W80 28.497 '; Tributary of Utuk River in Pond Inlet area, N72 ${ }^{\circ} 36.988^{\prime}$ W78 $7.878^{\prime}$.

Ecology and habitats. Larvae of this species have an optimum temperature of $13.4 \pm 5.2^{\circ} \mathrm{C}$ (Rossaro, 1991b).

Nearctic distribution. CANADA: Ontario, Saskatchewan, and $1^{\text {st }}$ record for Nunavut; Mexico: Puebla; USA: Florida, Mississippi, New York, North Carolina, Ohio, and South Carolina.

\section{Cricotopus (Isocladius) intersectus (Staeger) \\ Larva $(n=1)$}

Figures 32A-G

Description. Head capsule yellowish brown (Figure 32A). Antenna 5 segmented, segment 4 equal to segment 3 (Figure 32B), LO large covering the $3^{\text {rd }}$ segment, blade longer than flagellum (Figure 32B), R0 at the base of $1^{\text {st }}$ segment, AR=0.83. SI bifid, SII and SIII simple. Pecten epipharyngis with single plate. Premandible simple with notch and large accessory tooth (Figure 32C). Mandible with 1 apical and 3 inner teeth, outer ridge crenulated (Figure 32D). Maxilla pecten galearis vestigial. Mentum with single dome shaped median teeth and 6 pairs of lateral teeth, mentum appearing triangular (Figure $32 \mathrm{E}$ ), VmP large, SSm wellposterior to mentum (Figure 32E). Tuft of setae on the abdomen are long (Figure 32F). Procercus small, each bearing 5 apical setae. Posterior parapods short. Anal tubules $2 / 3^{\text {rd }}$ of the posterior parapods (Figure $32 \mathrm{G}$ ).

Notes. Larva of $C$. intersectus and Cricotopus (Isocladius) laricomalis Edwards are very similar. $C$. intersectus can be distinguished from $C$. laricomalis based on the combination of lower number of setae in abdominal hair bundles, long and lamellate SII, and more prominent pecten galearis of maxilla. The specimen obtained in this study is probably $3^{\text {rd }}$ instar larva.

Sampling sites. Tributary of Borden River in Baffin Island, $\mathrm{N}^{\circ}{ }^{\circ}$ $48.800^{\prime} \mathrm{W} 68^{\circ} 24.482$ '.

Ecology and habitats. Larvae of this species occur in the littoral zone of lakes and in streams and rivers. Larvae are grazers and detritus feeders, and can resist low oxygen levels (Marziali et al., 2010).

Nearctic distribution. CANADA: Saskatchewan, Manitoba, and $1^{\text {st }}$ record for Nunavut; USA: North Carolina, Ohio.

\section{Cricotopus (Isocladius) laricomalis Edward \\ Larva $(n=1)$}

Figures 33A-G

Description. Larva $\mathrm{L}=4.5 \mathrm{~mm}$ (Figure $33 \mathrm{~A}$ ). Antenna 5 segmented, $4^{\text {th }}$ segment sub-equal to $3^{\text {rd }}$ (Figure $33 \mathrm{~B}$ ), LO small not covering the entire $3^{\text {rd }}$ segment (Figure 33B), blade sub-equal to flagellum, $A R=1.3$. SI bifid, SII and SIII simple. Pecten epipharyngis with single conical plate and 2 large notch (Figure 33C). Premandible simple (Figure 33C.). Maxilla pecten galearis absent. Mandible with 1 apical tooth and 3 inner teeth, SSd small, outer ridge crenulated (Figure 33D). Mentum with 1 median tooth and 5 pairs of lateral teeth, $1^{\text {st }}$ two laterals appear fused, median tooth $<1.5 \mathrm{X}$ of the $1^{\text {st }}$ lateral teeth (Figure $33 \mathrm{E}$ ), $\mathrm{VmP}$ small, SSm posterior to mentum. Body with cluster of long setae, longer than segment each bearing them (Figure 33F). Procercus small, each bearing 6 apical setae (Figure 33G). Anal tubules as long as posterior parapods and conical (Figure 33G).

Sampling sites. Unnamed stream in Baffin Island, N63 ${ }^{\circ} 46.552$ ' W68 39.440 '.

Ecology and habitats. Larva is described by Oliver \& Dillon (1988) as a limnobiotic species, occurring mainly in ponds. This species is univoltine with a 2 year life cycle (Oliver \& Dillon, 1988). In this study larvae occurred in streams.

Nearctic distribution. CANADA: Nunavut, Quebec; GREENLAND; USA: Alaska.

\section{Cricotopus (Isocladius) reversus group \\ Larva $(n=1)$}

\section{Figures 34A-H}

Description. Head capsule yellowish brown (Figure 34A). Antenna 5 segmented, $4^{\text {th }}$ segment sub-equal to $3^{\text {rd }}$ (Figure $34 \mathrm{~B}$ ), blade slightly longer than flagellum, LO small (Figure 34B), AR=2.5. SI bifid, SII and SIII simple. Pecten epipharyngis with single conical plate. Premandible simple. Maxilla pecten galearis absent (Figure 34C). Mandible with 1 apical tooth and 3 inner teeth (Figure 34D), outer ridge with minor crenulation, large SSd. Mentum with 1 median tooth and 5 pairs of lateral teeth, median tooth $2 \mathrm{X}$ the lateral teeth (Figure $34 \mathrm{E}$ ), $\mathrm{VmP}$ small and narrow, SSm posterior to mentum. Body hairs in cluster and longer than segments which bearing them (Figure 34F). Procercus sclerotized and small, each bearing 6 long apical setae and 2 sub-apical setae (Figure 34G). Anal tubules as long as posterior parapods. Posterior parapods $2 \mathrm{X}$ as long as wide (Figure $34 \mathrm{H}$ ).

Sampling sites. Cuesa Brook in Lake Hazen area, N81 ${ }^{\circ} 52.8370002^{\prime}$ W70 12.9049998 '.

Nearctic distribution. CANADA: Nunavut.

\section{Diplocladius cultriger Kieffer}

Larva $(n=3)$

\section{Figures 35A-G}

Description. Larva $\mathrm{L}=5.8 \mathrm{~mm}$ (Figure $35 \mathrm{~A})$. Antenna 5 segmented, segments sequentially decreasing in size (Figure $35 \mathrm{~B}$ ), blade reaching the base of segment $4, \mathrm{AR}=2.1$. SI plumose, SII and SIII simple, SIII lamellate (Figure 35C). Labral lamella present, lobe shaped and plumose (Figure 35C). Pecten epipharyngis with 3 equal scales (Figure $35 \mathrm{C}$ ), 1 chaetula lateralis comb-shape with multiple teeth, chaetula basalis present (Figure 35C). Premandible bifid. Mandible with 1 apical teeth and 4 inner teeth (Figure 35D). Mentum appears truncated with 2 median and 6 pairs of lateral teeth(Figure $35 \mathrm{E}$ ), VmP well-developed extending anteriorly to the base of the second lateral teeth (Figure 35E), cardinal bread present, with cluster of hair extending to the base of last lateral teeth (Figure 35E), SSm anteriad. Procercus longer than wide, each bearing 9-10 apical setae (Figure 35F). Anal tubules large and conical extending to the base of posterior parapod, dorsal tubules larger than ventral tubules (Figure 35G). Posterior parapod with group of claws.

Notes. The $D$. cultriger is the only Holarctic species known. However, variation in larvae from different geographical regions may suggest multiple species for this genus (Andersen et al., 2013).

Sampling sites. Unnamed creek near Iqaluit airport in Baffin Island, N63 ${ }^{\circ} 75.086^{\prime} \mathrm{W}^{\circ} 8^{\circ}$ 53.172'; unnamed river in Resolute Bay, N74 ${ }^{\circ} 40.972^{\prime}$ W68 ${ }^{\circ} 47.688^{\prime}$; Ptarmigan Creek in Lake Hazen area, N81 ${ }^{\circ}$ 47.3839' W71 ${ }^{\circ} 55.938^{\prime}$.

Ecology and habitats. Larvae of this species occur in slow-flowing cool streams, small bodies of still water and spring runs. This species is univoltine in North temperate regions with emergence occurring in the cooler part of the season, late winter and early spring. Adults are found to walk on snow around the open bodies of flowing water during these times (Oliver \& Dillon, 1997). 
Nearctic distribution. CANADA: Alberta, Nunavut, Saskatchewan, and Quebec; GREENLAND; USA: Alabama, Connecticut, Georgia, Kansas, Nebraska, New York, North Carolina, Ohio, Pennsylvania, South Carolina, and South Dakota.

\section{Doncricotopus cf. bicaudatus Sæther}

Larvae $(n=1)$

\section{Figures 36A-E}

Description. $\mathrm{HL} / \mathrm{HW}=0.9$. Antenna 5 segmented, $5^{\text {th }}$ segment longer than $4^{\text {th }}$ (Figure $\left.36 \mathrm{~A}\right), \mathrm{AR}=1.3$, blade shorter than flagellum. SI-SIII simple. Premandible simple (Figure 36B). Mandible with 1 long apical tooth and 3 inner teeth (Figure 36C). Mentum with bifid wide and dome shaped median tooth and 6 pairs of lateral teeth (Figure 36D), VmP prominent not extending beyond the margin of mentum, cardinal beard present (Figure 36E).

Notes. Only the head capsule of the larva was recovered in this study. This larva is probably $3^{\text {rd }}$ instar. Larva of Doncricotopus bicaudatus is described by Sæther (1981).

Study sites. Ruggles River in Lake Hazen area N81 ${ }^{\circ} 43.459^{\prime}$ W69 ${ }^{\circ}$ 26.653 '.

Nearctic distribution. CANADA: Nunavut.

Note on the Nearctic distribution. Doncricotopus bicaudatus Sæther has not been reported in Nunavut. In Canada it has only been reported in the Northwest Territories. In the USA it has been reported in Minnesota and Ohio.

\section{Eukiefferiella Thienemann}

Generic diagnosis. Head capsule brown to dark brown; Antenna 45 segmented (Figures 37A, 42A); SI simple; Premandible simple; Mandible with inner ridge serrated (Figures 38C, 44B), 1 apical and 3 inner teeth; Mentum with 1-2 median and 4-5 pairs of lateral teeth; abdominal segments usually with fringe of setae; Procercus well-sclerotized each bearing up to 7 apical setae; Anal tubules shorter than posterior parapods (Figure 38E).

\section{Eukiefferiella brehmi group \\ Larva $(\mathrm{n}=3)$ \\ Figures 37A-F}

Description. Antenna 5 segmented, $4^{\text {th }}$ segment longer than $3^{\text {rd }}$ (Figure 37A), LO small, blade shorter than flagellum reaching tip of $4^{\text {th }}$ segment, RO close to the base of $1^{\text {st }}$ segment, AR=1.4. SI-SIII simple, SII very small. Pecten epipharyngis with 3 equal sized scales. Premandible simple (Figure 37B). Mandible with 1 apical and 3 inner teeth (Figure 37C), 2-3 serration at the base of inner ridge. Mentum with 2 median and 5 pairs of lateral teeth (Figure 37D), SSm well posterior to mentum, VmP developed but visible only under high resolution. Maxilla pecten galearis present but weak. Long abdominal setae, about $1 / 2 \times$ of the segment each bearing them. Procercus short and sclerotized, each bearing 7 apical setae and 2 sub-apical setae (Figure 37E). Anal tubules about $2 / 3^{\text {rd }}$ of posterior parapods (Figure $37 \mathrm{~F}$ ). Posterior parapods with group of claws (Figure 37F).

Notes. At least 3 undescribed Nearctic species belong to this group (Bode, 1983).

Sampling sites. Nakvak River in Seglak region, N58 $32.129^{\prime}$ W63 ${ }^{\circ}$ 18.966'; Tributary of Cove River N59 $9^{\circ} 1.569^{\prime}$ W63 $3^{\circ} 31.972^{\prime}$ in Torngats region; Unnamed creek near Iqaluit airport in Baffin Island, N63 ${ }^{\circ}$ 75.086' W68 ${ }^{\circ}$ 53.172'; Pond Stream in Borden Peninsula, N72 ${ }^{\circ} 49.021^{\prime}$ W80 $28.497^{\prime}$.

Ecology and habitats. Larvae of species in this group occur on bare stones of low to mid mountain streams and brooks with summer temperature of $17^{\circ} \mathrm{C}$ and flow of $0.9 \mathrm{~m} / \mathrm{s}$ (Bode, 1983; Thienemann, 1954).

Nearctic distribution. CANADA: Nunavut, Labrador.

\section{Eukiefferiella brevicalcar group sp. 3 Bode}

Pupa $(n=1)$

Figures 38A-F

Description. Pupa is small, $\mathrm{L}=3.5 \mathrm{~mm}$, brown. Frontal apotome without setae (Figure 38A), Pc1=99 $\mu \mathrm{m}, \mathrm{Pc} 2=143 \mu \mathrm{m}, \mathrm{Pc} 3=45 \mu \mathrm{m}$. Thoracic horn (Figures 39B-C), $\mathrm{L}=364 \mu \mathrm{m}, \mathrm{W}_{\text {base }}=45 \mu \mathrm{m}, \mathrm{L}_{\text {base }}=102.8$ $\mu \mathrm{m}, \mathrm{L}_{\mathrm{tip}}=275.0 \mu \mathrm{m}, \mathrm{L}_{\mathrm{tip}} / \mathrm{L}_{\mathrm{base}}=2.7$. Wing sheet without pearl rows. Tergite I without spines, tergite II with rows of simple spines (Figure $39 \mathrm{D}$ ), tergites III-V with 28,32 and 34 recurved hooks and rows of anal spines (Figure $39 \mathrm{E}$ ), tergite VIII with $4 \mathrm{~L}$ setae, $\mathrm{L}_{\mathrm{s}}=32-40 \mu \mathrm{m}$. Anal lobes with 3 equal macrosetae, $\mathrm{L}=149.5 \mu \mathrm{m}$. Genitalia sacs shorter than caudal lobes in female and longer in males (Figure 38F).

Notes. Thoracic horns of species in this group are unique. They have a long tapering tip (Bode, 1980).

\section{Larva $(n=2)$}

\section{Figures 39A-E}

Description. Head capsule light brown (Figure 39A). Antenna 5 segmented, $4^{\text {th }}$ segment longer than $3^{\text {rd }}$ (Figure 39B), R0 located at the base of $1^{\text {st }}$ antennal segment, LO large, blade shorter than flagellum, $\mathrm{AR}=1.4$. SI simple. Pecten epipharyngis with 3 equal scales. Premandible appear bifid. Mandible with 1 apical and 3 inner teeth, apical tooth longer than $1^{\text {st }}$ inner (Figure 39C), 2-3 serration at the base of inner ridge (Figure 39C). Mentum with 2 median and 5 pairs of lateral teeth, median teeth appear wrench shaped (Figure 39D), VmP extend posteriorly to SSm (Figure 39D). Abdominal setae long. Procercus short, each bearing 7 apical setae (Figure 39E). Posterior parapods long (Figure 39E). Anal tubules short and conical $1 / 2$ of the posterior parapods (Figure 39E).

Notes. Larva of this species is distinguished by long body setation and 5 segmented antennae (Bode, 1980).

Sampling sites. Henrietta Brook in Lake Hazen area, N81 ${ }^{\circ} 46.138^{\prime}$ W72 24.076 '.

Ecology and habitats. Larvae of species in this group were reported in cold spring brooks and mountain streams in moss and algae (Bode, 1983; Thienemann, 1954). According to Bode (1980) larvae of $E$. brevicalcar group sp. 3 can be found only in green algae attached to rocks in fast flowing brook streams. Adults emerge sooner than other species in this group. This species is probably univoltine (Bode, 1980).

Nearctic distribution. CANADA: Nunavut; USA: New York.

\section{Eukiefferiella claripennis group sp. 3 Bode}

Pupa $(n=1)$

\section{Figures 40A-D}

Description. Pupae is small, $\mathrm{L}=2.3 \mathrm{~mm}$, brown. Frontal apotome without setae. Thoracic horn (Figure 40A), Wbase $=46.0 \mu \mathrm{m}$, Lbase $=107.0 \mu \mathrm{m}, \mathrm{L}_{\mathrm{tip}}=66.4 \mu \mathrm{m}, \quad$ Ltip/Lbase $=0.62 . \mathrm{Pc} 1=99.0 \mu \mathrm{m}$, Pc2 $=143.0 \mu \mathrm{m}, \mathrm{Pc} 3=45.0 \mu \mathrm{m}$. Wing sheet without pearl rows (Figure 40B). Tergites III-V with 10 recurved hooks on each side and rows of anal spines (Figure 40C), tergite VIII with L3 and L4 long and spine like, $\mathrm{L}=87.0 \mu \mathrm{m}$ (Figure 40D). Anal lobes with 3 equal macrosetae, $\mathrm{L}=18.0 \mu \mathrm{m}$ (Figure 40D), genitalia sacs shorter than caudal lobes in female and longer in male (Figure 40D).

Notes. According to Bode (1980) this species is related to the European Eukiefferiella claripennis (Lundbeck).

\section{Larva $(n=2)$}

\section{Figures 41A-D}

Description. Head capsule brown, $\mathrm{HW}=257 \mu \mathrm{m}$. Antenna 4 segmented, $4^{\text {th }}$ segment longer than $3^{\text {rd }}$ (Figure $41 \mathrm{~A}$ ), blade short reaching the base of $3^{\text {rd }}$ segment, LO located at the base of $2^{\text {nd }}$ antennal segment, R0 large, sense pit located centrally on the $1^{\text {st }}$ segment, $A R=1.9$. SI sim- 
ple. Premandible simple. Mandible with 1 apical tooth and 3 inner teeth, apical tooth equal to $1^{\text {st }}$ inner teeth (Figure 41B), 2-3 serration at the base of inner ridge (Figure 41D). Mentum with 2 median and 5 pairs of lateral teeth (Figure 41C), $1^{\text {st }}$ lateral stand a bit higher than other laterals giving an appearance of quadruple shaped median teeth, VmP small. Abdominal setae about $1 / 3^{\text {rd }}$ of the segments bearing them. Procercus small, each bearing 7 apical setae and 2 sub-apical setae (Figure 41D). Posterior parapods long each bearing group of claws. Anal tubules short about 1/3 $3^{\text {rd }}$ of posterior parapods (Figure 42D).

Notes. The combination of four segmented antenna, centrally located antennal sense pit, rounded VmP and shape of mentum are the main characteristics that separate this group from others in the genus Eukiefferiella (Bode, 1983). Higher head width, apical and sub-apical setae lengths separates larvae of this assigned species from others in this group (Bode, 1980).

Sampling sites. McCornick Brook in Torngats Mountains National Park, N58 ${ }^{\circ} 59^{\circ} .093^{\prime} \mathrm{W} 63^{\circ} 47.477$ '.

Ecology and habitats. Larvae of species in this group tend to occur in higher latitude and altitude brooks and streams in moss and algae (Bode, 1983). Larvae of $E$. claripennis group sp. 3 are reported to occur in mats of blue-green algae (Bode, 1980).

Nearctic distribution. CANADA: Labrador. USA: New York.

\section{Eukiefferiella cyanea group \\ Larva $(n=1)$}

\section{Figures 42A-E}

Description. Head capsule dark brown (Figure 42A). Antenna 5 segmented, $4^{\text {th }}$ segment longer than $3^{\text {rd }}$ (Figure 42B), L0 large covering the $3^{\text {rd }}$ and base of the $4^{\text {th }}$ segment, blade longer than flagellum, $\mathrm{AR}=1.4$. SI-SIII simple. Premandible simple. Mandible with 1 apical tooth and 3 inner teeth (Figure 42C), large spine like SSm, two large spine at the base of inner ridge. Mentum with large central tooth appearing truncated and 5 pairs of lateral teeth (Figure 42D), $1^{\text {st }}$ laterals appear as small notch, VmP small and visible. Body yellowish brown with traces of blue color (Figure 42E). Procercus reduced, each bearing 4 short apical setae (Figure 42E). Posterior parapods with group of large brown claws (Figure 42E). Anal tubules small.

Sampling sites. Unnamed stream in Iqaluit, Baffin Island, $\mathrm{N} 63^{\circ}$ $56.110^{\circ} 6^{\prime} \mathrm{W} 68^{\circ} 11.401$ '.

Ecology and habitats. Larvae of species in this group occur in spring brooks and on stony substrates. Larvae are adapted for attachment to the clear surfaces of rocks (Bode, 1983; Thienemann, 1954).

Nearctic distribution. CANADA: Nunavut.

\section{Eukiefferiella rectangularis group Larva $(n=3)$}

\section{Figures 43A-E}

Description. Head capsule brown. Antenna 5 segmented, $4^{\text {th }}$ segment sub-equal to $3^{\text {rd }}$, blade short reaching the base of $4^{\text {th }}$ segment, LO small (Figure 43A), blade shorter than flagellum, AR=1.7. SI simple and long, SII and SIII simple. Premandible simple. Mandible with 1 apical tooth and 4 inner teeth (Figure 43B), SSd large with small pointed hook-shaped tip, 3 large serrations at the base of the inner ridge (Figure 43B), outer ridge slightly crenulated. Mentum with 2 median teeth and 5 pairs of lateral teeth (Figure 43C), two median teeth truncated and hoofed shape, VmP small and bow-shaped (Figure 43C). Body with setae about $1 / 3^{\text {rd }}$ of the segments each bearing them (Figure 43D). Procercus well-sclerotized each bearing 7 apical setae and 1 sub-apical setae (Figure 43E). Posterior parapods longer than wide, each bearing group of claws (Figure 43E). Anal tubules shorter than posterior parapods constricted at the base (Figure 43E).

Notes. The combination of a nearly quadrate shaped median teeth of mentum, antennal sense pit positioned in mid point of $1^{\text {st }}$ antennal segment, and posterolaterally rounded VmP, separate the larvae of this group from other groups in Eukiefferiella (Bode, 1983).

Sampling sites. Burton River in Baffin Island, N63 ${ }^{\circ} 52.800^{\prime}$ W68 $6{ }^{\circ}$ 18.894'; Unnamed creek near Iqaluit airport in Baffin Island, N63 ${ }^{\circ}$ 75.086' W68 53.172 '; Unnamed river in Resolute Bay, N74 $44.809^{\prime}$ W94 $47.688^{\prime}$.

Ecology and habitats. Larvae of species in this group occur in high altitude and latitude streams and rivers with temperature ranges of $2-5^{\circ} \mathrm{C}$ (Bode, 1983). Bode (1983) suggested that because of the stout posterior parapods of the larvae, they may inhabit moss and filamentous algae.

Nearctic distribution. CANADA: Nunavut.

\section{Eukiefferiella tirolensis Goetghebuer \\ Larva ( $n=2)$}

\section{Figures 44A-D}

Description. Head capsule yellow. Antenna 5 segmented, $4^{\text {th }}$ segment sub-equal to $3^{\text {rd }}$ (Figure 44A), blade short reaching the base of $3^{\text {rd }}$ segment, LO large covering the $3^{\text {rd }}$ segment, $A R=1.9$. SI-SIII simple. Premandible simple. Mandible as in Figure 44B, inner ridge spines small, SSd large and conical. Mentum with 1 median tooth and 5 pairs of lateral teeth (Figure 44C), VmP narrow. Body greenish-brown, setae are very short. Procercus well-sclerotized each bearing 7 apical setae and 2 sub-apical setae (Figure 44D). Posterior parapods $2 \mathrm{X}$ as long as anal tubules, each bearing group of claws (Figure 44D). Anal tubules conical (Figure 44D).

Notes. Species is a member of brevicalcar group and is described from the reared specimens by Epler (2003). Larvae are similar to Tvetenia, especially the mentum and the coloration of head capsule (i.e. similar to Tvetenia tshernovskii (Pankratova)); however, SI is simple in this species.

Sampling sites. Tributary of St. Johns Harbour, Torngats National Park, N58 $26.616^{\prime}$ W62 ${ }^{\circ} 46.908^{\prime}$.

Ecology and habitats. Larvae of this species are reported to live among moss in high elevation streams and rivers with maximum water temperature of $7-15^{\circ} \mathrm{C}$ (Bode, 1983).

Nearctic distribution. CANADA: $1^{\text {st }}$ record for Labrador; USA: Georgia, Ohio, and South Carolina.

\section{Euryhapsis cilium Oliver \\ Larva $(n=1)$}

\section{Figures 45A-H}

Description. Head capsule yellow (Figure 45A), HL/HW=1.2. Labral sclerites divided, $\mathrm{Sc1}$ is divided in two with large gap between the plates, Sc2 not divided and quadrate (Figure 45B). Antenna 4 segmented, slightly bent, segments decreasing in size sequentially, $2^{\text {nd }}$ segment well-sclerotized and not divided (Figure 45C), antennal blade long about $2 \mathrm{X}$ the flagellum (Figure 45C), R0 close to the base of antenna, AR=2.3. SI plumose, SII and SIII simple. Pecten epipharyngis with 3 equal plates. Premandible bifid with accessory tooth (Figure 45D). Mandible with lapical and 4 inner teeth, apical smaller than combined inner teeth (Figure 45E), SSd present and long reaching the $3^{\text {rd }}$ inner teeth (Figure 45E). MP with R0 at the base (Figure 45F), ALCh serrated. Mentum with 1 receded median tooth and 6 pairs of lateral teeth (Figure 45G), $1^{\text {st }}$ laterals much larger than median, $6^{\text {th }}$ lateral teeth slightly longer than $5^{\text {th }}$ (Figure 45G), VmP thin extending to base of $3^{\text {rd }}$ lateral teeth, SSm well posteriad to mentum located in the mid-section of head capsule (Figure 45A). Procercus well-sclerotized, each bearing 6-7 apical setae (Figure $45 \mathrm{H})$. Posterior parapods with group of claws and several spines at the base (Figure $45 \mathrm{H}$ ). 4 anal tubules of capsule shape reaching the base of posterior parapods (Figure $45 \mathrm{H}$ ), tubules constricted at the base.

Notes. Species in this genus may resemble Brillia species. Larvae of 
Euryhapsis have an undivided second antennal segment whereas larvae Brillia have a divided one. Larva is described by Oliver (1981).

Sampling sites. Upper Nakvak River in Labrador, N $58^{\circ} 39.446^{\prime}$ W $63^{\circ}$ 35.946'; Unnamed creek in Baffin Island, N63 ${ }^{\circ} 65.112^{\prime}$ W $68^{\circ} 11.372$ '.

Ecology and habitats. Larvae of this species inhabit medium sized streams (Oliver, 1981).

Nearctic distribution. CANADA: Alberta, Northwest Territories, Yukon Territory, $1^{\text {st }}$ record for Labrador, and $1^{\text {st }}$ record for Nunavut.

\section{Heterotanytarsus perennis Sæther}

Larva $(n=1)$

\section{Figure 46A-C}

Description. Antenna is longer than mandible, 4 segmented, although it appears 5 segmented (Figure $46 \mathrm{~A}$ ), $2^{\text {nd }}$ segment with alternating LOs, AR=0.42. SI with apical dissections, SII and SIII simple and lamellate. Premandible with 4 teeth. Mandible with 1 apical tooth and 3 inner teeth, apical slightly longer than $1^{\text {st }}$ inner teeth (Figure $46 \mathrm{~A}$ ). Mentum with grooved central teeth and 6 laterals, $3^{\text {rd }}$ lateral longer than $2^{\text {nd }}$ giving the mentum a convex shape (Figure 46B), inner tooth and the first 2 laterals lighter in colour, VmP well developed reaching the base of $2^{\text {nd }}$ laterals (Figure 46B). Procercus not well-sclerotized, small as long as wide, each bearing 6 very long apical setae (Figure 46C). posterior parapods no longer than wide, each bearing group of claws (Figure 46C). Anal tubules about $1 \frac{1}{2}$ of posterior parapods (Figure $46 \mathrm{C}$ ).

Notes. Only 2 Holarctic species are described (Bryce \& Hobart ,1972; Sæther, 1975). Larvae of $H$. perennis cannot be easily separated from Heterotanytarsus apicalis (Kieffer). However, given the geographical distribution (i.e. H. apicalis is Palearctic species) larva is most probably H. perennis.

Sampling sites. Torr Bay Brook in Torngats Mountains National Park, N58 ${ }^{\circ} 27.944^{\prime}$ W62 ${ }^{\circ} 49.287^{\prime}$.

Ecology and habitats. Larvae of Heterotanytarsus are inhabitants of lentic and slower reaches of lotic aquatic habitats. Larvae construct cases similar to larvae of Abiskomyia (Anderson et al., 2013).

Nearctic distribution. CANADA: British Columbia, and $1^{\text {st }}$ record for Labrador.

\section{Heterotrissocladius marcidus group \\ Larva $(n=1)$ \\ Figures 47A-F}

Description. Head capsule yellow, submentum area dark brown (Figure 47A). Antenna 7 segmented, $3^{\text {rd }}$ segment sub-equal to $2^{\text {nd }}, 7^{\text {th }}$ segment vestigial and hair-like (Figure 47B), AR=0.85, R0 near the $1 / 3^{\text {rd }}$ of the base of the $1^{\text {st }}$ segment, blade long reaching the base of $4^{\text {th }}$ segment. SI plumose, SII simple (Figure 47C). Premandible simple with a notch (Figure 47C). Mandible with 1 apical and 3 inner teeth, SSd small (Figure 47D). Maxillae with large pecten galearis. Mentum with 2 median and 5 pairs of lateral teeth (Figure 47E), VmP large. Procercus small, each bearing 6 long apical setae (Figure 47F). Posterior parapods as long as wide, each bearing group of claws (Figure 47F). Anal tubules small and conical (Figure 47F).

Notes. The larval specimen is similar to both Heterotrissocladius marcidus (Walker) and Heterotrissocladius latilaminus Sæther in having a dark submentum area. However, based on the geographical distribution and habitat type (i.e., H. latilaminus occurs only in lentic and large lotic habitats of the western Nearctic), this larva is most likely Heterotrissocladius marcidus (Walker). This specimen is perhaps a $2^{\text {nd }}$ instar larva (See Sæther, 1976 and Table 2 in this study for additional diagnosis).

Sampling sites. Burton River in Baffin Island, N63 ${ }^{\circ} 52.800^{\prime}$ W68 18.894'.

Ecology and habitats. Larvae of species in this group are found in springs, streams, rivers and littoral zones of lakes, and are usually restricted to cold waters (Sæther, 1976). Larvae of $H$. marcidus occur in both lentic and lotic habitats with more preference for the littoral zone of lakes (Sæther, 1976). Brundin (1949) has indicated that larvae can occur at depths of $15 \mathrm{~m}$. H. marcidus is reported as the least stenothermic member of the genus; however, it does not occur in freshwaters with mean annual temperature exceeding $18^{\circ} \mathrm{C}$ (Sæther, 1976).

Nearctic distribution. CANADA: Nunavut.

Note. In Canada H. marcidus is reported in British Columbia, Ontario and Quebec. In the USA this species is reported in Florida, Georgia, Michigan, North Carolina, Ohio, and South Carolina.

\section{Hydrobaenus Fries}

Generic diagnosis. Antenna 6 segmented (Figure 48A). SI plumose to serrated (Figures $48 \mathrm{C}$ and $49 \mathrm{C}$ ), SII and SIII simple. Pecten epipharyngis with 3 spine-like plates. Premandible bifid with accessory teeth (Figure 49D). Mentum with 2 median and 6 pairs of lateral teeth, well developed VmP without cardinal beard. Procercus present and well-sclerotized. Posterior parapods well-developed (may be short).

\section{Hydrobaenus conformis group}

Larva $(n=3)$

\section{Figures 48A-F}

Description. Antenna 6 segmented, segments decrease in size sequentially (Figure 48A), blade shorter than flagellum, L0 covering the $3^{\text {rd }}$ segment (Figure 48A), AR=1.3. SI appears bifid and pectinate at the tip (Figure 48B), SII-SIII simple. Pecten epipharyngis with 3 long spine-like scales. Premandible bifid with accessory teeth (Figure 48C). Maxilla with pecten galearis present, posterior lamella of galea simple. Mandible with 1 apical tooth and 3 inner teeth (Figure 48D), apical tooth sub-equal to combined length of inner teeth, mandible is evenly colored. Mentum with 2 median and 6 lateral teeth (Figure 48E). VmP narrow sitting just on the lateral teeth and curves parallel to them (Figure 48E), SSm closer to median suture (Figure 48E). Procercus not well-sclerotized, bearing 6 apical setae. Anal tubules circular and larger than posterior parapods (Figure 48F).

Notes. Presence of swollen anal tubules and anal tubules being longer than posterior parapods put the larvae in conformis group (Andersen et al., 2013).

Sampling sites. A southwest tributary of Arm River in Saglek, N58 28.027' W63 ${ }^{\circ} 33.384^{\prime}$; a north tributary of Arm River in Saglek, N58 ${ }^{\circ}$ 33.021' W63 ${ }^{\circ} 28.102$ '; Ptarmigan Creek in Lake Hazen area, N81 ${ }^{\circ}$ $47.383^{\prime} \mathrm{W}^{\circ} \mathrm{1}^{\circ} 55.938^{\prime}$.

Nearctic distribution. CANADA: Nunavut, and Labrador.

\section{Hydrobaenus fusistylus (Goetghebuer)}

Larva $(n=3)$

\section{Figure 49A-G}

Description. Head capsule brown (Figure 49A), HL/HW=1.05. Antenna 6 segmented, $4^{\text {th }}$ segment sub-equal to $3^{\text {rd }}$ (Figure $\left.49 \mathrm{~B}\right)$, LO large, blade longer than flagellum, $A R=1.5$. SI plumose (Figure 49C), SII and SIII simple, SII long and lamellate $\mathrm{L}=28.3 \mu \mathrm{m}$. Pecten epipharyngis with 3 spine like plates. Premandible trifid with accessory teeth (Figure 49D).Maxilla with pecten galearis present, posterior lamella of galea simple; Mandible with 1 apical tooth and 3 inner teeth (Figure 49E), apical tooth longer than $1^{\text {st }}$ inner teeth, mandible becomes darker at the apex. Mentum with 2 median teeth and 6 pairs of lateral teeth (Figure 49F), median teeth equal in size to $1^{\text {st }}$ laterals, $\mathrm{VmP}$ large extending just beyond the lateral margin of mentum (Figure 49F), no cardinal beard, SSm closer to VmP than median suture. Posterior parapods well reduced (Figure 49G), posterior parapods as long as wide. Procercus short, wider than long and sclerotized, each 
bearing 6-7 long apical setae (Figure 49G). Anal tubules conical, ventral tubules sub-equal to posterior parapods.

Notes. Larva is described by Sæther (1976).

Sampling sites. Sylvia Grennel River in Iqaluit in Baffin Island, N63 ${ }^{\circ} 45.931$ ' W68 ${ }^{\circ} 34.863$ '; Unnamed creek near Iqaluit airport in Baffin Island, N63 ${ }^{\circ} 75.086$ W68 53.172; Mesa Creek in Lake Hazen area, N81 ${ }^{\circ} 55.039^{\prime}$ W69 ${ }^{\circ} 46.105$ '.

Ecology and habitats. Larvae of this species inhabit the Arctic and high mountain lakes and ponds. This species is bivoltine (Sæther, 1976).

Nearctic distribution. CANADA: Alberta, and Nunavut; GREENLAND; USA: Alaska, Colorado, and Montana.

\section{Hydrosmittia Ferrington et Sæther}

Generic diagnosis. Antenna is 4 segmented, with Al usually as wide or wider than long. SI and SII bifid (Figures 50A, 52B). Premandible bifid with 1-2 accessory teeth (Figures 50B and 52C). Mandible with 3-4 inner teeth (Figures 50C, 52D). Mentum with broader median teeth and 4-5 lateral teeth (Figure 50D), VmP large and crescent shape not extending beyond mentum edge. Anterior parapods usually fused with 20-60 serrated claws (Figure 50E). Posterior parapods long to vestigial each bearing 7-12 smooth to serrated claws (Figure 50F). Procercus is absent and 1-3 apical setae are present.

Note. Larvae described in this study do not match the descriptions for the known Hydrosmittia larvae given by Ferrington \& Sæther (2011).

\section{Hydrosmittia sp. 1}

Larva ( $n=1)$

\section{Figures 50A-F}

Description. Larva $\mathrm{L}=4.1 \mathrm{~mm}$. Head capsule brown, $\mathrm{HL} / \mathrm{HW}=0.93$. Antenna 4 segmented, $1^{\text {st }}$ segment wider than long, $1^{\text {st }}$ segment $\mathrm{W}=13.3$ $\mu \mathrm{m}$, blade longer than flagellum. AR=1.3. SI bifid (Figure 50A), SII bifid. Pecten epipharyngis with 3 small equal scales (Figure 50A). Premandible bifid with accessory tooth (Figure 50B). Mandible with 1 apical tooth and 3 inner teeth, apical tooth equal to inner teeth (Figure 50C). Mentum with 1 wide flat median tooth and 4 pairs of lateral teeth (Figure 50D), median tooth $3.5 \mathrm{X}$ the $1^{\text {st }}$ laterals. VmP prominent, crescent shape (Figure 50D) not extending beyond the margin of mentum, SSm posterior to the mentum (Figure 50D). Postmentum $=101 \mu \mathrm{m}$. Anterior parapods well-developed with group of serrated claws, spines sparse (Figure 50E). Procercus absent, 4 apical setae. Posterior parapod developed each bearing 11 claws (Figure 50F) Ls=190.8 $\mu \mathrm{m}$, largest claws $\mathrm{L}=72.7-80.4 \mu \mathrm{m}$, spines on posterior $1 / 3^{\text {rd }}$ of posterior parapods. Anal tubules shorter than posterior parapods conical with no constrictions.

Notes. Posterior parapods of this larva is similar to Hyrosmittia ruttneri (Strenzke et Thienemann) and its mentum is similar to Hydrosmittia falsicostata Ferrington et Sæther. Anterior parapods are developed and not fused which does not match the description for known Hydrosmittia larvae. However, size and number of posterior parapods' claws identifies the specimen as Hydorsmittia.

Study sites. Unnamed creek near Iqaluit airport in Baffin Island, N63 ${ }^{\circ} 75.086^{\prime}$ 'W68 53.172 '.

Nearctic distribution. CANADA: Nunavut.

\section{Hydrosmittia sp. 2 \\ Larva $(n=4)$}

\section{Figures 51A-E}

Description. Larva L=3.4 mm. Head capsule brown (Figure 51A), $\mathrm{HL} / \mathrm{HW}=0.91$. Antenna 4 segmented, $1^{\text {st }}$ segment wider than long, $\mathrm{AR}=1$.2. SI and SII bifid. Pecten epipharyngis with 3 small equal scales. Premandible bifid, with accessory tooth (Figure 51B). Mandible with 1 apical tooth and 3 inner teeth, apical tooth longer than inner teeth (Figure 51C), seta interna absent. Mentum with 1 semi-squared medi- an tooth and 4 pairs of lateral teeth (Figure 51D), median tooth $2 \mathrm{X}$ the $1^{\text {st }}$ lateral teeth. VmP prominent, crescent shape (Figure 51D) not extending beyond the margin of mentum. Procercus absent, 4 short apical setae. Anterior parapod short with serrated claws, Posterior parapod present, each bearing 9-10 serrated claws (Figure 51E), posterior parapods $\mathrm{L}=64.4 \mu \mathrm{m}$, largest claws $\mathrm{L}=77.4 \mu \mathrm{m}$.

Notes. This species resembles Hydrosmittia ruttneri (Strenzke et Thienemann); however, seta interna is missing in this species and posterior parapods lengths differs from $H$. ruttneri.

Study sites. Tributary of Apex River in Iqaluit, N63 ${ }^{\circ} 45.523^{\prime}$ W68 ${ }^{\circ}$ 27.493'; Unnamed stream in Iqaluit, N63 ${ }^{\circ} 46.315^{\prime}$ W68 ${ }^{\circ}$ 51.116'; Mesa Creek in Lake Hazen area, N81 ${ }^{\circ} 55.039^{\prime}$ W69 46.105 '.

Nearctic distribution. CANADA: Nunavut.

\section{Hydrosmittia sp. 3}

Larva $(n=1)$

\section{Figures 52A-F}

Description. Larva $\mathrm{L}=3.3 \mathrm{~mm}$. Head capsule brown, looks circular (Figure $52 \mathrm{~A}$ ), HL/HW=1.0. Antenna 4 segmented, $1^{\text {st }}$ segment wider than long, blade $1.5 \mathrm{X}$ as long as the flagellum. $\mathrm{AR}=0.83$. SI and SII bifid (Figure 52B). Pecten epipharyngis with 3 small equal scales. Premandible trifid with accessory tooth (Figure 52C). Mandible with 1 apical tooth and 4 inner teeth, apical tooth longer than inner teeth (Figure 52D), no seta interna. Mentum with 1 wide and flat median tooth (worn) and 5 pairs of lateral teeth (Figure 52E), median tooth 3.3X the $1^{\text {st }}$ lateral teeth. VmP prominent, crescent shape and narrow (Figure 52E) not extending beyond the margin of mentum. Postmentum=74 $\mu \mathrm{m}$. Anterior parapods $\mathrm{L}=105.4 \mu \mathrm{m}$ each bearing simple claws. Procercus absent, apical setae absent (Figure 52F). Posterior parapod with 6-8 simple claws. Anal tubules small and semicircular (Figure 52F), dorsal $\mathrm{L}=64.0 \mu \mathrm{m} \mathrm{W}=61.0 \mu \mathrm{m}$, ventral $\mathrm{L}=56.0 \mu \mathrm{m} \mathrm{W}=49.0 \mu \mathrm{m}$.

Notes. This larva resembles Hydrosmittia oxoniana (Edwards) larva. However, a damaged posterior end of the specimen does not allow an accurate identification.

Study sites. Muskox Creek in Lake Hazen area, N81 ${ }^{\circ} 50.332^{\prime}$ W71 ${ }^{\circ}$ 20.182'.

Nearctic distribution. CANADA: Nunavut.

Notes. H. oxoniana is a truly aquatic species living on algal growths (Ferrington \& Sæther, 2011). In Canada it has been reported in Nunavut and in the USA it has been reported in South Dakota. H. oxoniana also has a distribution in Greenland.

\section{Hydrosmittia sp. 4 \\ Larva $(n=1)$}

\section{Figure 53A-G}

Description. Larva $\mathrm{L}=1.8 \mathrm{~mm}$; Head capsule yellow (Figure 53A), $\mathrm{HL}=118.0 \mu \mathrm{m}, \mathrm{HL} / \mathrm{HW}=0.8$; Antenna 4 segmented, ${ }^{\text {st }}$ segment $2 \mathrm{X}$ as wide as long, blade longer than flagellum (Figure 53B), AR=1.0; SI and SII bifid (Figure 53C); Premandible bifid; Mandible with 1 apical tooth and 3 inner teeth, apical tooth longer than $1^{\text {st }}$ inner tooth, $2^{\text {nd }}$ inner tooth slightly shorter than other inner teeth (Figure 53D), SSd L=2.5 $\mu \mathrm{m}$, seta interna absent; Mentum with 1 dome shaped median tooth and 4 pairs of lateral teeth, median tooth lighter than laterals, median tooth $\mathrm{W}=11.0 \mu \mathrm{m}$ (3.3X of $1^{\text {st }}$ laterals), SSm well posteriad to mentum (Figure 53E); postmentum $\mathrm{L}=38.1 \mu \mathrm{m}$; Anterior parapods with around 40 claws, larger claws of anterior parapods serrated, $\mathrm{L}=17.0-21.0 \mu \mathrm{m}$ (Figure 53F); Posterior parapods with 7-8 simple claws, larger claws of posterior parapods $\mathrm{L}=13.0 \mu \mathrm{m}-15.0 \mu \mathrm{m}$ (Figure $53 \mathrm{G}$ ) ; 1-2 apical setae present (Figure 53G) Anal tubules $\mathrm{L}=28.0 \mu \mathrm{m}, \mathrm{W}=17.2 \mu \mathrm{m}$.

Study sites. Pond Stream in Borden Peninsula, N72 ${ }^{\circ} 49.021^{\prime}$ W80 ${ }^{\circ}$ 28.497'.

Nearctic distribution. CANADA: Nunavut. 


\section{Krenosmittia sp.}

Larva $(n=7)$

\section{Figures 54A-G}

Description. Larva $\mathrm{L}=2.8 \mathrm{~mm}$. Antenna 5 segmented, $5^{\text {th }}$ segment vestigial and hair-like, $3^{\text {rd }}$ segment smaller than $4^{\text {th }}$ (Figure 54A), blade short reaching the base of $3^{\text {rd }}$ segment (Figure 54A), AR=1.4, R0 close to the middle of $1^{\text {st }}$ antennal segment. SI long and dissected at the tip (Figure 54B), SII and SIII simple. Pecten epipharyngis with 3 equal small scales (Figure 54B). Premandible bifid with accessory tooth (Figure 54B). Mandible with long apical tooth and 3 inner teeth, apical longer than combined inner teeth (Figure $54 \mathrm{C}), \mathrm{SSd}$ long $(\mathrm{L}=15.1 \mu \mathrm{m})$ reaching the base of apical tooth. MP is elongated about $1 / 2$ length of mentum (Figure 54D). Mentum with 1 nipple shaped median tooth and 6 pairs of lateral teeth (Figure 54E), VmP wide at the base, $\mathrm{SSm}$ long $(\mathrm{L}=53.7 \mu \mathrm{m})$. Anal tubules small (Figure 54F). Posterior parapods longer than wide, each bearing group of simple large claws (Figure 54F). Procercus small, each bearing 4 apical setae, 2 apical setae very long (Figures 54F-G).

Notes. Examination of larvae from 4 streams using scanning electron microscope indicates the presence of a $5^{\text {th }}$ antennal segment which agrees with Thienemann \& Krüger's (1939) description for Krenosmittia (see Appendix 1).

Sampling sites. Tributary of Mala River in Borden Peninsula, N72 ${ }^{\circ}$ 57.408' W81 ${ }^{\circ} 12.207 '$; Pond Stream in Borden Peninsula, N72 ${ }^{\circ} 49.021^{\prime}$ W80 28.497'; Tributary of lower Borden River in Borden Peninsula, N72 ${ }^{\circ} 44.098^{\prime}$ W80 23.135 '; McCornick Brook in Torngats Mountains National Park, N58 ${ }^{\circ} 55.236$ ' W63 ${ }^{\circ} 39.882$ '.

Nearctic distribution. CANADA: Nunavut, Labrador.

\section{Limnophyes Eaton}

Generic diagnosis. Antenna 5 segmented, segments consecutively decrease in size (Figures 55A, 56A), blade sub-equal to longer than flagellum. SI bifid with accessory teeth (Figure 55B), SII and SIII simple. Mentum with 2 median and 5 pairs of lateral teeth (Figures 55E, 56C). Procercus each bearing 6-7 long apical setae.

Ecology and habitats. Larvae of Limnophyes species are eurytopic, occurring in aquatic, terrestrial and semi-aquatic habitats (Andersen $e t$ $a l ., 2013)$. In aquatic habitats they occur in moss and on rock surfaces (Epler, 2001).

\section{Limnophyes sp. 1 \\ Larva $(n=5)$}

\section{Figures 55A-F}

Description. Antenna 5 segmented, $4^{\text {th }}$ segment longer than $3^{\text {rd }}$, blade very long ( $2 x$ the length of flagellum) and annulated (Figure $55 \mathrm{~A}), \mathrm{AR}=1.6$, R0 close to mid-section of $1^{\text {st }}$ antennal segment. SI bifid with accessory blade appearing trifid (Figure 55B), SII and SIII simple, SII long and lamellate (Figure 55B). Pecten epipharyngis with 3 equal small scales (Figure 55B). Premandible bifid with bifid accessory tooth (Figure 55C). Mandible with 1 apical and 3 inner teeth, apical longer than $1^{\text {st }}$ inner tooth (Figure 55D). Mentum with 2 median teeth and 5 pairs of laterals (Figure 55E), VmP narrow, SSm posterior to mentum. Procercus present, each bearing 6 long apical setae and 2 sub-apical setae, supra-apical setae as long as apical setae (Figure 55F). Dorsal anal tubules longer than ventral and equal to posterior parapods (Figure 55F), tubules constricted at the base. Posterior parapods longer than wide, each bearing group of claws (Figure 55F).

Notes. Specimens antenna and mentum are similar to the FigureVI.25a-b in Moller Pillot (1985).

Sampling sites. Unnamed creek near Iqaluit airport in Baffin Island, $\mathrm{N}^{\circ} 3^{\circ} 75.086 \mathrm{~W}^{\circ} 8^{\circ}$ 53.172; Burton River in Baffin Island, N63 ${ }^{\circ}$ 47.728' W68 17.521 '; Tributary of Mala River in Borden Peninsula, N72 ${ }^{\circ} 57.408^{\prime}$ W81 ${ }^{\circ} 12.207^{\prime}$; Very River in Lake Hazen area, N81 ${ }^{\circ} 32.970^{\prime}$
W73 ${ }^{\circ} 35.046^{\prime}$; Tributary of Ruggles River in Lake Hazen area, N81 ${ }^{\circ}$ 43.141' W69 25.512 '; Blister Creek in Lake Hazen area, N81 ${ }^{\circ} 49.147^{\prime}$ W71 ${ }^{\circ} 31.741$ '.

Nearctic distribution. CANADA: Nunavut.

\section{Limnophyes sp. 2}

Larva $(n=5)$

\section{Figures 56A-E}

Description. Antenna 5 segmented, $4^{\text {th }}$ segment longer than $3^{\text {rd }}$, blade sub-equal to flagellum (Figure 56A), AR=1.8, R0 close to mid-section of $1^{\text {st }}$ antennal segment, LO is robust. SI serrated, SII and SIII simple, SII long and lamellate. Pecten epipharyngis with 3 equal small scales. Premandible bifid with accessory tooth. Mandible (Figure 56B). Mentum with 2 median teeth and 5 pairs of laterals (Figure 56C), VmP wide at the base, anteriorly reaches the base of $2^{\text {nd }}$ lateral teeth (Figure 56D), SSm posterior to mentum. Procercus well-sclerotized, each bearing 6 apical setae (Figure 56E), supra-apical setae as long as apical setae. Dorsal anal tubules longer than ventral tubules and equal to posterior parapods, ventral tubules smaller than posterior parapods (Figure 56E), tubules constricted at the base. Posterior parapods longer than wide, each bearing group of claws (Figure 56E).

Notes. Larvae differ from the Limnophyes sp.1 in length of antennal blade, shape of SI, and shape and size of ventromental plates. Additionally, both the head capsule and mandibles appear darker in this species.

Sampling sites. Burton River in Baffin Island, N63 ${ }^{\circ} 47.728^{\prime}$ W68 ${ }^{\circ}$ 17.521'; Nonet Stream in Pond Inlet area, N72 ${ }^{\circ} 40.24806^{\prime}$ W77 ${ }^{\circ} 57.3417^{\prime}$; Tributary of Mala River in Borden Peninsula, N72 ${ }^{\circ} 57.408^{\prime}$ W81 ${ }^{\circ}$ 12.20754'; Very River in Lake Hazen area, N81 ${ }^{\circ} 32.970^{\prime}$ W73 $35.046^{\prime}$; Tributary of Ruggles River in Lake Hazen area, N81 ${ }^{\circ} 43.141^{\prime}$ W69 25.512'; Blister Creek in Lake Hazen area, N81 ${ }^{\circ} 49.147^{\prime}$ W71 ${ }^{\circ} 31.741^{\prime}$ '.

Nearctic distribution. CANADA: Nunavut.

\section{Metriocnemus van der Wulp}

Generic diagnosis. Antenna 5 segmented, 4 in Metriocnemus fuscipes (Figures 57A, 58D). SI is plumose (simples in M. fuscipes) (Figure 57B). Labral lamellae well developed, absent in M. fuscipes. Anal setae short (Figure 57G).

\section{Metriocnemus (Metriocnemus) eurynotus (Holmgren) Larvae $(n=4)$ \\ Figures 57A-F}

Description. Antenna 5 segmented, $4^{\text {th }}$ segment subequal to $3^{\text {rd }}$ blade longer than flagellum (Figure 57A), AR=1.9. SI pectinate (Figure 57B), SII and SIII small and simple. Labral lamellae well developed (Figure 57B). Pecten epipharynges with 3 small scales. Premandible bifid with prominent accessory teeth and brush (Figure 57C). Mandible with 1 apical tooth and 4 inner teeth (Figure 57D), SSd small. Mentum with 2 median teeth slightly receded and 5 pairs of laterals (Figure 57E), VmP small, setae submenti located parallel and adjacent to the posterior tip of mentum. Body setae short, body light brown with dark brown contrast. Procercus as long as wide and sclerotized, each bearing 6 apical setae (Figure 57F). Posterior parapods about 1.5X long as wide. Anal tubules present and sub-equal to posterior parapods (Figure 57F).

Notes. Larva is described by Pankratova (1970) and Moller Pillot (1984) as Metriocnemus hygropetricus Kieffer and by Epler (2001).

Sampling sites. Unknown stream in Resolute Bay N74 4480.9720002' 'W94 ${ }^{\circ} 47.688$ '; Resolute Creek in Resolute Bay, N74 ${ }^{\circ}$ 4481.028' W94 ${ }^{\circ}$ 54.6679998'; Pond Stream in Borden Peninsula, N72 ${ }^{\circ}$ 47.94858' W80 20.86374 '; Tributary or Ruggles River in lake Hazen area, $\mathrm{N}^{\circ} 1^{\circ} 43.1419998^{\prime} \mathrm{W}^{\circ} 9^{\circ} 25.512$ '.

Ecology and habitats. According to Epler (2001) larvae of this species occur in madicolous habitats with water flowing in thin sheets 
over rocks. They may also occur in organically enriched habitats, such as sewage treatment beds.

Nearctic distribution. CANADA: Northwest Territories, New Brunswick, $1^{\text {st }}$ record for Nunavut, Ontario; GREENLAND; USA: Minnesota, North Carolina, Ohio, South Carolina, and Tennessee.

\section{Metriocnemus (Metriocnemus) cf. fuscipes (Meigen) \\ Early Instar Larvae $(n=2)$ \\ Figures 58A-E}

Description. Larva small (Figure 58A), L=1.9 mm. Antenna 4 segmented and reduced (Figure $58 \mathrm{~B}$ ), $1^{\text {st }}$ antennal segments as long as wide, blade longer than flagellum, $\mathrm{AR}=0.96$; SI-SIII are simple. Premandible bifid (Figure 58C). Mandible with 1 apical tooth and 4 inner teeth (Figure 58A). Mentum with 2 median teeth well receded and 6 pairs of laterals (Figure 58D), mentum appears oriented inward, the $6^{\text {th }}$ lateral teeth sit well below the $5^{\text {th }}, \mathrm{VmP}$ indistinct, $\mathrm{SSm}$ well posterior to mentum (Figure 58D). Body yellowish grey with bands of blue stripes (Figure 58A). Procercus short and as long as wide, each bearing 6 short apical setae (Figure 58E); Posterior parapods well reduced each bearing group of claws (Figure 58E). Anal tubules small and conical (Figure 58E).

Notes. Larva of $M$. fuscipes described by Pankratova (1970), Moller Pillot (1958) and by Epler (2001). The specimens obtained are probably the $3^{\text {rd }}$ instar larvae.

Sampling sites. Nakvak Book in Turngats Municipality, N58 $39.1305^{\prime}$ W64 3.15072 '.

Ecology and habitats. Larva inhibits pitcher plants, slow reaches of streams and also occurs among wet moss in streams and on the rocks adjacent to the streams.

Note on Nearctic distribution. Metriocnemus (Metriocnemus) fuscipes (Meigen) has not been reported in Labrador. In Canada occurs in New Brunswick, Ontario. It also occurs in Greenland. In USA occurs in Georgia, New York, North Carolina, South Carolina, South Dakota, and Tennessee.

\section{Metriocnemus sp. 1}

Larva $(n=1)$

Figures 59A-F

Description. Larva L=3.9 mm. Head capsule yellow, HL/HW=0.62. Antenna 5 segmented, segments decrease in size sequentially (Figure $59 \mathrm{~A}), \mathrm{R} 0$ at basal $1 / 3^{\text {rd }}$ of $1^{\text {st }}$ segment, L0 prominent covering most of $3^{\text {rd }}$ segment, blade longer than flagellum, $\mathrm{AR}=2.0$. SI looks more palmate than pectinate (Figure 59B), SII-SIII simple, labral lamellae well developed (Figure 59B). Pecten epipharyngis with 3 equal scales (Figure 59B). Premandible bifid with accessory tooth and brush (Figure 59C), brush present. Mandible with 1 long apical tooth and 3 inner teeth (Figure 59D), SSd simple and short. Mentum with bifid median tooth and 5 pairs of lateral teeth (Figure 59E), median tooth with is squared shouldered and pointed at the tips (Figure 59E), SSm posteriad, VmP narrow. Procercus well-sclerotized and longer than wide, each bearing 5 apical setae (Figure 59F). Posterior parapods with group of large simple claws (Figure 59F). Dorsal anal tubules $(\mathrm{L}=212.5 \mu \mathrm{m})$ longer than ventral tubles $(\mathrm{L}=139.7 \mu \mathrm{m})$ and the posterior parapods.

Notes. Setae interna of mandible are not very clear; however, it appears that it consists of 3-4 long lamellate branches that are serrated at the tip.

Sampling sites. Tributary of Snow Goose River in Lake Hazen area, N81 ${ }^{\circ} 55.234^{\prime} \mathrm{W} 71^{\circ} 5.457^{\prime}$.

Nearctic distribution. CANADA: Nunavut.

\section{Nanocladius Kieffer}

Generic diagnosis. Antenna 5 segmented (Figure 60A). SI-SIII usually simple. Premandible simple (Figure 61B). Mandible with long api- cal tooth and 3 inner teeth. Mentum with usually wide nipple shaped bifid median tooth and 5 pairs of lateral teeth, large VmP reaching the lateral margin of the mentum, cardinal beard absent. Anterior parapods with or without serrated claws. Posterior parapods with simple claws. Well-developed procercus with 3-6 apical setae.

\section{Nanocladius (Nanocladius) dichromus group Larva $(n=3)$}

\section{Figures 60A-G}

Description. Larvae medium size, $\mathrm{L}=4 \mathrm{~mm}$. Head capsule yellow. Antenna 5 segmented, $5^{\text {th }}$ segment vestigial and hair like (Figure $60 \mathrm{~A}$ ), $1^{\text {st }}$ segment $\mathrm{L}=46.0 \mu \mathrm{m}, \mathrm{LO}$ prominent covering most of $3^{\text {rd }}$ segment (Figure 60A), R0 at the base of $1^{\text {st }}$ segment, blade shorter than flagellum, large accessory blade $\mathrm{L}=25.1 \mu \mathrm{m}$ (Figure 60A), AR=1.5. SI and SII simple and hair like. Pecten epipharyngis with 3 equal scales (Figure60B). Premandible simple with notch, accessory tooth large. Mandible with 1 long apical tooth and 3 inner teeth (Figure 60C), apical tooth $2 \mathrm{X}$ the width of 3 inner teeth, inner teeth are darker than rest of mandible. Mentum with wide bifid and crest like median teeth and 5 pairs of lateral teeth, $1^{\text {st }}-2^{\text {nd }}$ lateral teeth wide and squared (Figure $60 \mathrm{D}), \mathrm{VmP}$ long, anteriorly extending to the $1^{\text {st }}$ lateral teeth, rounded at the caudolateral apex (Figure 60D), SSm anterior to VmP (Figure 60D). Claws of anterior parapods strongly serrated (Figure 60E). Claws of posterior parapods are simple (Figure 50F). Procercus well-sclerotized, each bearing 4-5 apical setae, at least 2 apical setae longer than remaining setae (Figure 60F). 4 anal tubules of equal size, anal tubules slightly shorter than posterior parapods (Figure 60F).

Notes. The long, apically rounded ventromental plates places the larvae in subgenus Nanocladius. A weakly serrated anterior parapods' claws places the larvae in dichromus group. Larvae are probably Nanocladius (Nanocladius) rectinervis (Kieffer) described by Lindegaard-Peterson (1972) and by Sæther (1977b). Measurements of the specimens and a developed thoracic horn in $4^{\text {th }}$ instars (Figure 60G) match the description given by Sæther (1977b) for $N$. rectinervis.

Study Sites. Pond Stream in Borden Peninsula, N72 ${ }^{\circ} 49.021^{\prime}$ W80 ${ }^{\circ}$ 28.497'.

Ecology and habitats. The $N$. rectinervis is reported by Fittkau \& Lehman (1970) as a rheophilous and cold-stenothermic species. In the Nearctic it has only been reported from lakes and reservoirs; however, in Europe larvae have been reported in lotic environments. In this study larvae occurred in stream habitat.

Nearctic distribution. CANADA: Nunavut.

Notes. Oliver et al. (1990) and Sæther (1977b) have indicated that $N$. rectinervis has a Holarctic distribution. In Canada it has been reported in Manitoba, Ontario. In the USA it has been reported in Colorado, Nebraska, New York, North and South Carolinas.

\section{Nanocladius (Plecopteracoluthus) sp. 1 \\ Larvae $(n=1)$}

\section{Figures 61A-G}

Description. Head capsule yellow. Antenna 5 segmented, $5^{\text {th }}$ segment slightly longer than $4^{\text {th }}$, (Figure $61 \mathrm{~A}$ ), LO prominent covering the $3^{\text {rd }}$ segment, R0 at the base of the $1^{\text {st }}$ segment, AR=1.0, blade much shorter than flagellum, accessory blade $\mathrm{L}=21 \mu \mathrm{m}$. Pecten epipharyngis with 3 equal scale (Figure 61B). Premandible simple with notch, accessory tooth large (Figure 61B). Mandible with 1 long apical tooth and 3 inner teeth, inner teeth darker (Figure 61C). Mentum with 1 wide double-crest median tooth and 5 pairs of lateral teeth (Figure 61D), $1^{\text {st }} 2^{\text {nd }}$ lateral teeth wider and squared, VmP not extremely long caudolaterally squared (Figure 61D), SSm posterior to VmP (Figure 61D). Anterior parapods claws strongly serrated (Figure 61E). Procercus well-sclerotized with 4-5 apical setae, at least 2 apical setae longer (Figure 61F). Posterior parapods claws simple (Figure 61G). 
Study site. Burton River in Iqaluit, Baffin Island, N63 ${ }^{\circ} 47.728^{\prime} \mathrm{W} 68^{\circ}$ 21.635'.

Nearctic distribution. CANADA: Nunavut.

Nanocladius (Plecopteracoluthus) sp. 2

Larva $(n=1)$

Figures 62A-E

Description. Head capsule reddish yellow. Antenna 5 segmented, $5^{\text {th }}$ segment shorter than $4^{\text {th }}$ (Figure $62 \mathrm{~A}$ ), LO covers $2 / 3^{\text {rd }}$ of the $3^{\text {rd }}$ segment, R0 at the base of $1^{\text {st }}$ segment, blade slightly shorter than flagellum, accessory blade $\mathrm{L}=25.5 \mu \mathrm{m}, \mathrm{AR}=1.7$. SI and SII are simple and long. Pecten epipharyngis with 3 equal scales (Figure 62B). Premandible simple with notch and prominent accessory tooth (Figure 62B). Mandible with 1 long apical tooth and 3 inner teeth (Figure 62C), inner teeth darker than rest of mandible. Mentum with 1 wide crestlike median teeth and 5 pairs of lateral teeth (Figure 62D), VmP not long, caudolaterally squared (Figure 62D), SSm located anteriorly to VmP (Figure 62D). Claws of anterior parapods strongly serrated. Procercus well-sclerotized, each bearing 4-5 apical setae, at least 2 setae longer than the others (Figure 62E). Claws of posterior parapods simple (Figure 62E).

Study site. Pond Stream in Borden Peninsula, N72 ${ }^{\circ} 49.021^{\prime}$ W80 ${ }^{\circ}$ 28.497'.

Nearctic distribution. CANADA: Nunavut.

Notes. Epler (2001) has indicated that there are several undescribed species of this subgenus in the southeast USA. Therefore, many larvae assigned to species must be viewed with skepticism. In both examined study specimens, VmPs are squared caudolaterally and claws of anterior parapods are strongly serrated. This suggests that both larvae belong to Plecopteracoluthus subgenus. The Nanocladius (Plecopteracoluthus) sp. 1 could be a younger instar (i.e. possibly $3^{\text {rd }}$ instar) of the Nanocladius (Plecopteracolutus) branchicolus (Sæther). The combination of mentum with 1 median tooth with sharp cusp, 5 pairs of lateral mental teeth, short antennal blade, and SSms locating posterior to $\mathrm{VmPs}$ resembles $N$. branchicolus. The Nanocladius (Plecopteracoluthus) sp. 2 differs from the first species by having an antennal blade which is sub-equal to flagellum, LO is less prominent, $5^{\text {th }}$ antennal segment is shorter than $4^{\text {th }}$ and SSms are located anteriorly to VmPs. However, without a $4^{\text {th }}$ instar larvae and/or associated pupae, it is not possible to identify these specimens with certainty.

Ecology and habitats. Larvae of species in this subgenus are usually phoretic on Plecoptera nymphs, usually of family Perlidae. They are also phoretic on Ephemeroptera, Megaloptera, Hemiptera and Odonata. Larvae construct a gelatinous or silken case and lives among the gills of aquatic insects (Epler, 2001; Sæther, 1977; Steffan, 1965).

\section{Oliveridia tricornis (Oliver)}

Larva $(n=1)$

\section{Figures 63A-E}

Description. Larva $\mathrm{L}=6.5 \mathrm{~mm}$. Antenna 6 segmented, segments sequentially decrease in size (Figure $63 \mathrm{~A}$ ), RO at basal 1/3 ${ }^{\text {rd }}$, LO small, blade reaching the base of $5^{\text {th }}$ segment, $A R=1.6$. SI plumose, SII simple (Figure 63B). Pecten epipharyngis with 3 long sub-equal scales (Figure 63B). Premandible bifid with accessory tooth (Figure 63B). Mandible with 1 apical tooth and 3 inner teeth (Figure 63C). Mentum with 1 wide flat median tooth and 6 pairs of lateral teeth (Figure 63D), VmP large extending beyond the edge of mentum (Figures 63D). Procercus wellsclerotized wider than long, each bearing 6 apical setae (Figure 63E). Posterior parapods longer than wide with group of claws (Figure 63E).

Notes. Larva is described by Sæther (1976) as Oliveria tricornis. Mentum of the retrieved specimen is damaged (see the drawing of median tooth in Figure 63D).
Study sites. McCornick Brook in Torngats Mountains National Park, N58 ${ }^{\circ} 56.553^{\prime}$ W63 ${ }^{\circ} 35.595$ '.

Ecology and habitats. Larvae of this species are typical inhabitants of ultraoligotrophic Arctic lakes (Sæther, 1973). In this study larvae occurred in streams.

Nearctic distribution. CANADA: $1^{\text {st }}$ record for Labrador, Nunavut; GREENLAND.

\section{Orthocladius van der Wulp}

Generic diagnosis Notes. A detailed keys and diagnoses of subgenera and species are given by Sæther (2005), and by Soponis (1977, 1990). Also, see notes under Cricotopus.

\section{Orthocladius (Euorthocladius) luteipes Goetghebuer \\ Larva $(n=1)$}

\section{Figures 64A-E}

Description. Head capsule yellow-brown getting darker in posterior. Antenna 5 segmented (Figure 64A), segments reduced in size consecutively, LO large covering $3^{\text {rd }}$ segment, blade short reaching the base of $5^{\text {th }}$ segment, AR=1.8. SI bifid (Figure 64B), SII and SIII simple (Figure 64B). Pecten epipharyngis with 3 sub-equal scales. Premandible simple (Figure 64B). Mandible with 1 apical and 3 inner teeth (Figure 64C), apical tooth slightly longer than $1^{\text {st }}$ inner, mandible outer ridge smooth. Mentum with 1 median tooth and 6 pairs of lateral teeth (Figure 64D), median tooth and the $1^{\text {st }}$ pairs of lateral teeth stand higher than other lateral teeth (Figure 64D), median tooth $1.5 \mathrm{X}$ the $1^{\text {st }}$ laterals, VmP thin extend anteriorly to $2^{\text {nd }}$ laterals and extended posteriorly parallel to SSm. Body yellowish, abdominal setae small. Procercus reduced, each bearing 6 apical setae (Figure 64E). Posterior parapods not much longer than wide, each bearing group of claws (Figure 64E). Anal tubules small, conical and equal in size.

Notes. Larva may resemble the Orthocladius (Euorthocladius) thienemanni Kieffer. O. luteipes has a wider median mental tooth and more posteriorly located SSms.

Sampling sites. Unnamed creek near Iqaluit airport in Baffin Island, N63 ${ }^{\circ} 75.086$ W68 53.172 ; Tributary of Very River in Lake Hazen area, $\mathrm{N} 81^{\circ} 32.950$ ' W73 35.757 '.

Ecology and habitats. Larvae of this species occur in rivers and creeks (Soponis, 1990). According to Thienemann $(1939,1954)$ freeliving larvae can construct gelatinous cases. Coffman (1973) reported the adult emergence in Pennsylvania from February till May with peak in April.

Nearctic distribution. $1^{\text {st }}$ record for CANADA: Nunavut; USA: Arizona, Georgia, New York, North Carolina, Ohio, Oregon, and Pennsylvania.

\section{Orthocladius (Euorthocladius) saxosus (Tokunaga) Larva $(\mathrm{n}=6)$ \\ Figures 65A-E}

Description. Head capsule light to dark brown. Antenna 5 segmented (Figure 65A), $4^{\text {th }}$ segment sub-equal to $3^{\text {rd }}$, LO large covering the $3^{\text {rd }}$ segment (Figure 65A), blade longer than flagellum, R0 at the base of $1^{\text {st }}$ antennal segment, $A R=1.7$. SI bifid, SII and SIII simple. Pecten epipharyngis consist of 3 sub-equal scales (Figure 65B). Premandible simple. Maxilla ChLA appear reduced. Mandible with 1 apical tooth and 3 inner teeth (Figure 65C), apical tooth same size as $1^{\text {st }}$ inner, mandible uniformly brown with patch of dark brown at the base, SSd and seta interna present and developed, mandible outer ridge smooth. Mentum with 1 median tooth and 6 pairs of lateral teeth (Figure 65D), median tooth same size as $1^{\text {st }}$ laterals and can be worn (Figure 65D), VmP thin extends posteriorly (Figure 65D). Body yellowish red, body hairs long $1 / 2$ of the segment bearing them, abdomen hair more prominent on seg- 
ments V- XII. Procercus reduced, each bearing 6 apical setae (Figure $65 \mathrm{E}$ ). Posterior parapods $2 \mathrm{X}$ as long as wide, each bearing group of dark claws (Figure $65 \mathrm{E}$ ). Anal tubules $1 / 2$ of posterior parapods and conical (Figure 65E), dorsal pair shorter than ventral pairs.

Notes. Larva of $O$. saxosus is similar to that of $O$. thienemanni. The O. saxosus has shorter dorsal pair of anal tubules than ventral pairs (Pankratova, 1970; Soponis, 1990) which is distinguishable from $O$. thienemanni.

Sampling sites. McCornick Brook in Torngats Mountains National Park, N58 56.553 ' W63 ${ }^{\circ} 35.595$ '; Tributary of Mala River in Borden Peninsula, N72 ${ }^{\circ}$ 57.408' W81 ${ }^{\circ}$ 12.207'; Angry Crane River in Bylot Island, $\mathrm{N}^{\circ}{ }^{\circ} 8.15646^{\prime}$ W80 ${ }^{\circ} 3.13272^{\prime}$; Unnamed river in Resolute Bay area, N74 ${ }^{\circ} 44.809^{\prime}$ W94 ${ }^{\circ} 47.688^{\prime}$; Salor Creek in Lake Hazen area, N81 ${ }^{\circ}$ $54.156^{\prime}$ W68 $54.457^{\prime}$; Tributary of Snow Goose River in Lake Hazen area, ${\mathrm{N} 81^{\circ}}^{\circ} 54.156^{\prime} \mathrm{W} 68^{\circ} 54.457$ '.

Ecology and habitats. Larvae of this species live in gelatinous tubes with irregular shapes attached to stones of small mountain streams. Larvae can over-winter (Soponis, 1990).

Nearctic distribution. CANADA: Alberta, $1^{\text {st }}$ record Nunavut and $1^{\text {st }}$ record Labrador; USA: Alaska, Colorado, Montana, North Carolina, Oregon, and Wyoming.

\section{Orthocladius (Euorthocladius) thienemanni Kieffer Larva $(n=2)$}

Figures 66A-F

Description. Head capsule yellow to brown. Antenna 5 segmented (Figure 66A), $4^{\text {th }}$ segment slightly shorter than $3^{\text {rd }}$, LO large covering the $3^{\text {rd }}$ segment (Figure 66A), R0 at $1 / 3$ of $1^{\text {st }}$ segment, blade short reaching the base of $4^{\text {th }}$ segment, AR=2.4. SI bifid (Figure 66B), SII and SII simple (Figure 66B). Pecten epipharyngis consist of 3 sub-equal scales (Figure 66B). Premandible simple with small notch at the base (Figure 66B). Mandible with 1 apical tooth and 3 inner teeth (Figure 66C), apical tooth and anterior portion of mandible darker than inner and base of mandible, apical tooth slightly longer than $1^{\text {st }}$ inner teeth, seta interna present with 6-7 setae, SSd spine-like, mandible outer ridge smooth. Mentum with 1 median tooth and 6 pairs of lateral teeth, median tooth $2 X$ the $1^{\text {st }}$ laterals (Figure 66D), VmP thin extends posteriorly (Figure 66D). Claws of anterior parapods as in Figure 66E. Body yellowish cream, abdominal setae not prominent. Procercus reduced, each bearing 6 apical setae (Figure 66F) and 2 sub-apical setae. Posterior parapods as long as wide each bearing group of claws (Figure 66F). Anal tubules long and sub-equal, constricted in the middle and at the base (Figure 66F).

Sampling sites. Unnamed creek near Iqaluit airport in Baffin Island, $\mathrm{N}^{\circ} 3^{\circ} 75.086^{\prime}$ W68 $53.17299^{\circ}$ '.

Ecology and habitats. Larvae of this species live on the surface of cold running waters and constructs gelatinous cases (Soponis, 1990). Larvae feed on diatoms but are often associated with algal growth on stones. Larvae of this species are rheobiontic (Drake, 1982; Soponis, 1990; Thienemann, 1954). Species is bivoltine with early spring to late summer emergence (Soponis, 1990; Lehman, 1971).

Nearctic distribution. CANADA: Northwest Territories, $1^{\text {st }}$ record for Nunavut, Ontario; GREENLAND; USA: Alaska, Arizona, Georgia, Kansas, North Carolina, Ohio, Pennsylvania, South Carolina, and Tennessee.

\section{Orthocladius (Mesorthocladius) frigidus Kieffer \\ Larva $(n=4)$}

Figures 67A-D

Description. Head capsule reddish brown to dark brown. Antenna 5 segmented (Figure $67 \mathrm{~A}), 4^{\text {th }}$ segment slightly longer than $3^{\text {rd }}$, LO small, $\mathrm{AR}=1.7$. SI bifid, SII and SIII simple. Premandible simple. Mandible with 1 apical teeth (same size as $1^{\text {st }}$ inner) and 4 inner teeth (Figure 67B), seta interna absent, outer ridge smooth to crenulated. Mentum with 1 median tooth and 6 pairs of lateral teeth (Figure 67C), median tooth $1.5 \mathrm{X}$ of $1^{\text {st }}$ lateral teeth, median tooth and the $1^{\text {st }}$ lateral teeth stand above remaining mentum' teeth, giving an appearance of trifid median tooth, VmP thin extends posteriorly. Abdominal setae short. Procercus short, each bearing 6 apical setae (Figure 67D). Anal tubules longer than posterior parapods, narrow and conical (Figure 67D). Posterior parapods $2 \mathrm{X}$ as long as wide, each bearing group of dark claws (Figure 67D).

Notes. This species was originally in Euorthocladius subgenus (see Soponis, 1987); however, it was placed in the Mesorthocladius by Sæther (2005). Larvae in this study have mandibles with smooth outer ridge.

Sampling sites. Angry Crane River in Bylot Island, N73 ${ }^{\circ} 8.156^{\circ}$ W80 3.132 '; Unnamed creek in Resolute Bay, N74 ${ }^{\circ} 4480.9720^{\prime}$ W94 ${ }^{\circ}$ 47.688'.

Ecology and habitats. Larvae are reported as rheophilous and hemistenotherm by Dittmar (1955). Larvae can occur as free living on boulders or in mud cases (Cranston, 1982; Soponis, 1987).

Nearctic distribution. $1^{\text {st }}$ record for CANADA: Nunavut; GREEANLAND; USA: Arizona, California, Georgia, North Carolina, and South Carolina.

\section{Orthocladius (Mesorthocladius) rousellae Soponis}

Larva $(n=2)$

\section{Figures 68A-F}

Description. Head capsule yellowish brown, postoccipital margin dark (Figure 68A). Antenna 5 segmented (Figure 68B), $4^{\text {th }}$ segment sub-equal to the $3^{\text {rd }}$, LO covers the $3^{\text {rd }}$ segment, blade reaching the base of $5^{\text {th }}$ segment, AR=2.4. SI bifid, SII and SIII simple (Figure 68C). Pecten epipharyngis consist of 1 slightly larger median and 2 lateral scales (Figure 68C). Premandible bifid (Figure 68C), accessory teeth prominent. Maxilla with ALCh larger than other chaeta. Mandible with 1 long apical tooth and 4 inner teeth (Figure 68D), outer ridge moderately crenulated, seta interna absent. Mentum with 1 median tooth and 7 pairs of lateral teeth (Figure 68E), median tooth $<1.5 \mathrm{X}$ the $1^{\text {st }}$ laterals, VmP extended posteriorly parallel to SSm. Abdominal setae short. Procercus small each bearing 6 apical setae (Figure 68F). Posterior parapods short and slightly longer than wide, each bearing group of dark claws (Figure 68F). Anal tubules about the same size as posterior parapods and conical (Figure 68F).

Notes. This species was originally in Euorthocladius subgenus (Soponis, 1987); however, it was placed in new subgenera, the Mesorthocladius, by Sæther (2005).

Sampling sites. Angry Crane River in Bylot Island, N73 ${ }^{\circ} 8.156^{\prime}$ W80 3.132 '; Unnamed creek near Iqaluit airport in Baffin Island, $\mathrm{N}^{\circ}{ }^{\circ}$ 75.086' W68 53.172 '.

Ecology and habitats. Larvae occur in algal mats of small to large lotic environments (Soponis, 1987).

Nearctic distribution. CANADA: Alberta, Northwest Territories, Nunavut, Yukon Territory; GREENLAND; USA: Alaska, Wyoming.

\section{Orthocladius (Orthocladius) charensis Soponis \\ Larva $(n=1)$}

\section{Figures 69A-F}

Description. Head capsule yellow. Antenna 5 segmented (Figure $69 \mathrm{~A}), 3^{\text {rd }}$ segment slightly longer than $4^{\text {th }}$, blade short reaching the base of $4^{\text {th }}$ segment, $A R=2.0$. SI bifid (Figure 69B), SII and SIII simple. Pecten epipharyngis consist of 3 equal scales. Premandible simple with notch (Figure 69C). Mandible with 1 apical tooth and 3 inner teeth (Figure 69D), apical tooth same size as $1^{\text {st }}$ inner, mandible outer ridge slightly crenulated. Mentum with 1 median tooth and 6 pairs of lateral teeth (Figure $69 \mathrm{E}$ ), median tooth and the $1^{\text {st }}$ lateral teeth give a trifid median tooth look, VmP narrow and small extending posteriorly (Figure 69E). 
Procercus small, each bearing 6 apical setae (Figure 69F). Posterior parapods no longer than wide, each bearing group of claws (Figure 69F). Anal tubules conical and same size as posterior parapods.

Notes. Larvae may resemble that of Orthocladius (Orthocladius) lapponicus Goetghebuer which also occurs in similar habitats and geographical regions. The combination of light body (i.e. white or light yellow) and rounded anal tubules of $\boldsymbol{O}$. charensis separate it from that of O. lapponicus (Soponis, 1977). Additionally, larvae of O. charensis occur on rocks and do not build tubes whereas 0 . lapponicus larvae build tubes in moss (Soponis, 1977).

Sampling sites. North Lake River in Resolute Bay, N74 $44.867^{\prime}$ W95 7.203 '.

Ecology and habitats. Larvae of this species occur in rocky habitat of lakes (Soponis, 1977).

Nearctic distribution. CANADA: Nunavut; GREENLAND.

\section{Orthocladius (Orthocladius) cf. clarkei Soponis \\ Larva $(n=1)$}

\section{Figure 70A-D}

Description. Head capsule brownish yellow. Antenna 5 segmented, $4^{\text {th }}$ segment sub-equal to the $3^{\text {rd }}$ (Figure 70A), LO small covering part of $3^{\text {rd }}$ segment, blade reaches the tip of $4^{\text {th }}$ segment, $A R=1.3$. SI bifid, SII and SIII simple. Pecten epipharyngis consist of 3 scales, lateral scales slightly longer. Premandible simple. Chaetulae of maxilla of same shape and size. Mandible with 1 apical tooth and 4 inner teeth (Figure 70B), apical tooth longer than $1^{\text {st }}$ inner teeth, outer ridge smooth. Mentum with 1 broad median tooth and 6 pairs of lateral teeth (Figure 70C), VmP large extending well posteriorly. Body yellowish green. Procercus small each bearing 6 apical setae (Figure 70D). Posterior parapods longer than wide, each bearing group of claws (Figure 70D). Anal tubules conical and as long as posterior parapods.

Notes. The smooth outer margin of $O$. clarkei mandibles separates the larvae from those of Orthocladius (Orthocladius) mallochi Kieffer and Orthocladius (Orthocladius) wiensi Sæther (Soponis, 1977). 0. wiensi is not recorded from the Arctic. However, O. mallochi is recorded from the Northwest Territories prior to 1990, which indicates that its distribution overlaps with that of $O$. clarkei in Nunavut.

Sampling sites. Salor Creek in Lake Hazen area, N81 ${ }^{\circ} 54.156^{\prime}$ W68 54.457 '.

Ecology and habitats. Larvae of this species occur in small bog fed streams and build tubules. The species is univoltine (Soponis, 1977).

Note on the Nearctic distribution. Orthocladius (Orthocladius) clarkei Soponis has not been reported in Nunavut. In Canada it has only been reported in Ontario. In the USA it has been reported from Illinois, Iowa, Minnesota, Pennsylvania, and Texas. According to Epler (2001) geographical reports from North and South Carolinas are doubtful.

\section{Orthocladius (Orthocladius) obumbratus Johannsen \\ Pupa $(n=3)$ \\ Figures 71A-I}

Diagnosis. Pupa L=4.6 mm. Frontal apotome (Figure 71A), Frontal setae $\mathrm{L}=152.0 \mu \mathrm{m}$. Thoracic horn with numerous spines (Figure 71Band C), widest at the base, $\mathrm{L}=289.3 \mu \mathrm{m}, \mathrm{Pc} 1=54.0 \mu \mathrm{m}, \mathrm{Pc} 2=159.4 .0$ $\mu \mathrm{m}, \mathrm{Pc} 3=143.0 \mu \mathrm{m}$. Wing sheet without peal row, $\mathrm{L}=1305.5 \mu \mathrm{m}$, $\mathrm{W}=360.0 \mu \mathrm{m}$. Tergite I bare, tergites II with 3 rows of recurved spines (Figures 71D and E), tergites III-V with large simple spines medially and anteriorly (Figures 71F and G), tergite VII-VIII with scattered small spines medially and anteriorly. Sternite I bare, sternite II with anterior spines, sternite III-VI with spines medially and anteriorly, sternite VIIVIII with small patches of spines anteriorly. Shagreens present on segment I-VIII, Segment I with 2 D setae, segments II-VIII with 5 D setae, B-spurii present on segment II (Figure 71D). Anal lobes with 3 apical setae of equal size $\mathrm{L}=120.0 \mu \mathrm{m}$, anal lobes with 2 spurs at the tip (Figures 71H-I), male genitalia sacs longer than anal lobes, females shorter (Figures 71H-I).

\section{Larva $(\mathrm{n}=3)$}

\section{Figures 72A-E}

Description. Larva $\mathrm{L}=4.6 \mathrm{~mm}$. Head capsule reddish brown. Antenna 5 segmented, $4^{\text {th }}$ segment slightly longer than $3^{\text {rd }}$ (Figure 72A), L0 small, blade shorter than flagellum (Figure 72A), AR=2.0. SI bifid, SII and SIII simple. Pecten epipharyngis with 3 scales, outer scales slightly longer. Premandible simple (Figure 72B). Mandible with 1 apical tooth and 3 inner teeth (Figure 72C), apical tooth same size as inner teeth, outer margin slightly crenulated, SSd large. Mentum with 1 median tooth and 6 pairs of lateral teeth, median tooth2X as large as $1^{\text {st }}$ laterals (Figure 72D), VmP small not extending posteriorly (Figure 72D). Body greenish brown. Procercus small, each bearing 6 apical setae (Figure 72E). Posterior parapods $2 \mathrm{X}$ as long as wide, each bearing group of claws (Figure 72E). Anal tubules conical and as long as posterior parapods (Figure 72E).

Notes. Adults and immature stages are described in detail by Soponis (1977).

Sampling sites. Grenier River in Korok area, N58 $50.753^{\prime}$ W64 ${ }^{\circ}$ 32.41698'; Torr Bay Brook in Torngats Mountains National Park, N58 ${ }^{\circ}$ 27.944' W62 $2^{\circ}$ 49.287'; McCornick Brook in Torngats Mountains National Park, N58 ${ }^{\circ} 59^{\circ} .0937^{\prime}$ W63 ${ }^{\circ}$ 47.477'; Unnamed creek near Iqaluit airport in Baffin Island N63 ${ }^{\circ} 75.086^{\prime}$ 'W68 53.172 '; Utuk River in Pond Inlet area, $\mathrm{N}^{\circ} 2^{\circ} 39.742^{\prime}$ W78 ${ }^{\circ}$ 2.99'; Traverse River in Lake Hazen area, $\mathrm{N}^{\circ} 1^{\circ} 39.885^{\prime} \mathrm{W} 72^{\circ} 1.5109^{\prime}$.

Ecology and habitats. This species is reported to have a univoltine to multivoltine life cycle, depending on the latitude in which it occurs (Soponis, 1977).

Nearctic distribution. CANADA: $1^{\text {st }}$ record for Labrador, Nunavut, Saskatchewan; USA: Alabama, Alaska, California, Georgia, Kansas, Michigan, Minnesota, New York, North Carolina, Pennsylvania, and South Carolina.

\section{Orthocladius (Symposiocladius) holsatus Goetghebuer}

\section{Larvae $(n=1)$}

\section{Figures 73A-D}

Description. Head capsule reddish brown. Antenna 5 segmented, $4^{\text {th }}$ segment shorter than $3^{\text {rd }}$ (Figure 73A), LO small, blade reaching the mid-section of $5^{\text {th }}$ segment, AR=1.2. SI bifid, SII and SIII simple. Pecten epipharyngis with 3 fork-like scales. Premandible simple; Maxilla with weak pecten galearis. Mandible with 1 apical tooth and 3 inner teeth, apical tooth longer than $1^{\text {st }}$ inner (Figure73B), SSd small reaching the base of last inner teeth, outer margin of mandible smooth. Mentum with 1 median tooth and 6 pairs of lateral teeth (Figure 73C), median teeth may be worn or have a cusp (Figure 73C), VmP large and triangular. Body yellowish green with long setae, setae in clusters of 3-4 longer than segments that bearing them. Procercus small, each bearing 6 long apical setae (Figure 73D), apical setae reaching the posterior portion of the $8^{\text {th }}$ segment. Posterior parapods $<1.5 \mathrm{X}$ as long as wide, each bearing group of pale claws (Figure 73D). Anal tubules as long as posterior parapods (Figure 73D).

Notes. Larva is described by Dettinger-Klemm (2000).

Sampling sites. Unnamed creek near Iqaluit airport in Baffin Island, N63 ${ }^{\circ} 75.086^{\prime}$ W68 53.172 '; Utuk River in Pond Inlet area, N72 ${ }^{\circ}$ 39.742 ' W78 2.995 '.

Ecology and habitats. This species is eurythermic with larvae feeding on algae and living on filamentous algae in lakes. The species is multivoltine (Dettinger-Klemm, 2000).

Nearctic distribution. CANADA: Alberta, Manitoba, Northwest Territories, $1^{\text {st }}$ record for Nunavut; USA: Minnesota. 


\section{Parakiefferiella Thienemann}

Generic diagnosis. Antenna 6-7 segmented, last segment usually vestigial (Figures 73A, 74A). SI simple to branched, SII and SIII simple. Mandible with apical tooth sub-equal to or longer than inner teeth (Figure 73B). Mentum with 1 to 2 median teeth and 5-6 pairs of lateral teeth.

\section{Parakiefferiella cf. bathophila (Kieffer) \\ Larva ( $n=2)$}

Figures 74A-D

Description. Antenna 6 segmented. $6^{\text {th }}$ segment vestigial and hair like, $5^{\text {th }}$ segment longer than $4^{\text {th }}$ (Figure 74A), blade short reaching the apex of $4^{\text {th }}$ segment, AR=1.3. SI bifid and branched at the tips, SII and SIII simple. Pecten epipharyngis with 3 sub-equal scales. Premandible simple with minute notch. Maxilla with pecten galearis present, chaetulae of same shape. Mandible with 1 apical tooth and 4 inner teeth (Figure 74B), apical tooth lighter and slightly longer than inner teeth, seta interna consist of single spine with 6-7 branches. Mentum with 1 dome-shaped median tooth (may be worn) and 6 pairs of lateral teeth (Figure 74C), $1^{\text {st }}$ laterals small and appear attached to median tooth, median and $1^{\text {st }}$ lateral teeth are lighter in color than rest of the lateral teeth, $\mathrm{VmP}$ large sits below the mentum lateral teeth (Figure 74C). Body is yellowish green. Procercus small, each bearing 7 apical setae (Figure 74D), apical setae are same size. Posterior parapods larger than anal tubules, dorsal tubules are pear shaped.

Notes. Larva is described by Cranston (1982).

Sampling sites. Tributary of Utuk River in Pond Inlet area, N72 ${ }^{\circ}$ $36.988^{\prime}$ W78 ${ }^{\circ} 7.878^{\prime}$; Salor Creek Lake Hazen area, N81 ${ }^{\circ} 54.156^{\prime}$ W68 ${ }^{\circ}$ 54.4570 '.

Ecology and habitats. Cranston (1982) has indicated that $P$. bathophila (Kieffer) is amongst the few Parakiefferiella species occurring in both lentic and lotic environments. Humphries \& Frost (1937) reported the larvae in moss habitat.

Note on the Nearctic distribution. Parakiefferiella bathophila (Kieffer) has not been reported in Nunavut. In Canada it has been reported in Manitoba and the Northwest Territories. In the USA it has been reported in Ohio.

\section{Parakiefferiella cf. gracillima (Kieffer) \\ Larva $(n=1)$}

\section{Figures 75A-E}

Description. Antenna 6 segmented, $6^{\text {th }}$ segment vestigial and hair like (Figure $75 \mathrm{~A}), 6^{\text {th }}$ slightly longer than $5^{\text {th }}$ segment, blade shorter than flagellum reaching the apex of $5^{\text {th }}$ segment, $A R=0.97$. SI simple and small, SII simple sits on top of what appears to be a tubercles, SIII simple. Pecten epipharyngis consist of 3 scales, middle plate shorter than laterals. Premandible simple with very small, almost minuscule, notch (Figure 74B). Maxilla with pecten galearis present, LCh and ALCh of maxilla of similar in shape and size. Mandible with 1 light apical tooth and 3 darker inner teeth, apical tooth not much longer than inner teeth (Figure 75C), SSd small, seta interna consist of single spine with 6-7 branches. Mentum with 1 single dome shaped median tooth and 5 pairs of lateral teeth (Figure 75D), median tooth slightly lighter in color than lateral teeth, VmP small not extending beyond the lateral margin of mentum, no beard present (Figure 75D). Body yellowish green. Procercus small, each bearing 6 apical setae, at least 2 apical setae long reaching the mid-section of $11^{\text {th }}$ segment. Anal tubules present and same length as posterior parapods, dorsal tubules wider than ventral tubules and less tubular (Figure 75E).

Notes Larval specimens examined in this study match the description given by Wülker (1957) for Parakiefferiella gracillima (Kieffer). The median tooth of the mentum described in Wülker (1957) has a notch whereas the specimens in this study have apparently worn median teeth. However, Schmid (1993) has reported a species with a single median tooth.

Sampling sites. Burton River in Baffin Island, N63 ${ }^{\circ} 52.800^{\prime} \mathrm{W}^{\circ} 8^{\circ}$ 18.894'; Unnamed creek near Iqaluit airport in Baffin Island, N63 ${ }^{\circ}$ $75.086^{\prime}$ W68 53.172 '

Note on the Nearctic distribution. Parakiefferiella gracillima (Kieffer) has not been recorded in Nunavut. In the USA it has been reported in Alaska.

Ecology and habitat. Wülker (1957) reported the larvae of $P$. gracillima in high altitude springs.

\section{Parametriocnemus boreoalpinus Gowin et Thienemann}

\section{Pharate female $(n=3)$}

\section{Figures 76A-G}

Description. Pharate female $\mathrm{TL}=2.4 \mathrm{~mm}$. Antenna 9 segmented, last flagellomere shorter than remaining flagellomeres with long setae at the tip (Figure 76A), AR=0.41. Eyes bear with dorsomedial extensions (Figure 76B). Clypeus with 13 setae (Ls=64-68 $\mu \mathrm{m})$. Palpomere 5 segmented $\mathrm{L}_{1-5=} 26.0 \mu \mathrm{m}, 28.0 \mu \mathrm{m}, 67.0 \mu \mathrm{m}, 62.0 \mu \mathrm{m}, 72.0$ $\mu \mathrm{m}$; Figure). Hind tibia with large comb and 1 large spur (Figure 76C), mid and fore legs combs are absent and spurs are single (Figure 76D). GP VIII divided into a larger ventrolateral lobe and a narrower dorsomesal lobe (Figure 76E), ApL is visible but not distinct (Figure 76E). GcIX with long setae at the tip reaching Ce (Figure 76F). Ce squared at the tip (Figure 76F). Seminal capsules ovoid with no visible neck (Figure 76G).

Legs lengths $(\mu \mathrm{m})$ and proportions:

\begin{tabular}{lccccccccccc} 
& $\mathbf{f e}$ & $\mathbf{t i}$ & $\mathbf{t a}_{\mathbf{1}}$ & $\mathbf{t a}_{\mathbf{2}}$ & $\mathbf{t a}_{\mathbf{3}}$ & $\mathbf{t a}_{\mathbf{4}}$ & $\mathbf{t a}_{\mathbf{5}}$ & $\mathbf{L R}$ & $\mathbf{B V}$ & $\mathbf{S V}$ & $\mathbf{B R}$ \\
\hline P1 & 484 & 488 & 401 & 236 & 178 & 123 & 90 & 0.8 & 2.2 & 1.2 & 3.6 \\
P2 & 354 & 418 & 289 & 153 & 116 & 81 & 77 & 0.7 & 2.5 & 2.7 & 2.5 \\
P3 & 554 & 624 & 379 & 192 & 168 & 98 & 90 & 0.6 & 2.8 & 3.1 & 2.2
\end{tabular}

Notes. Female of Parametriocnemus boreoalpinus was originally described by Gowin \& Thienemann (1942). However, authors did not provide a detailed taxonomic description and referred illustration for the female. The $P$. boreoalpinus female's genitalia are similar to that of Parametriocnemus lundbecki (Johansenn). The females of the two species can probably be separated by the following characteristics: In $P$. boreoalpinus $\mathrm{Ce}$ is squared at the tip and not tongue shaped, ApL is visible but not distinct (Figure 76F), DmL appears ticker, setae of Gc IX reach the tip of $\mathrm{Ce}$ and not longer. It must be noted that these measurements and diagnoses are based on pharate females.

\section{Pupae $(n=4)$}

\section{Figures 77A-F}

Description. Pupa medium size, $\mathrm{L}=3.0 \mathrm{~mm}$. Frontal apotome without frontal setae (Figure 77A). Thoracic horn long, with large outer spines (Figures 77B-C), L=291 $\mu$ m. Abdominal segments mainly without prominent shagreens, more visible in the last segments. Tergite I- VII with simple spines increasing in size posteriorly (Figure 76D), Tergite I with 2 L setae and 5D setae. Tergite II-VIII with 3 L setae (Figure 76D). Anal lobes with 3 macrosetae, inner setae longer than median and outer, median setae shorter than the remaining setae (Figure 77E), macro setae L1-3=175.0 $\mu \mathrm{m} \mathrm{1,} 110.0$ $\mu \mathrm{m}, 115.2 \mu \mathrm{m}$, male genitalia sac sub-equal to slightly longer than anal lobe (Figure 77E), females genitalia sacs are shorter than anal lobes, anal lobes with group of small tubercles at the tip but no fringe of setae (Figure 77F).

Notes. Pupa is described by Gowin \& Thienemann (1942) and by Kownacka \& Kownacki (1967). 
Larva $(n=5)$

Figures 78A-G

Description. Head capsule yellow (Figure 78A). Antenna 6 segmented (Figure 78B), $5^{\text {th }}$ segment sub-equal to $4^{\text {th }}$, LO prominent covering $3^{\text {rd }}$ and part of $4^{\text {th }}$ segments (Figure 78B), blade shorter than flagellum, AR=1.7. SI plumose, SII serrated and lamellate (Figure SIII simple (Figure 78C). Pecten epipharyngis consist of 3 small scales; Premandible with 6 teeth (Figure 78D). Maxilla chaetulae of similar shape with serrations; Mandible as in Figure 78E, SSd large with 3-4 inner spines and the tip hook shaped (Figure 78E), seta interna with 6 7 serrated spines. Mentum with 2 median teeth and 5 pairs of lateral teeth (Figure $78 \mathrm{~F}$ ), median teeth appears receded sitting just below the $1^{\text {st }}$ lateral teeth, VmP large extending beyond the lateral margin of mentum, SSm sitting half way between anterior and posterior portion of mentum (Figure 78F). Procercus very small, each bearing 6-7 apical setae (Figure 78G). Posterior parapods $2 \mathrm{X}$ as long as wide, each bearing group of claws (Figure 78G). Anal tubules conical and longer than posterior parapods (Figure 78F).

Notes. Larva is described by Kownacka \& Kownacki (1967). Sæther (1969). Parametriocnemus sp. B is probably $P$. boreoalpinus. Examination of 5 larvae from 3 localities using scanning elctron microscope indicates the presence of $6^{\text {th }}$ antennal segment in the larvae of this species (see Appendix 1).

Sampling sites. Nakvak Brook in Torngats Mountains National Park, N58 ${ }^{\circ} 37.221^{\prime}$ W63 ${ }^{\circ} 23.287$ ' McCornick Brook in Torngats Mountains National Park, N58 $59^{\circ}$ 0.093' W63 $3^{\circ}$ 7.477'; Torr Bay Brook in Torngats Mountains National Park, N58 ${ }^{\circ} 27.944^{\prime}$ W62 ${ }^{\circ}$ 49.287'; Sylvia Grennel River in Iqaluit, Baffin Island, N63 ${ }^{\circ} 45.9319266^{\prime}$ W68 $^{\circ} 34.863756$ '; Unknown Stream in Iqaluit, Baffin Island, N63 ${ }^{\circ} 46.552998^{\prime} \mathrm{W} 68^{\circ}$ 39.440994'; Tributary of Utuk River in Pond Inlet area, N72 $36.988^{\prime}$ W78 ${ }^{\circ}$ 7.878'; Pond Stream in Borden Peninsula, N72 ${ }^{\circ} 49.021^{\prime}$ W80 ${ }^{\circ}$ 28.497'.

Ecology and habitats. Larvae of this species occur mainly in stony banks of high altitude streams (1100 $\mathrm{m}$ above sea level) with low currents and in low abundance in high currents areas (Kownacka \& Kownacki, 1967).

Nearctic distribution. $1^{\text {st }}$ record for the NEARCTIC: CANADA: Labrador, and Nunavut.

\section{Paraphaenocladius exagitans exagitans (Johannsen) \\ Larva $(n=1)$}

\section{Figures 79A-G}

Description. Head capsule yellow (Figure 79A). Antenna is small and 5 segmented (Figure $78 \mathrm{~B}$ ), $5^{\text {th }}$ segment slightly longer than $4^{\text {th }}$, blade longer than flagellum (Figure 79C), LO large covering the $3^{\text {rd }}$ and $4^{\text {th }}$ segment, R0 located apically on segment $1, \mathrm{AR}=0.89$. SI plumose to pectinate, SII and SIII simple. Premandible with 3 teeth and large accessory tooth (Figure 79D). Maxilla with MP short, ALCh lamellate and without serrations, pecten galearis absent. Mandible with 1 apical and 4 inner teeth of equal size (Figure 79E), seta interna with 8 serrated branches SSd small and conical. Postmentum $\mathrm{L}=93 \mu \mathrm{m}$. Mentum with 1 large median tooth and 5 pairs of lateral teeth (Figure 79F), median tooth dome shaped and notched and $3.1 \mathrm{X}$ of the $1^{\text {st }}$ laterals, $1^{\text {st }}$ and $2^{\text {nd }}$ laterals stand higher than $3^{\text {rd }}-5^{\text {th }}$ laterals, $3^{\text {rd }}-5^{\text {th }}$ laterals appear to be on a same plane, VmP long and wide extending beyond the lateral margin of the mentum. Smaller claws of anterior parapods serrated, larger claws simple. Claws of posterior parapods simple. 4 anal tubules of equal size, tubules $2 X$ longer than posterior parapods (Figure 79G). Procercus small not sclerotized, each bearing 5-6 short apical setae (Figure 79G).

Notes. The postmentum length of this species is $86-111 \mu \mathrm{m}$ and anal tubules are longer than posterior parapods which distinguishes the larvae of this species from other species in this genus. The larva belongs to subspecies exagitans according to Sæther \& Wang (1995).
Study sites. Mesa Creek in Lake Hazen area, N81 ${ }^{\circ} 55.039^{\prime}$ W69 ${ }^{\circ}$ 46.105'.

Ecology and habitats. Larvae of this species occur in moist soils, margins of streams, creeks, springs and seepages (Sæther \& Wang, 1995).

Nearctic distribution. CANADA: Nunavut; GREENLAND.

\section{Psectrocladius Kieffer}

Generic diagnosis. Generic diagnosis: Antennae 5 segmented (Figures 80Aand 81A), Segments sequentially decrease in size. SI serrated to palmate (Figure $81 \mathrm{~B}$ ), SII-SIII simple. Premandible simple (Figures 80B, 81C). Mandibles with 1 long apical tooth and 3 smaller inner teeth (Figures $80 \mathrm{C}, 81 \mathrm{E}$ ). Mentum with 1-2 median tooth and 5 pairs of lateral teeth, VmP distinguished with cardinal beard present (Figures 80D, 81F). Procercus large with or without spurs and with up to 7 apical setae.

Notes. The combination of absence of seta interna on mandibles, longer mandibular apical tooth $(>1.8 \mathrm{X})$ than inner teeth, trifid SI, and procercus with bifid spurs separates the larvae in subgenus Allopsectrocladius from subgenus Psectrocladius.

\section{Psectrocladius (Allopsectrocladius) obvius (Walker) \\ Larva $(n=2)$ \\ Figures 80A-E}

Description. Head capsule yellowish-white. Antenna 5 segmented, segments reduce in size sequentially (Figure $80 \mathrm{~A}), 1^{\text {st }}$ segment much longer than flagellum, LO small, RO at the base of $1^{\text {st }}$ segment, AR=3.2. Pecten epipharyngis with 3 long scale. SI broadly trifid. Premandible simple and long (Figure 80B). Maxilla with ALCh lamellate and pectinate, A setae of MP $\mathrm{L}=37.5 \mu \mathrm{m}$ long, Aa setae $\mathrm{L}=49.2 \mu \mathrm{m}$ long. Mandible with long apical tooth and 3 inner teeth (Figure 80C), apical tooth about 2.2X longer than inner teeth combined, Setae interna absent (Figure 80C), SSd large and pear shape with pincer like apical tip. Mentum with 1 large, flat, square-edged, nipple-like median teeth and 5 pairs of apical teeth (Figure 80D), VmP large with cardinal beard ( $\sim 20$ setae) (Figure $80 \mathrm{D})$. Procercus longer than wide, well-sclerotized with 2 long spurs at the base (Figure 80E), each bearing 7 apical setae (Figure 80E). Posterior parapods longer than wide with groups of dark claws (Figure 80E).

Notes. Larva is described by Cranston (1982). Epler (2001) suggested that Psectorocladius (Allopsectrocladius) flavus (Johannsen) is probably synonym with $P$. obvius, with $P$. obvius having priority in naming. Moller Pillot (1984) indicates AR is 3.7-4.8. There seems to be variability in the Nearctic species and those of the Palearctic with AR probably ranging from 3.2 to 4.8. Examination of more material is required to further reveal this.

Study Sites. Burton River in Baffin Island, N63 ${ }^{\circ} 52.800^{\prime}$ W68 18.894'.

Ecology and habitats. Larvae occur in various habitats such as peat fen ditches, broads, reservoirs, lochs and streams (Langton, 1980).

Nearctic distribution. CANADA: $1^{\text {st }}$ record for Nunavut, Saskatchewan; USA: Illinois, New York, Pennsylvania, and South Dakota.

\section{Psectrocladius (Psectrocladius) sordidellus group}

Larva $(n=1)$

\section{Figures 81A-F}

Description. Antenna 5 segmented, segments sequentially decrease in size (Figure 81A), R0 at the base of $1^{\text {st }}$ antennal segment, blade shorter than flagellum, $A R=3.7$. Pecten epipharyngis with 3 equal scale. SI palmate with 7 lobes (Figure 81B), SII-SIII simple, SII long. Premandible simple with small accessory tooth (Figure 81C). Mandible with 1 apical 
tooth and 3 inner teeth (Figure 81D), apical tooth sub-equal to combined width of inner teeth, SSd large, seta interna with 7 branches that are serrated at the tip. Maxilla with ALCh large and wider than other lacinial chaeta, pecten galearis prominent (Figure 81E). Mentum with bifid wide-shouldered median tooth and 5 pairs of lateral teeth (Figure 81F), VmP large with cardinal beard, each bearing 17-18 long setae.

Notes. The specimen's mentum resembles that of Psectorocladius (Psectrocladius) octomaculatus Wülker described by Cranston (1982), Moller Pillot (1984) and Epler (2001). However; AR is larger (i.e., >3.5) than the larva described by Cranston (1982). The abdomen was missing on this specimen. The larva has a mentum with double median tooth, mandible are evenly darkened, and occipital margin of the head capsule has same color as reminder of the head capsule which puts the larva in the sordidellus group.

Study site. Burton River in Baffin Island, N63 ${ }^{\circ} 52.800^{\prime}$ W68 $6{ }^{\circ} 18.894$ '.

Ecology and habitat. Larvae of species in this group are reported to occur in boggy seepages (Cranston, 1982).

Nearctic distribution. CANADA: Nunavut.

\section{Pseudosmittia sp.}

Larva $(n=1)$

Figures 82A-D

Description. Larvae small, $\mathrm{L}=3.4 \mathrm{~mm}$. Head capsule yellowishbrown and round, HL/HW=1.1. Antenna 4 segmented, $1^{\text {st }}$ segment as wider than long, $A R=0.55$. SI bifid, SII bifid. Pecten epipharyngis with 3 small equal scales. Premandible bifid with accessory tooth. Mandible with 1 apical tooth and 3 inner teeth (Figure $82 \mathrm{~A}$ ), $2^{\text {nd }}$ inner teeth shorter than other inner teeth. Mentum with 1 wide flat median tooth and 4 pairs of lateral teeth (Figure $82 \mathrm{~B}$ ), median tooth $3.1 \mathrm{X}$ the $1^{\text {st }}$ laterals. VmP prominent, crescent shape (Figure 82B) not extending beyond the margin of mentum. Anterior parapod small with group of serrated claws, spines scarce (Figure 82C). Posterior parapod reduced, each bearing 2 claws (Figure 82D), no spines on posterior parapods. Anal tubules longer than posterior parapods, constricted at the tip.

Notes. The larva specimen does not match the description given by Ferrington \& Sæther (2011) for known Pseudosmittia larvae.

Study sites. Blister Creek in Lake Hazen area, N81 ${ }^{\circ} 49.1470$ ' W71 ${ }^{\circ}$ 31.741'.

Nearctic distribution. CANADA: Nunavut.

\section{Rheocricotopus Brundin}

Generic diagnosis. Antenna 5 segmented, $5^{\text {th }}$ segment may be subequal or slightly longer than $4^{\text {th }}$ (Figure $83 \mathrm{~A}, 84 \mathrm{~A}$ ). SI bifid, SII-SII simple. Pecten epipharyngis with 3 equal scales (Figure 83B). Premandible simple (Figures 83B, 84B). Mandible with apical teeth smaller than combined inner teeth (Figures 83D, 84D). Mentum with single dome shaped or 2 median teeth and 5 laterals appearing triangular (Figures 83E, 84D). VmP well-developed, cardinal beard with $12-13$ hairs.

\section{Rheocricotopus (Psilocrictopus) chalybeatus group \\ Larvae $(n=2)$ \\ Figure 83A-G}

Description. Antenna 5 segmented (Figure $83 \mathrm{~A}$ ), $5^{\text {th }}$ slightly longer than $4^{\text {th }}$, blade shorter than flagellum, LO covering $2 / 3^{\text {rd }}$ of $3^{\text {rd }}$ segment, basal antennal segment $\mathrm{L}=26.0 \mu \mathrm{m}, \mathrm{AR}=1.1$. SI bifid, SII and SIII simple. Pecten epipharyngis with 3 equal size scales (Figure 83B). Premandible simple (Figure 83B). Maxilla with pecten galearis well developed, Aa not as high as wide (Figure 83C), ALCh L=16.7 $\mu \mathrm{m}$, ALCh $\mathrm{W}=4.8 \mu \mathrm{m}$. Mandible with apical teeth longer than $1^{\text {st }}$ inner, outer ridge with slight hump (Figure 83D). Mentum with 2 median teeth, each with an accessory tooth, and 5 pairs of lateral teeth (Figure 83E), VmP well-developed, cardinal beard with $\sim 15$ setae each (Figure 83F).
Procercus well-sclerotized, each bearing 6 long apical setae (Figure 83G). Posterior parapods not much longer than wide (Fig 83G.). Anal tubules about $2 / 3$ of posterior parapods and conical (Figure $83 \mathrm{G}$ ).

Notes. Larvae could be a variation of Rheocricotopus (Psilocrictopus) chalybeatus (Edwards) described by Cranston (1982) and Sæther (1985). However, the description of pecten epipharyngis and antaxial chaeta of maxilla given by Cranston (1982) and Sæther (1985) for $R$. chalybeatus does not hold for these specimens. The two specimens examined are probably $3^{\text {rd }}$ instars.

Sampling sites. Burton River in Baffin Island, N63 $52.800^{\prime} \mathrm{W} 68^{\circ}$ 18.894'.

Ecology and habitats. Larvae of $R$. chalybeatus in this group are reported by Lehman (1971) to have the highest abundance in middle reaches of rivers and streams. Larvae of $R$. chalybeatus also, occur in springs (Cranston, 1982).

Nearctic distribution. CANADA: Nunavut.

\section{Rheocricotopus (Rheocricotopus) eminellobus Sæther Larvae $(n=1)$}

\section{Figures 84A-E}

Description. Antenna 5 segmented, $5^{\text {th }}$ segment sub-equal to $4^{\text {th }}$, LO present but small, $\mathrm{AR}=0.84$, R0 close to the base of $1^{\text {st }}$ Antenna segment, blade smaller than flagellum (Figure 84A). SI bifid, SII and SIII simple. Pecten epipharyngis consist of 3 equal scales. Premandible simple without brush (Figure 84B). Mandible apical equal in size to inner teeth (Figure 84C), SSd large appearing forked at the tip (Figure $84 \mathrm{C}$ ), seta interna with 56 setae. Mentum appear triangular with 2 median teeth and 5 laterals (Figure 84D) VmP well-developed extending to $1^{\text {st }}$ lateral teeth of mentum (Figure 84D), cardinal beard present with 12-13 hairs. Procercus small, each bearing 5apical setae (Figure $84 \mathrm{E})$. Posterior parapods with group of claws. Anal tubules conical $1 / 2$ of posterior parapods (Figure 84E).

Notes. Mentum of this species resembles that of Psectrocladius (Psectrocladius) sordidellus (Zetterstedt); however, the combination of bifid SI (compared to palmate SI in Ps. sordidellus) and smaller mandibular apical teeth separates the two species. Within the subgenera larvae resembles those of Rheocricotopus (Rheocricotopus) effusus (Walker) and Rheocricotopus (Rheocricotopus) effusoides Sæther. The combination of smaller number of cardinal beard setae (12-13) and smaller AR separates larvae of this species from those of latter (i.e. AR $>1.5$ and cardinal beard with $>25$ setae).

Sampling sites. Nakvak Brook in Torngats Mountains National Park, N58 ${ }^{\circ} 37.221^{\prime}$ W63 $23.287^{\prime}$.

Ecology and habitats. Larvae of this species are categorized as shredders with high abundance in leaf litters.

Nearctic distribution. CANADA: Alberta, Ontario, $1^{\text {st }}$ record for Labrador; USA: North Carolina, Ohio, South Carolina, South Carolina, and Tennessee.

\section{Rheocricotopus (Rheocricotopus) pauciseta Sæther Pharate male \\ Figures 85A-I}

Description. Pharate male $\mathrm{TL}=2.82 \mathrm{~mm}$. Head brown, vertex (Figure $85 \mathrm{~A}$ ). Eyes pubescent with microtrichia reaching above the ommatidium (Figure 85B), no dorsomedial extension. Antenna 13 segmented (Figure 85C), AR=0.96. Palpomere 4 segmented (L1-4=69.0 $\mu \mathrm{m}, 72.0 \mu \mathrm{m}, 91.1 \mu \mathrm{m}, 150.7 \mu \mathrm{m})$. Clypeus with 12 setae (Ls=57-85 $\mu \mathrm{m}$; Figure $85 \mathrm{C}$ ). Tentorium $\mathrm{L}=161 \mu \mathrm{m}$ (Figure 85D). Thorax light brown dorsally and laterally, lighter ventrally, scutellum white in middles with a thin rounding band of brown. Acrostichals present and short ( $\mathrm{L}=29.2$ $\mu \mathrm{m}), 11-12$ setae in each single row, 10 dorsocentrals present in 2 rows $(\mathrm{L}=128.0 \mu \mathrm{m})$. Scutellum with 6 setae in single row. Fore leg with 1 
long spur $(\mathrm{L}=49.0 \mu \mathrm{m})$ and no comb, mid leg with 2 short spurs ( $\mathrm{Ls}=19.5 \mu \mathrm{m}, 21.0 \mu \mathrm{m}$ ) and no comb, hind leg with 1 long and 1 short spurs (Ls=43.2 $\mu \mathrm{m}, 17.0 \mu \mathrm{m})$ and well developed comb (Figure 85E), legs empodium and pulvili (Figure $85 \mathrm{~F}$ ), empodium $\mathrm{L}=30.2 \mu \mathrm{m}$, pulvilli $\mathrm{L}=17.3 \mu \mathrm{m}$. Abdominal segments I-VIII with long scattered setae (Figure 85G). Anal point short and triangular with apex bare and pointed and laterally with 8 setae (Figure $85 \mathrm{H}$ ), anal point $\mathrm{L}=25.4 \mu \mathrm{m}$. Sternapodeme convex with oral projection simple (Figure 85I). Gonocoxite longer than wide almost squared each bearing 25-27 long setae, gonostyle triangular with outer projections rounded (Figure 85I), microtrichia present, mega setae $\mathrm{L}=15.0 \mu \mathrm{m}, \mathrm{HR}=2.7, \mathrm{HV}=4.7$.

Legs lengths $(\mu \mathrm{m})$ and proportions:

\begin{tabular}{lccccccccccc} 
& $\mathbf{f e}$ & $\mathbf{t i}$ & $\mathbf{t a}_{\mathbf{1}}$ & $\mathbf{t a}_{\mathbf{2}}$ & $\mathbf{t a}_{\mathbf{3}}$ & $\mathbf{t a}_{\mathbf{4}}$ & $\mathbf{t a}_{\mathbf{5}}$ & $\mathbf{L R}$ & $\mathbf{B V}$ & $\mathbf{S V}$ & $\mathbf{B R}$ \\
\hline P1 & 443 & 612 & 426 & 275 & 194 & 143 & 97 & 0.7 & 2.1 & 2.5 & 2.4 \\
P2 & 455 & 581 & 303 & 161 & 117 & 72 & 82 & 0.5 & 3.1 & 3.4 & 4.7 \\
P3 & 466 & 659 & 365 & 202 & 156 & 102 & 91 & 0.6 & 2.7 & 3.1 & 4.8
\end{tabular}

Notes. Male is described by Sæther (1969).

\section{Pupae $(n=1)$}

Figures 86A-D

Description. Thoracic horn (Figure 86A), $\mathrm{L}=284.2 \mu \mathrm{m}, \mathrm{W}=58.8 \mu \mathrm{m}$, $\mathrm{Pcl}=112.6 \mu \mathrm{m}, \mathrm{Pc} 3=81.5 \mu \mathrm{m}$. Shagreens present on segments II-VI. Pedes spurii present on segments II-III. Tergites I bare, tergites II-VI with posterior spines (Figures 86B, 86C), tergite VII with faint posterior spines, tergites IV-VI with median patch of spines (Figures $86 \mathrm{~B}$, 86C), fainter on tergite IV, Segment II with 2 L setae, segments III-IV with 3 L setae, segments V-VIII with 4 L setae. Male's genitalia sacs longer than anal lobes (Figure 86D), anal lobes with 13 long lamelliform setae (Figure 86D), L=302.4 $\mu \mathrm{m}$.

Notes. Detailed description of the pupa is given by Sæther (1969).

Study site. Nakvak Brook in Torngats Mountains National Park, N58 ${ }^{\circ} 37.221^{\prime}$ 'W63 ${ }^{\circ} 23.287$ '.

Ecology and habitats. Larvae of this species are reported in streams of mountainous regions (Hudson et al., 1990).

Nearctic distribution. CANADA: Alberta, British Columbia, $1^{\text {st }}$ record for Labrador; USA: North Carolina.

\section{Rheosmittia sp. A \\ Larva $(\mathrm{n}=4)$ \\ Figures 87A-D}

Description. Head capsule yellow, $\mathrm{HL}=154.0 \mu \mathrm{m}$. Antenna 5 segments (Figure $87 \mathrm{~A}), 5^{\text {th }}$ segment longer than $4^{\text {th }}, 2^{\text {nd }}$ segment unevenly sclerotized and appearing 2 segmented (Figure $87 \mathrm{~A}$ ), R0 on basal $1 / 10^{\text {th }}$ of $1^{\text {st }}$ segment, $A R=0.65$. SI-SIII simple. Premandible with 1 apical and 9 inner teeth (Figure 87B). Mandible with 1 apical and 7 inner teeth of equal size (Figure 87C). Mentum with 18 teeth (Figure 86B), hypopharyngeal scales with 12-13 teeth (Figure 87B). Procercus well-sclerotized, each bearing 5 apical setae, which at least 2 setae are longer (Figure 87D). Posterior parapods longer than anal tubules (Figure 87D). Anal tubules conical, dorsal tubules longer than ventral tubules (Figure 87D).

Notes. Larvae are described for only two Nearctic Rheosmittia, the Rheosmittia arcuata Caldwell and Rheosmitta spinicornis (Brundin). Larval specimens in this study differ from above species in size of head capsule, number of inner teeth in premandible and mandible, antenna size, AR, number of teeth in hypopharyngeal scales, number and size of apical setae on procercus, and size of anal tubules (See Caldwell, 1996; Cranston \& Sæther, 1986 for details). Larva may represent a new species.

Study site. Torr Bay Brook in Torngats Mountains National Park, N58 ${ }^{\circ}$ 27.9444' W62 ${ }^{\circ}$ 49.287'; Nakvak Brook in Torngats Mountains National Park, N58 ${ }^{\circ} 37.22196^{\prime}$ W63 ${ }^{\circ} 23.28786$ '.
Ecology and habitats. Larvae of Rheosmittia are psammophilous, occurring in the sandy substrates of rivers (Zvereva, 1950).

Nearctic distribution. CANADA: Nunavut, Labrador.

\section{Smittia sp.}

Larva $(n=1)$

\section{Figures 88A-F}

Description. Larva $\mathrm{L}=4 \mathrm{~mm}$. Head capsule brown. Antenna 5 segmented, $4^{\text {th }}$ segment longer than $3^{\text {rd }}$ (Figure $88 \mathrm{~A}$ ), blade longer than flagellum, $\mathrm{L}=28.3 \mu \mathrm{m}, \mathrm{R} 0$ in mid-section of $1^{\text {st }}$ antennal segment, LO large and prominent covering segment 3 and $2 / 3^{\text {rd }}$ of $4^{\text {th }}$ segment, $A R=0.97$. SI appears palmate but is pectinate, SII simple (Figure 88B). Pecten epipharyngis with 3 scales, middle scale longer and wider. Premandible bifid with accessory tooth (Figure $87 \mathrm{C}$ ). Maxilla with pecten galearis absent, ALCh lamellate and longer than wide. Mandible with 1 apical and 3 inner teeth (Figure 88D). Mentum with 1 dome shaped median tooth and 5 pairs of laterals (Figure 88E), median tooth nipple shape or with cusp and $3.7 \mathrm{X}$ of the $1^{\text {st }}$ laterals, SSm anteriad to mentum. Posterior parapods are reduced with simple claws (Figure 88E). Procercus absent, apical setae absent. Anal tubules very small (Figure 88F).

Study sites. Muskox Creek in Lake Hazen area, N81 ${ }^{\circ} 50.332^{\prime}$ W71 ${ }^{\circ}$ 20.182'.

Ecology and habitats. Larvae of Smittia are generally considered to be terrestrial; however, they could occur in the margin and shallow (i.e. in leaf packs) regions of the streams.

Nearctic distribution. CANADA: Nunavut.

\section{Synorthocladius semivirens (Kieffer)}

\section{Larva $(\mathrm{n}=5)$}

\section{Figures 89A-F}

Description. Larva $\mathrm{L}=4 \mathrm{~mm}$. $\mathrm{HL} / \mathrm{HW}=1$. Antenna 5 segmented (Figure 89A), segments sequentially decrease in size, blade longer than flagellum, $R 0$ at the very base of $1^{\text {st }}$ segment, AR=1.5. SI-SIII simple. Pecten epipharyngis with 3 equal scales (Figure 89B), Premandible simple. Mandible with 1 apical tooth and 3 inner teeth (Figure 89C), base of Mandible wide, mandible $\mathrm{L} / \mathrm{W}=1.01$, SSd long reaching base of apical tooth, 1 spine below SSd. Mentum with 2 large and lifted median teeth and 4 pairs of lateral teeth (Figure 89D), VmP long and extended (Figure 89D), cardinal beard setae long and plumose (Figure 89B), SSm well posteriad to mentum. Body ventrally with setae in clusters (Figure 89E), Posterior parapods slightly longer than anal tubules with group of simples claws (Figure 89F). Procercus well developed, each bearing 6 apical setae (Figure 89F).

Notes. Larva of this species is described by Pankratova (1970) and by Cranston (1982).

Study sites. Torr Bay Brook in Torngats Mountains National Park, N58 ${ }^{\circ} 27.9444^{\prime}$ W62 ${ }^{\circ}$ 49.287'; Burton River in Baffin Island, N63 ${ }^{\circ}$ 47.728776' W68 ${ }^{\circ}$ 21.635412'; Tributary of Utuk River in Pond Inlet area, N72 ${ }^{\circ} 36.98868^{\prime}$ W78 ${ }^{\circ}$ 7.87824'; Pond Stream in Borden Peninsula, N72 ${ }^{\circ}$ $49.02198^{\prime}$ 'W $80^{\circ} 28.49784^{\prime}$ '

Ecology and habitats. Larvae of this species occur in running waters and littoral zone of lakes (Cranston, 1982).

Nearctic distribution. CANADA: Northwest Territories, $1^{\text {st }}$ record for Labrador; $1^{\text {st }}$ record Nunavut, Saskatchewan; MEXICO: Mexico state; USA: Alabama, Florida, Georgia, Michigan, North Carolina, Ohio, South Carolina, and Tennessee.

\section{Thienemanniella Kieffer}

Generic diagnosis. Larva small $<4 \mathrm{~mm}$. Antenna 5 segmented (Figures 90A and 91A), 0.5X head L. SI-SIII simple. Premandible simple. Mandible with 1 short apical and 4 inner teeth (Figures 90B, 91B). Mentum with 2-3 median teeth and 5 pairs of laterals (Figures $90 \mathrm{C}$, 
91C), Procercus each bearing 4-5 apical setae. Pair of stiff setae above posterior parapods.

\section{Thienemanniella boltoni Hestenes et Sæther}

Larva $(n=1)$

\section{Figures 90A-E}

Description. Larvae small, L=2.0 mm. Head brown, HL/HW=1.1. Antenna 5 segmented, $5^{\text {th }}$ segment longer than $4^{\text {th }}, 3^{\text {rd }}$ segment subequal to $2^{\text {nd }}$ segment, $2^{\text {nd }}$ segment dark brown (Figure $90 \mathrm{~A}$ ), $\mathrm{AR}=1.2$. Premandible simple. Mandible with 1 apical tooth and 4 inner teeth (Figure 90B), $3^{\text {rd }}$ inner tooth slightly longer than $2^{\text {nd }}$. Mentum with 2 median teeth and 5 pairs of lateral teeth (Figure 90C). Procercus each bearing 4 apical setae (Figure 90D)). Posterior parapods longer than tubules with simple large claws (Figure 90D), pair of stiff setae above posterior parapods (Figure $90 \mathrm{E}$ ), $\mathrm{L}=39.7 \mu \mathrm{m}$

Notes. Larva is described by Hestenes \& Sæther (2000).

Study sites. Torr Bay Brook in Torngats Mountains National Park, N58 ${ }^{\circ} 27.944^{\prime}$ W62 ${ }^{\circ} 49.287$ '.

Ecology and habitats. Larvae of this species occur in springs and small spring-fed streams (Hestenes \& Sæther, 2000).

Nearctic distribution. CANADA: Nova Scotia, $1^{\text {st }}$ record Labrador, Ontario, Prince Edward Island; USA: Minnesota, North Carolina, and Ohio.

\section{Thienemanniella caspersi Sæther}

Larva ( $n=1)$

\section{Figures 91A-D}

Description. Larva is small, $\mathrm{L}=1.9 \mathrm{~mm}$. $\mathrm{HL} / \mathrm{HW}=1.2$. Antenna 5 segmented, $3^{\text {rd }}$ segment 0.7X segment 2. $2^{\text {nd }}$ segment light (Figure 91A), $\mathrm{AR}=1.5$. Mandible with 1 apical and 4 inner teeth (Figure 91B). Mentum with 3 median teeth and 5 pairs of laterals, $1^{\text {st }}$ median tooth slightly shorter than $2^{\text {nd }}$ medians, ${ }^{\text {st }}$ lateral teeth appear fused to $2^{\text {nd }}$ median teeth (Figure 91C). Posterior parapods slightly longer than anal tubules, each bearing 4 short apical setae (Figure 91D).

Notes. Larva is described by Hestenes \& Sæther (2000) as Thienemanniella similis.

Study sites. Torr Bay Brook in Torngats Mountains National Park, N58 $27.944^{\prime}$ 'W62 ${ }^{\circ} 49.287$ '.

Ecology and habitats. Larvae of this species occur in lotic habitats. Nearctic distribution. $1^{\text {st }}$ record for CANADA: Labrador.

\section{Thienemanniella sp. A \\ Larva $(n=1)$}

Figures 92A-E

Description. Larvae $2.7 \mathrm{~mm}$. Antenna 5 segmented (Figure 92A). $3^{\text {rd }}$ segment $0.8 \mathrm{X}$ of $2^{\text {nd }}$ segment, $\mathrm{AR}=1.1$, blade shorter than flagellum, Mandible with 1 apical and 3 inner teeth (Figure 92B). Mentum with 3 median teeth and 5 pairs of lateral teeth (Figure $92 \mathrm{C}$ ), $1^{\text {st }}$ median tooth slightly longer than $2^{\text {nd }}$ median teeth (Figure 92C), $1^{\text {st }}$ lateral teeth not fused. Procercus each bearing 4 apical setae (Figure 92D). Posterior parapods longer than anal tubules, each bearing group of large simple claws (Figure 92D), stiff setae above posterior parapods (Figure 92E), $\mathrm{L}=66.6 \mu \mathrm{m}$. Anal tubules constricted at the base.

Notes. The AR, ratio of $3^{\text {rd }}$ antennal segment to $2^{\text {nd }}$ segment, and form and shape of the median teeth of the mentum are distinct from described species by Hestenes \& Sæther (2000). Additionally, SSm seems to be more anteriad in this larva compared to other described larvae (See Table 2 for further diagnosis). Larva may represent a new species. Single mounted larva specimen with damaged mentum was obtained in this study.

Study sites. McCornick Brook in Torngats Mountains National Park, N58 $59^{\circ} .093^{\prime}$ W63 ${ }^{\circ} 7.477$ '.

Nearctic distribution. CANADA: Labrador.
Thienemanniella taurocapita Sæther

Larva $(n=1)$

Figures 93A-G

Description. Larva small, L=3.1 mm (Figure 93A). Head brown (Figure 93A), HL/HW=1.0. Antenna 5 segmented (Figures 93B). $5^{\text {th }}$ segment longer than $4^{\text {th }}, 2^{\text {nd }}$ segment dark brown (Figure 93B). $3^{\text {rd }}$ segment $0.7 \mathrm{X}$ the $2^{\text {nd }}$ segment, LO small, AR=1.6. Premandible simple. Mandible with 1 short apical tooth and 4 inner teeth (Figure 93C). Mentum with 3 median teeth and 5 pairs of lateral teeth (Figure 93D), $1^{\text {st }}$ laterals slightly fused to $2^{\text {nd }}$ inner teeth (Figure 93D), median inner teeth sub-equal to slightly shorter than $2^{\text {nd }}$ medians. Claws of anterior parapods serrated (Figure 93E). Procercus reduced, each bearing 4 apical setae (Figures 93F-G). Posterior parapods longer than anal tubules, each bearing simple large claws (Figures 93F-G).

Notes. Larva is described by Hestenes \& Sæther (2000). Segment 3 of the antenna in this specimen is in lower range for the described larvae $(21.4 \mu \mathrm{m})$ and $2^{\text {nd }}$ antennal segment is slightly longer than the upper range for the described larva $(30.3 \mu \mathrm{m})$. However, characteristics of the mentum and AR matche the described larva of T. taurocapita.

Study sites. Pond Stream in Borden Peninsula, N72 ${ }^{\circ} 49.021^{\prime}$ W80 ${ }^{\circ}$ 28.497'.

Ecology and habitats. Larvae of this species occur in headwater streams (Hestenes \& Sæther, 2000).

Nearctic distribution. $1^{\text {st }}$ record for CANADA: Nunavut; USA: Michigan, North Carolina, and Ohio.

\section{Tvetenia Kieffer}

Generic diagnosis. Antenna 5 segmented, blade sub-equal to flagellum (Figures 95A, 97B), LO prominent. SI branched to plumose, SII and SIII simple. Premandible simple or with notch. Mandible with short apical tooth and 3 inner teeth. Mentum with 1 or 2 median teeth and 5 pairs of lateral teeth (Figures 95C, 96E), VmP narrow. Prominent body setae (Figure 95D). Procercus well-sclerotized, each bearing 5-8 apical setae. Anal tubules shorter than posterior parapods.

\section{Tvetenia bavarica (Goetghebuer)}

Pupa (n=2)

\section{Figures 94A-G}

Description. Frontal apotome (Figures 94A), frontal setae $\mathrm{L}=148$ $\mu \mathrm{m}$. Thoracic horn (Figure 94B), $\mathrm{L}=599.0 \mu \mathrm{m}, \mathrm{W}_{\text {base }}=66.2 \mu \mathrm{m}, \mathrm{L}_{\text {base }}=159.5$ $\mu \mathrm{m}, \mathrm{L}_{\mathrm{tip}}=433.1 \mu \mathrm{m}, \mathrm{L}_{\mathrm{tip}} \mathrm{L}_{\mathrm{base}}=1.4$. Pc1=133 $\mu \mathrm{m}, \mathrm{Pc} 2=136 \mu \mathrm{m}, \mathrm{Pc} 3=164$ $\mu \mathrm{m}$. Wing sheet with pearl row and spine-like structures (Figure 94C), wing sheet $\mathrm{L}=1358 \mu \mathrm{m}$. Tergite I with no spine, Tergite II with few hooked spines, tergite III-VIII with large hooked spines (Figure 94D). Sternite I-II with no spines, sternite III-VIII with large spines. Shagreens becoming more observable on basal segments. L1 $(\mathrm{L}=120.0$ $\mu \mathrm{m})$ and $\mathrm{L} 2(\mathrm{~L}=160.0 \mu \mathrm{m})$ longer and more prominent on segments IVII, segment VIII with L4 $(\mathrm{L}=186.0 \mu \mathrm{m})$ and $\mathrm{L} 5(\mathrm{~L}=91.0 \mu \mathrm{m})$ (Figure 94E). Anal lobes with 3 macrosetae of equal size, $L s=349 \mu \mathrm{m}$, and 2 median setae, $L s=271.0 \mu \mathrm{m}$. Genitalia sac longer than anal lobes in male and shorter in female (Figures 94F-G).

Notes. Thoracic horn and abdomen of pupae are described by Zav el (1939) and by Pankratova (1970).

\section{Tvetenia cf. bavarica (Goetghebuer) Larva $(n=2)$}

\section{Figures 95A-E}

Description. Head capsule yellow evenly, HL/HW=1.1. Antenna 5 segmented, $4^{\text {th }}$ segment $3.4 \mathrm{X}$ longer than $3^{\text {rd }}$ (Figure 95A), $2^{\text {nd }}$ segment $6.5 \mathrm{X} 3^{\text {rd }}$ segment, $\mathrm{AR}=1.3, \mathrm{RO}$ at the base of the $1^{\text {st }}$ segment. SI branched. Premandible simple. Mandible with 1 apical tooth and 3 inner 
teeth (Figure 95B), inner margin with spines (Figure 95B). Mentum with 2 median teeth and 5 pairs of lateral teeth (Figure 95C), VmP narrow. Body with scattered long setae (Figure 95D). Procercus longer than wide, each bearing 5 apical setae (Figure 95E). Posterior parapods longer than anal tubules each bearing groups of claws (Figure 95E).

Notes. Larva of T. bavarica is described by Epler (2001). The larvae described in this study were not associated with pupa, although they occurred in the same streams. Mentum, mandible and postoccipital margins (i.e. pale) of T. bavarica larva and Tvetenia paucunca (Sæther) larva are very similar; however, they can be separated based on the ratio of $4^{\text {th }}$ antennal segment to $3^{\text {rd }}$ segment. Larvae specimens resemble the description given for T. bavarica; however, this could not be verified. The A4/A3 is 3.4 which do not exactly match the description given by Epler (2001). Epler (2001) indicates that $4^{\text {th }}$ antennal segment is about 4-6X as long as $3^{\text {rd }}$ in T. bavarica which is based on the description given by Schmid (1993).

Study sites. Tributary of Arm River in Saglek, N58 $33.021^{\prime}$ W63 ${ }^{\circ}$ 28.102'; Torr Bay in Torngats Mountains National Park, N58 ${ }^{\circ} 27.944^{\prime}$ W62 ${ }^{\circ} 49.287$ '.

Ecology and habitats. Larvae of T. bavarica have temperature optima of $7.7 \pm 2.6^{\circ} \mathrm{C}$ (Rossaro, 1991b). Larvae of this species were reported in streams of piedmont plateaus (Hudson et al., 1990).

Nearctic distribution. $1^{\text {st }}$ record for CANADA: Labrador; USA: North Carolina and South Carolina.

Notes. Hudson et al. (1990) and Caldwell et al. (1997) have reported this species in North and South Carolina; however, Ashe \& 0'Connor (2012) have not reported this species in the Nearctic.

\section{Tvetenia discoloripes group \\ Larva $(n=2)$}

\section{Figures 96A-F}

Description. Larvae 4-6 mm. Head capsule yellow, postoccipital margin dark brown (Figure 96A), HL/HW=1. Antenna 5 segmented, $5^{\text {th }}$ segment sub-equal to $4^{\text {th }}$ segment, $4^{\text {th }}$ segment slightly longer than $3^{\text {rd }}$ (Figure 96B), L0 prominent, blade shorter than flagellum, AR=2.5. SI serrated. Premandible simple, Mandible with 1 apical tooth and 3 inner teeth (Figure 96C), inner ridge with small and sparse spines. Mentum with 2 median teeth, may be worn (Figure 96D), and 5 pairs of laterals (Figure 96E), VmP narrow. Body with scattered long setae. Procercus well-sclerotized, longer than wide, each bearing 8 apical setae and 2 sub-apical setae (Figure 96F). Posterior parapods longer than anal tubules, each bearing group of claws (Figure $96 \mathrm{~F}$ ).

Study sites. Burton River in Baffin Island, N63 ${ }^{\circ} 52.800^{\prime}$ W68 ${ }^{\circ}$ 18.894'; Unnamed creek near Iqaluit airport in Baffin Island, $\mathrm{N}^{\circ}{ }^{\circ}$ 75.086' W68 ${ }^{\circ} 53.172$ '.

Ecology and habitats. Larvae of species in this group inhabit a wide range of lotic and lentic habitats with preference for larger and warmer waters (Bode, 1983).

Nearctic distribution. CANADA: Nunavut.

\section{Tvetenia paucunca (Sæther)}

Larva $(n=2)$

\section{Figures 97A-E}

Description. Larva $\mathrm{L}=3 \mathrm{~mm}$. Head yellow with postoccipital margin light (Figure 97A) HL/HW=1.3. Antenna 5 segmented (Figure 97B), $4^{\text {th }}$ segment $2.5 \mathrm{X}$ the $3^{\text {rd }}$ segment. $A R=1.6$. Pecten epipharyngis with 3 small scales. SI branched. Mandible with 1 apical and 3 inner teeth (Figure 97C) inner margin with spines. Mentum with 2 median teeth and 5 pairs of laterals (Figure 97D). Body with scattered setae. Procercus well-sclerotized, longer than wide, each bearing 7 apical setae and 2 sub-apical setae (Figure 97E). Posterior parapods longer than anal tubules, each bearing group of claws.
Notes. Larva is described by Epler (2001) and by Sæther (1969).

Study sites. Burton River in Baffin Island, N63 ${ }^{\circ} 52.800^{\prime} \mathrm{W}_{68^{\circ}}$ 18.894'; Unnamed creek near Iqaluit airport in Baffin Island, N63 ${ }^{\circ}$ 75.086' W68 53.172 '.

Ecology and habitats. This species has an asynchronous life history with indistinguishable overlapping cohorts (Berg \& Hellenthal, 1991). The T. paucunca is common in mountain streams and coastal plains (Epler, 2001). Larvae of T. paucunca are reported as collectorgatherers and as tolerant of organic pollution (Fiorentino, 2005).

Nearctic distribution. CANADA: Alberta, Northwest Territories, $1^{\text {st }}$ record for Nunavut, Manitoba, Ontario, and Yukon Territory; USA: Georgia, Michigan, North Carolina, Ohio, and South Carolina.

Figure 97. Tvetenia paucunca (Sæther), larva (A-E). A Head; B Antenna; C Mandible; D Mentum; E Posterior portion of the larva.

\section{Zalutschia sp.}

Larva $(n=1)$

\section{Figures 98A-G}

Description. Larva $\mathrm{L}=4.8 \mathrm{~mm}$, Head yellowish brown (Figure 98A), $\mathrm{HL} / \mathrm{HW}=0.92$. Antenna 5 segmented, segments decrease in size sequentially (Figure 98B), blade longer than flagellum, LO prominent covering majority of the $3^{\text {rd }}$ segment, RO at the base of the $1^{\text {st }}$ segment, $\mathrm{AR}=1.8$. Pecten epipharyngis with 3 scale of equal size. SI coarsely serrated (Figure 98C), SII and SIII simple. Premandible bifid with large accessory tooth (Figure 98D). Maxilla with ALCh wider than other chaeta and lamellate, lamella of galea not serrated, pecten galearis present. Mandible with 1 apical tooth and 3 inner teeth, apical tooth and most of mandible lighter than inner teeth (Figure 97E), SSd is large, seta interna with 6-7 serrated branches. Mentum with wide bifid median tooth and 6 pairs of lateral teeth (Figure 98F), median tooth appears slightly lighter than lateral teeth, $1^{\text {st }}$ laterals shorter than other laterals and semi-attached to median tooth, VP narrow and long, cardinal beard with 7-8 setae (Figure 98F), SSm anterior to base of VP. Procercus longer than wide, each bearing 8 setae (Figure 98G). Anal tubules $2 \mathrm{X}$ the posterior parapods (Figure 98G). Posterior parapods with group of small simple claws.

Notes. Mentum and mandible of this larva resemble that of Zalutschia obsepta (Webb). However, antennal blade is longer in this larvae compared to $Z$. obsepta, $\mathrm{AR}=1.8$ compared to $\mathrm{AR}=1.56$ in $Z$. obsepta, and $\mathrm{SI}$ is coarsely serrated compared to finely plumose SI in $Z$. obsepta.

Study sites. Burton River in Baffin Island, N63 ${ }^{\circ} 52.800$ ' W68 ${ }^{\circ} 18.894$ '.

Ecology and habitat. Larvae of Zalutschia occur mainly in lakes; however, they may also occur in lotic environments. Known species usually have more northern distributions and prefer oligotrophic and dystrophic lakes (Sæther, 1976).

Nearctic distribution. CANADA: Nunavut.

\section{Orthocladiinae genus "Bilyj" \\ Larva $(n=3)$ \\ Figures 99A-H}

Description. Larva is small, $\mathrm{L}=1.9-2.0 \mathrm{~mm}$. Head capsule brown, $\mathrm{HL}=121.3 \mu \mathrm{m}, \mathrm{HL} / \mathrm{HW}=0.85$. Antenna 4 segmented, $2^{\text {nd }}$ segment longer than $1^{\text {st }}$ (Figures 99A-B), LO large covering $2 / 3^{\text {rd }}$ of the $3^{\text {rd }}$ segment, R0 at base of $1^{\text {st }}$ segment (Figure 99B), blade $=16.5 \mu \mathrm{m}$, blade slightly longer than flagellum, AR=0.40. SI appears bifid, SII-SIII simple. Pecten epipharyngis appears to have 3 small sclerites. Premandible bifid with large accessory tooth (Figure 98C). Maxilla with ALCh apparently lamellate and not serrated, pecten galearis appears absent. Mandible with 1 apical tooth and 3 inner teeth, $3^{\text {rd }}$ inner teeth appears lighter than the rest (Figure 99D), SSd small, seta interna absent. Mentum with 3 median and 6 pairs of lateral teeth (Figure 99E), SSm posterior to mentum (Figure 99E), VmP large and triangular. Anterior parapods 
with serrated claws (Figure 99F). Posterior parapods with group of simple setae (Figure 99G), 2X as long as anal tubules. Anal tubules cone shaped and rounded (Figure 99G). Procercus appears absent, 6 pairs of apical setae (Figures 99G-H).

Notes. We obtained 3 mounted specimens of this species and 3 preserved larvae from the collection. These larvae were identified and recognized as a possible new genus by Mr. Bohdan Bilyj during his contract with Environment Canada for IPY project. For his contribution to this study we named this unassociated larva after him. Morphological features that separates larva of this genus from other genera in Orthocladiinae are the combination of 4 segmented antenna, $1^{\text {st }}$ antennal segment being shorter than $2^{\text {nd }}$, lack of seta interna in mandibles, shape and number of teeth in mentum, shape of VmP, larvae lacking procercus and body setae. Larvae most probably represent a new genus (i.e., and species). It is hard to recognize characteristics of labrum, maxilla and pecten epipharyngis (See Table 2 for further diagnosis).

Study sites. Very River in Lake Hazen area, N81 ${ }^{\circ} 32.970^{\prime}$ W73 ${ }^{\circ}$ 35.046'; Tributary of Very River in Lake Hazen area, N81 ${ }^{\circ} 32.950^{\prime}$ 'W73 ${ }^{\circ}$ 35.757'; Ptarmigan Creek in Lake Hazen area, N81 ${ }^{\circ} 47.3839^{\prime}$ W71 ${ }^{\circ}$ 55.938'.

Nearctic distribution. CANADA: Nunavut.

\section{Subfamily Chironominae Micropsectra Kieffer}

Generic description. Antenna 5 segmented and on pedestals, pedestal bears spur or not, LO on long parallel-sided pedicels (Figure 100A, 101A). SI comb like, SII simple or serrated, SIII Simple. Premandible bifid with brush. Mandible with or without outer ridge hump, 1 dorsal tooth, 1 apical tooth and 3 inner teeth, SSd usually long, pecten mandibularis present. Mentum with 1 median tooth and 5 pairs of lateral teeth, median tooth can be trifid or simple or with notch, $\mathrm{VmP}$ long and elongate and close medially. Posterior parapods bears a group of dense claws in a horseshoe format (Figures 100F, 101E).

Notes. The 3 larvae described in this study are different from each other based on the following characters: presence of spur on antennal pedestals in Micropsectra sp. 1 and its absence on Micropsectra sp. 2 and Micropsectra sp. 3, number of teeth on scales of pecten epipharyngis (5, 4, 7 in Micropsectra sp. 1; 4, 4, 4 in Micropsectra sp. 2 and 6, 4, 6 in Micropsectra sp. 3), ratio of VmP W/ Mentum W (1.1 in Micropsectra sp. 1, 0.63 in Micropsectra sp. 2 and 2.5 in Micropsectra sp. 3), and number of claws on posterior parapods ( $\sim 50$ in Micropsectra sp. 1and 2, and >> 50 in Micropsectra sp. 3).

Ecology and habitat. Although many species of Micropsectra are cold stenothermic, larvae may occur in a wide range of lotic and lentic habitats (Epler et al., 2013).

\section{Micropsectra sp. 1}

Larva $(n=2)$

\section{Figures 100A-F}

Description. Larva $\mathrm{L}=4.1 \mathrm{~mm}$. Antenna 5 segmented, segments decrease in size sequentially (Figure 100A), Antenna pedestal with triangular spur ( $\mathrm{L}=17.2 \mu \mathrm{m}$, Figure $100 \mathrm{~A})$, pedicels of $\mathrm{LO} \mathrm{L}=86.0 \mu \mathrm{m}$, $\mathrm{AR}=1.7$. Clypeus $\mathrm{S} 3$ setae simple, $\mathrm{L}=57.3 \mu \mathrm{m}$. SI comb like, SII with serrations (Figure 100B). Labral lamella with 30 teeth (Figure 100B). Pecten epipharyngis with 3 scales and 5, 4, 7 teeth combination (Figure 100B). Premandible bifid. Mandible without outer hump (Figure 100C), 1 dorsal tooth,1apical tooth and 3 inner teeth, SSd long $(\mathrm{L}=44.0 \mu \mathrm{m})$ reaching the tip of apical tooth, pecten mandibularis with $\sim 15$ lamellae. Mentum with 1 trifid (worn) median tooth and 5 pair of lateral teeth, median tooth lighter in middle and brown in lateral edges $(\mathrm{W}=16.2$ $\mu \mathrm{m})$, lateral teeth all brown (Figure 100D), VmP W/Mentum $\mathrm{W}=1.1$. Procercus shorter than wide, each bearing 8 apical setae (Figure 100E). Posterior parapods not much longer than wide, each bearing horse shoe shape cluster of $\sim 52$ simple claws (Figures 100E-F). Ventral anal tubules longer than dorsal tubles (Figure 100E) $\mathrm{Ls}=131.4 \mu \mathrm{m}$ and $113.4 \mu \mathrm{m}$.

Study sites. Burton River in Baffin Island, N63 ${ }^{\circ} 52.800^{\prime} \mathrm{W}^{\circ} 8^{\circ}$ 18.894'.

Nearctic distribution. CANADA: Nunavut.

Notes. Larva is probably Micropsectra polita (Malloch) larva.

\section{Micropsectra sp. 2 \\ Larva $(n=1)$}

\section{Figures 101 A-F}

Description. Larva $\mathrm{L}=2.0 \mathrm{~mm}$. Antenna 5 segmented, segments decrease in size sequentially (Figure 101A), Antenna pedestal without spur, pedicels of $\mathrm{LO} \mathrm{L}=43.2 \mu \mathrm{m}, \mathrm{AR}=1.2$. Clypeus $\mathrm{S} 3$ setae simple, $\mathrm{L}=43.0 \mu \mathrm{m}$. SI comb like, SII with serrations (Figure 101B). Labral lamella with 28 teeth (Figure 101B). Pecten epipharyngis with 3 scales and 4, 4, 4 teeth combination. Premandible bifid with brush. Mandible without outer ridge hump (Figure 101C), 1 dorsal tooth, 1 apical tooth and 3 inner teeth, SSd long, reaching the tip of apical tooth, pecten mandibularis with $\sim 15$ lamellae. Mentum with 1 trifid median tooth and 5 pair of lateral teeth, median tooth lighter in middle and brown in lateral edges $(\mathrm{W}=10.3 \mu \mathrm{m})$, lateral teeth all brown (Figure 101D), VmP $\mathrm{W} /$ Mentum W=0.63, VmP (Figure 101D). Procercus shorter than wide, each bearing 8 apical setae. Ventral anal tubules same size as dorsal tubules (Figure 101E) Ls=54.8 $\mu \mathrm{m}$. Posterior parapods slightly shorter than wide, each bearing horse shoe shape cluster of $\sim 50$ simple claws (Figure 101F).

Study sites. North Lake River outlet in Resolute Bay, N74 44.867' W95 7.203 '.

Nearctic distribution. CANADA: Nunavut.

\section{Micropsectra sp. 3}

\section{Larva $(n=1)$}

\section{Figures 102A-F}

Description. Larva $\mathrm{L}=6.7 \mathrm{~mm}$. Antenna 5 segmented, segments decrease in size sequentially (Figure 102A), Antenna pedestal without spur (Figure 102B), pedicels of $\mathrm{LO} \mathrm{L}=68.0 \mu \mathrm{m}, \mathrm{AR}=2.1$. Clypeus $\mathrm{S} 3$ setae simple, $\mathrm{L}=67.0 \mu \mathrm{m}$. SI comb like, SII with serrations (Figure 102C). Labral lamella with 28 teeth (Figure 102C). Pecten epipharyngis with 3 scales and 6, 4, 6 teeth combination. Premandible bifid with brush. Mandible without outer hump (Figure 102D), 1 dorsal tooth, 1 apical tooth and 3 inner teeth, SSd long $(\mathrm{L}=70.0 \mu \mathrm{m})$ reaching the tip of apical tooth, pecten mandibularis with $\sim 15$ lamellae. Mentum with 1 trifid median tooth and 5 pair of lateral teeth (Figure 102E), median tooth lighter in middle and brown in lateral edges, median tooth $\mathrm{W}=25.0 \mu \mathrm{m}$, lateral teeth all brown (Figure 102E), VmP W/Mentum W=2.5. Procercus shorter than wide, each bearing 8 apical setae. Posterior parapods slightly shorter than wide, each bearing horse shoe shape cluster of $>50$ simple claws (Figure 102F). Anal tubules $\mathrm{Ls}=115.0 \mu \mathrm{m}$.

Study sites. North Lake River outlet in Resolute Bay, N74 $44.867^{\prime}$ W95 $7.203^{\prime}$.

\section{Nearctic distribution. CANADA: Nunavut.}

\section{Micropsectra polita (Malloch)}

Pharate female $(n=3)$

\section{Figures 103A-E}

Description. Antenna 5 segmented (Figure 103A). Shaft starts at $2^{\text {nd }}$ segment, Antennal segments L1-5=70.3 $\mu \mathrm{m}, 71.5 \mu \mathrm{m}, 71.6 \mu \mathrm{m}, 74.8 \mu \mathrm{m}$, $104.3 \mu \mathrm{m}, \mathrm{AR}=0.36$. Eyes bare, with parallel-sided dorsomedial extension (Fig 103A). Clypeus wider than long with 20 setae, cornea of ciboria pump turned and lobed shape (Figure 103B). Tentorium $(\mathrm{L}=111.1 \mu \mathrm{m})$. 
Palpomere 5 segmented, segments sequentially increase in size (L4$5=109.1 \mu \mathrm{m}, 112.4 \mu \mathrm{m}$, dorsocentrals in 2 rows each with 9 setae (Figure 103C), acrostichals present in single row $\sim 7$ setae. Scutellum white with single row of 6 setae (Figure 103C). Abdomen brownish with scattered long setae on segments I-VIII. Fore tibia without spur and comb, mid tibia without spur and a well-developed comb, hind leg with no spur and a well-developed comb, pseudo spurs present on tibias. GP VIII divided (Figure 103D), VIL and DmL (Figure 103D), Ce (Figure 103D), Ce $\mathrm{L}=71.7 \mu \mathrm{m}, \mathrm{Ce} \mathrm{W}=39.3 \mu \mathrm{m}$. Seminal capsules semicircular (Figure 103E), $\mathrm{L}=47.3 \mu \mathrm{m}$ and $\mathrm{W}=42.0 \mu \mathrm{m}$.

Legs lengths $(\mu \mathrm{m})$ and proportions:

\begin{tabular}{cccccccccccc} 
& $\mathbf{f e}$ & $\mathbf{t i}$ & $\mathbf{t a}_{\mathbf{1}}$ & $\mathbf{t a}_{\mathbf{2}}$ & $\mathbf{t a}_{\mathbf{3}}$ & $\mathbf{t a}_{\mathbf{4}}$ & $\mathbf{t a}_{\mathbf{5}}$ & $\mathbf{L R}$ & $\mathbf{B V}$ & $\mathbf{S V}$ & $\mathbf{B R}$ \\
\hline P1 & 815 & 1019 & 575 & 363 & 291 & 177 & 121 & 0.6 & 2.5 & 3.2 & - \\
P2 & 625 & 705 & 398 & 220 & 162 & 120 & 102 & 0.6 & 2.9 & 3.3 & - \\
P3 & 1030 & 964 & 619 & 386 & 333 & 188 & 141 & 0.6 & 2.5 & 3.2 & 3.0
\end{tabular}

Notes. All 3 pharate females were damaged and many morphological charcters were hard to distinguish. Tentorium and clypeus were turned in the specimens. The female is described by Oliver \& Dillon (1994).

\section{Pupae $(n=2)$}

\section{Figures 104A-F}

Description. Frontal setae $\mathrm{L}=79.3 \mu \mathrm{m}$ (Figure 104A). Thoracic horn (Figure 103B) $\mathrm{L}=373.0 \mu \mathrm{m}$. Wing sheet without pearl rows, $\mathrm{L}=997.0$ $\mu \mathrm{m}$. Tergite I with row of small recurved spines posteriorly (Figure 104C), tergite II with small simple spines anteriorly and 2 fringe of long parallel-sided spines posteromedially (Figure 104C-D), tergite III with 2 dark patches of small simple spines anteriorly and 2 fringe of long parallel-sided spines that start anteriorly and square off posteromedial (Figure 104D), tergite IV with 2 dark patches of small simple spines (Figure 104E). Segment II with $4 \mathrm{~L}$ setae, segment III with $3 \mathrm{~L}$ setae and 1 LS seta, segment IV with 1 L setae and 3 LS setae, segment V-VIII with 4 LS setae. Segment VIII with anal comb consisting of 6-7 spines (Figure 104F). Anal lobes with fringe of 25 lamelliform setae. Genitalia sacs almost reaching the tip of anal lobes in female (Figure 104F).

Notes. Pupa is described by Oliver \& Dillon (1994).

Study sites. Burton River in Baffin Island, N63 ${ }^{\circ} 52.800^{\prime}$ W68 ${ }^{\circ} 18.894$ '.

Ecology and habitats. Larvae of this species prefer cold low ordered streams with maximum summer temperature of $10-18^{\circ} \mathrm{C}$. Larvae also occur in slow seepage of slow flowing streams (Oliver \& Dillon, 1994).

Nearctic distribution. CANADA: Alberta, Saskatchewan, Quebec, Ontario, $1^{\text {st }}$ record for Nunavut; USA: Arizona, Illinois, Main, Maryland, New Mexico, Ohio, Oregon, Pennsylvania, and South Dakota.

\section{Paratanytarsus sp.}

Larva $(n=3)$

\section{Figures 105A-E}

Description. Larva $\mathrm{L}=3.9 \mathrm{~mm}$. Head capsule yellowish brown $\mathrm{HL} / \mathrm{HW}=1.2$. Antenna 5 segmented with segments decrease in size sequentially (Figures $105 \mathrm{~A}-\mathrm{B}$ ), LO on short pedicels ( $\mathrm{L}=5.8 \mu \mathrm{m}$; Figures $105 \mathrm{~B}), \mathrm{R} 0$ at the base of the $1^{\text {st }}$ segment, blade shorter than flagellum, $\mathrm{AR}=2.2$. SI comb shape, SII and SIII simple, SII long (Figure 105C). Labral lamella with 20 teeth (Figure 105C). Pecten epipharyngis with 3 scales of equal size (Figure 105C). Clypeus S3 simple $(\mathrm{L}=43.3 \mu \mathrm{m})$. Premandible bifid with prominent brush. Mandible with 1 dorsal, 1 apical tooth and 3 inner teeth, moderate hump on outer ridge, inner ridge with scattered spines, SSd long $(\mathrm{L}=49.3 \mu \mathrm{m})$ reaching the middle of apical tooth. Mentum with notched median tooth and 5 pairs of lateral teeth (Figure 105D), VmPs meet in the middle, VmP W/mentum $\mathrm{W}=0.87$. Procercus longer than wide, each bearing 7 apical setae and 2 short sub-apical setae (Figure 105E). Posterior parapods shorter than anal tubules, each bearing 20 simple claws. Anal tubules of same size and conical ( $\mathrm{L}=153.5 \mu \mathrm{m}$; Figure 105E).

Study sites. Burton River in Baffin Island, N63 $52.800^{\prime}$ W68 ${ }^{\circ} 8.894^{\prime}$.

Nearctic distribution. CANADA: Nunavut.

\section{Polypedilum (Uresipedilum) cf. flavum (Johannsen) \\ Larvae $(n=1)$}

\section{Figures 106A-E}

Description. Larva $\mathrm{L}=1.7 \mathrm{~mm}$. Antenna 5 segmented (Figure 106A), segment 2 1.3X segments 3-5, blade shorter than flagellum, $A R=1.0$. SI plumose, SII serrated at tip. Pecten epipharyngis with 3 scales and 4-5 teeth. Premandible trifid (Figure 106B) with brush. Mandible with 1 dorsal, 1 apical and 3 inner teeth, inner ridge with scattered spines (Figure 106C). Mentum with constricted bifid median tooth and 7 pairs of lateral teeth (Figure 106D), median teeth and $2^{\text {nd }}$ laterals stand higher than $1^{\text {st }}$ lateral teeth, VmP with posterior lobe (Figure 106D) VmP W /mentum $\mathrm{W}=0.87$. Procercus slightly wider than long, each bearing 6 anal and 2 sub-apical setae (Figure 106E). 4 Anal tubules of equal size ( $\mathrm{L}=36.0$ $\mu \mathrm{m})$, constricted at $1 / 3^{\text {rd }}$ from the base. Posterior parapods longer than anal tubules, each bearing group of simple claws (Figure 106E).

Notes. Larva of this species is described by Maschwitz \& Cook (2000). Larva described in this study is probably $3^{\text {rd }}$ instar.

Study sites. Tributary of Turnabout River in Lake Hazen area, N82 ${ }^{\circ}$ $1.647^{\prime}$ W68 $63.978^{\prime}$.

Ecology and habitats. Larvae of $P$. flavum occur on rock in riffle habitat of streams. Adults have bimodal emergence pattern in north temperate regions with first emergence occurring in the first two weeks of June and the second in mid-July. However, in Florida a year around emergence occurs (Harper \& Cloutier, 1979; Maschwitz \& Cook, 2000; Soponis \& Russell, 1982).

Note on the Nearctic distribution. Polypedilum (Uresipedilum) flavum (Johannsen) has not been reported in Nunavut. In Canada it has been reported in Ontario, Québec and Saskatchewan. In the USA it has been reported in Arizona, Illinois, Iowa, Kansas, Louisiana, Maryland, Massachusetts, Michigan, Minnesota, Nebraska, New York, Ohio, Pennsylvania, South Dakota, and Texas.

\section{Rheotanytarsus sp.}

Larva $(\mathrm{n}=4)$

\section{Figures 107A-F}

Description. Larva $\mathrm{L}=4.3 \mathrm{~mm}$. Head capsule yellow, $\mathrm{HL} / \mathrm{HW}=1.1$. Antenna 5 segmented, segments decrease sequentially (Figure 107A), $\mathrm{R} 0$ at the base of the $1^{\text {st }}$ segment, pedicels of $\mathrm{LO}$ short $(\mathrm{L}=9.6 \mu \mathrm{m})$. Blade shorter than flagellum, AR=2.3. SI comb like, SII-SII serrated at the tips (Figure 107B). Labral lamellae with $\sim 37$ teeth. Pecten epipharyngis with 3 scales and 5, 4, 7 teeth combination. Premandible bifid with prominent brush (Figure 107B). Mandible with 1 dorsal tooth, 1 apical tooth and 3 inner teeth, SSd long reaching the tip of apical tooth $(\mathrm{L}=54.8 \mu \mathrm{m})$, mandible base wide $(\mathrm{W}=67.1 \mu \mathrm{m})$, mandible $\mathrm{L} / \mathrm{W}=1.6$, inner margin with spines (Figure $107 \mathrm{C}$ ). Mentum with trifid median tooth and 5 pairs of lateral teeth (Figure 107D), median tooth $2.3 \mathrm{X}$ of the $1^{\text {st }}$ lateral teeth, $\mathrm{VmP}$ meet in the middle, VmP W/ mentum $\mathrm{W}=0.99$. Body segments I-IV with long setae, setae on segments sequentially decreasing in size and numbers (88.2 -177.0 $\mu \mathrm{m}$; Figure 107E). Posterior parapods shorter than anal tubules each bearing 14 simple claws (Figure 107F). Procercus longer than wide, each bearing 5 apical and 2 sub-apical setae. Anal tubules egg shaped and constricted at the base ( $\mathrm{L}=161.3 \mu \mathrm{m}$; Figure 107F).

Study sites. Nakvak River in Saglek, N58 $39.449^{\prime}$ W63 ${ }^{\circ} 35.944$ '; Unnamed stream in Iqaluit, Baffin Island, N63 ${ }^{\circ} 56.110^{\prime}$ W68 11.401 '.

Ecology and habitats. Larvae of Rheotanytarsus species occur in small to large rivers and the littoral zones of lakes. Rheotanytarsus' lar- 
vae use detritus to build cases with long arm-like extensions and attach these to rocks or macrophytes (Epler et al., 2013).

Nearctic distribution. CANADA: Nunavut, Labrador.

\section{Saetheria tylus (Townes) \\ Larva $(n=2)$}

\section{Figures 108A-E}

Description. Larva $\mathrm{L}=4.5 \mathrm{~mm}$. Antenna 6 segmented, $5^{\text {th }}$ longer than $4^{\text {th }}$, blade shorter than flagellum, R0 at the basal $1 / 4^{\text {th }}$ of the $1^{\text {st }}$ segment (Figure 108A), AR=1.3. SI-SIII simple (Figure 108B). Pecten epipharyngis with 3 equal scales. Premandible trifid (Figure 107B). Mandible with 1 long dark apical tooth and 2 lighter inner teeth (Figure 108C). Maxillary palp $\mathrm{L}=17.8 \mu \mathrm{m}, \mathrm{W}=11.5 \mu \mathrm{m}, \mathrm{L} / \mathrm{W}=1.5$. Mentum with 1 wide dome shaped median tooth and 6 pairs of lateral teeth (Figure 108D), median tooth $4 \mathrm{X}$ the $1^{\text {st }}$ lateral teeth, $\mathrm{VmP}$ squate and with about 15 full length striae (Figure 108D), VmP W/mentum W=0.90. Procercus wider than long, each bearing 6 long apical setae (Figure 108E). Posterior parapods shorter than anal tubules, each bearing group of simple claws (Figure 108E). Anal tubules of equal size $(\mathrm{L}=145.6 \mu \mathrm{m})$, ventral with constriction in the middle.

Notes. Larva is described by Jackson (1977). The ventromental plates of the 2 specimens examined are slightly larger than the description given by Jackson (1977); however, ratios are the same.

Study sites. Nakvak River in Saglek, N58 ${ }^{\circ} 39.449^{\prime}$ W63 ${ }^{\circ} 35.944^{\prime}$.

Ecology and habitats. Larvae of this species occur in sandy littoral zones of oligotrophic lakes and streams (Jackson, 1977).

Nearctic distribution. CANADA: Yukon Territory, $1^{\text {st }}$ record for Labrador, Northwest Territories; USA: Indiana, Kansas, North Carolina, South Carolina, Georgia.

\section{Stempellina sp.}

Larva $(n=1)$

\section{Figures 109A-J}

Description. Larva $\mathrm{L}=2.5 \mathrm{~mm}$. Head capsule with strong dorsal sculpturing (Figure 111A), S3 on moderately long pedestals $(\mathrm{L}=21 \mu \mathrm{m})$ and bifid (Figure 109B). Antenna pedestals with palmate processes (Figure 109C). SI comb like, SII on pedestals $(\mathrm{L}=13.9 \mu \mathrm{m})$ and long with serration at the tip (Figure 109D). Labral lamella well developed and acorn shaped with $\sim 25$ teeth (Figure 109D). Pecten epipharyngis with 3 small scales (Figure 109D). Premandible with 4 teeth, brush present. Mandible with 1 dorsal, 1 apical and 3 inner teeth, dorsal tooth and inner teeth lighter than apical tooth (Figure 109E), base wide and inner margin of the base with spine, mandible $\mathrm{L} / \mathrm{W}=1.5$, SSd large and long $(\mathrm{L}=55.0 \mu \mathrm{m})$ extending to the tip of dorsal tooth. Mentum with 1 wide median tooth and 6 pairs of lateral teeth (Figure 109F), median tooth and $1^{\text {st }}$ laterals lighter than other lateral teeth, VM separated by the combined width of median tooth and $1^{\text {st }}$ lateral teeth, VM W/ mentum W=0.75. Abdominal segment I with long lamellate setae, Ls=53.8 $\mu \mathrm{m}-115.6 \mu \mathrm{m}(77.3 \mu \mathrm{m}$; Figure 109G), segment II with simple lamellate setae, $L s=60.2 \mu \mathrm{m}-137.9$ $\mu \mathrm{m}(105.0 \mu \mathrm{m})$ and tuft of lamellate setae, $\mathrm{Ls}=39.4-119.5 \mu \mathrm{m}(80.3 \mu \mathrm{m})$, segment III with tuft of setae, $\mathrm{L}=42.8 \mu \mathrm{m}$ ) and simple setae, $\mathrm{L}=32.1 \mu \mathrm{m}$ Figure 109G). Posterior parapods not much longer than wide and shorter than dorsal anal tubules with 17 simple hooked claws (Figure 109H). Dorsal anal tubules longer than ventral tubules, $\mathrm{L}=78.1 \mu \mathrm{m}$ and $\mathrm{L}=53.7$ $\mu \mathrm{m}$ (Figure 109H). Procercus not well-sclerotized and long with few spurs at the base (Figure 109I), dark spots at the tip, each bearing 8 long apical setae and 2 sub-apical setae (Figure 109I). Portable case made of sand and grains of rocks (Figure 109J).

Notes. Antennae were missing in the specimen that was retrieved from the collection.

Study sites. Bay Brook in Torngats Mountains National Park, N58 27.944' W62 49.287'.
Ecology and habitats. Larvae of Stempellina construct long, curved, transportable cases of silt and sand. They occur in all freshwater habitats.

Nearctic distribution. CANADA: Labrador.

\section{Tanytarsus van der Wulp}

Generic diagnosis. Antenna 5 segmented, located on pedestal (Figure 110A), pedicels of LO long arising parallel from the base of antennal segment 2. SI comb like, SII simple or serrated on pedicels, SIII simple. Pecten epipharyngis with 3 toothed scales. Premandible with 3-5 teeth (Figure 110C), brush present. Mandible with 2-3 dorsal tooth and 1-2 additional teeth on dorsal surface, 1 apical, 2-3 inner teeth, SSd usually long. Mentum with median tooth rounded (Figure $110 \mathrm{E}$ ), notched or trifid (Figures 110B, 111C) and 5 pairs of laterals, VmP narrowly separated. Posterior parapods with simple hooked claws.

Ecology and habitat. Larvae of Tanytarsus species occur in a variety of freshwater habitats. Larvae usually construct long soft tube cases which they attach to substrates.

\section{Tanytarsus chinyensis group \\ Larva $(n=5)$}

Figures 110A-F

Description. Larva L=2.0 mm. Clypeus S3 simple. Antenna 5 segmented, segments sequentially decrease in size, blade shorter than flagellum (Figure 110A), R0 at the base of the $1^{\text {st }}$ segment, antennal pedestals with long conical spur $(\mathrm{L}=20.5 \mu \mathrm{m})$, pedicels of $\mathrm{LO} \mathrm{L}=106.8$ $\mu \mathrm{m}, \mathrm{LOR}=3.0$ (Figure 110B), $\mathrm{AR}=1.3$. SI comb shape, SII long and lamellate with serration at the tip located on pedicels, $\mathrm{L}=18.1 \mu \mathrm{m}$, SIII simple. Labral lamellae with $\sim 16$ teeth, Pecten epipharyngis with 3 scales and apparently 5, 4, 5 teeth combination. Premandible with 5 inner teeth and well-developed brush (Figure 110C). Mandible with no hump, 1 large and 1 very small dorsal tooth, 1 apical tooth and 3 inner teeth (Figure 110D), SSd reaching the middle of apical tooth $(\mathrm{L}=28.8$ $\mu \mathrm{m})$, Mandible $\mathrm{L} / \mathrm{W}=1.9$, inner ridge with small spines, pecten mandibularis with $\sim 15$ lamellae. Mentum with trifid median tooth (could be worn) and 5 pairs of lateral teeth (Figure 109E), median tooth 1.6X the $1^{\text {st }}$ laterals, mentum evenly yellow, VmPs about the size of $1^{\text {st }}$ lateral teeth separated from one another, VmP L/W=0.40, VmP W/ Mentum $\mathrm{W}=1.1$. Procercus well-sclerotized, each bearing 5 long apical setae (Figure 110F). Posterior parapods shorter than ventral anal tubules each bearing 9 simple hooked shaped claws (Figure 110F). Anal tubules long and slender, ventral anal tubules longer than dorsal tubules (Figure 110F), dorsal anal tubules $\mathrm{L}=68.5 \mu \mathrm{m}$ and ventral tubules $\mathrm{L}=76.0 \mu \mathrm{m}$.

Notes. According to Hofmann (1971) Tanytarsus larvae with long antennal spur belong to chinyensis group.

Study sites. Burton River in Baffin Island, N63 ${ }^{\circ} 52.800^{\prime}$ W68 ${ }^{\circ}$ 18.894'.

Nearctic distribution. CANADA: Nunavut.

\section{Tanytarsus sp. \\ Larva $(n=1)$ \\ Figures 111A-D}

Description. Larva L=2.4 mm. Antenna 5 segmented (Figure 111A), segments sequentially decrease in size, R0 at the base of the $1^{\text {st }}$ segment, pedicels of $\mathrm{LO} \mathrm{L}=112.0 \mu \mathrm{m}, \mathrm{LOR}=4.2, \mathrm{AR}=1.9$. SI comb shape, SII long and lamellate with no serration at the tip located on pedicels $(\mathrm{L}=12.0 \mu \mathrm{m})$, SIII simple. Labral lamellae well developed, Pecten epipharyngis with 3 scales. Premandible with apparently 5 inner teeth and well-developed brush. Mandible with no hump, 1 large and 1 very small dorsal tooth, 1 apical tooth and 3 inner teeth (Figure 111B), SSd reaching the middle of apical tooth $(\mathrm{L}=40.5 \mu \mathrm{m})$, Mandible $\mathrm{L} / \mathrm{W}=1.6$, 
inner ridge with small spines, pecten mandibularis with $\sim 20$ lamellae. Mentum with trifid median tooth and 5 pairs of lateral teeth (Figure $111 \mathrm{C})$, median tooth $1.5 \mathrm{X}$ the $1^{\text {st }}$ laterals, entire mentum brown with exception of median tooth which is lighter and yellow, VmPs about the size of $1^{\text {st }}$ lateral teeth separated from one another, VmP L/W=2.7, VmP $\mathrm{W} /$ mentum $\mathrm{W}=0.97$. Procercus well-sclerotized, each bearing 5 long apical setae (Figure 111D). Posterior parapods shorter than ventral anal tubules each bearing about 14 simple hooked shaped claws (Figure 111D). Ventral anal tubules longer than dorsal tubules, dorsal anal tubules $\mathrm{L}=36.6 \mu \mathrm{m}$ and ventral tubules $\mathrm{L}=67.7 \mu \mathrm{m}$.

Notes. Antennal blade is not discernible in this larval specimen. Pecten epipharyngis and premandible are also hard to detect.

Study sites. Unnamed stream in Baffin Island, N63 ${ }^{\circ} 46.315^{\prime}$ W68 ${ }^{\circ}$ 51.116

Nearctic distribution. CANADA: Nunavut.

\section{References}

ANDERSEN T., SÆTHER 0.A., CRANSTON P.S., EPLER J.H., 2013 - The larvae of Orthocladiinae (Diptera: Chironomidae) of the Holarctic Region-Keys and diagnoses. In: ANDERSEN T., CRANSTON PS., EPLER JH. (Eds.), Chironomidae of the Holarctic Region. Keys and diagnoses - Larvae. - Insects Syst. Evol. Suppl. 66: 189-385.

ASHE P., O'CONNOR J.P., 2009 - A World Catalogue of Chironomidae (Diptera). Part 1. Buchonomyiinae, Chilenomyiinae, Podonominae, Aphroteniinae, Tanypodinae, Usambaromyiinae, Diamesinae, Prodiamesinae and Telmatogetoninae. - Irish Biogeographical Society and National Museum of Ireland, Dublin.

ASHE P., O'CONNOR J.P., 2012 - A World Catalogue of Chironomidae (Diptera) Part 2 Orthocladiinae A and B. - Irish Biogeographical Society and National Museum of Ireland, Dublin.

BERG M.B., HELLENTHAL R.A., 1991 - Secondary production of Chironomidae (Diptera) in a north temperate stream. - Freshwater Biol. 25:497-505.

BODE R.W., 1983 - Larvae of North American Eukiefferiella and Tvetenia (Diptera: Chironomidae). - NY. State Mus. Bull. 452: 1-40.

BODE R.W., 1980 - Larvae and pupae of Eukiefferiella (Diptera: Chironomidae) found in New York State. - Cornel University.

BOLTON M., 2007 - Ohio EPA Supplemental Keys to the Larval Chironomidae (Diptera) of Ohio and Ohio Chironomidae Checklist. - Available from : http:/www.epa.ohio.gov/Portals/35/documents/Midge_Larvae_Key_nov2012.pdf Accessed: 4 April 2016.

BRUNDIN L., 1949 - Chironomiden und andere Bodentiere des südschwedischen Urgebirgsseen. Ein Beitrag zur Kenntnis der bodenfaunistischen Charakterzüg schwedischer oligotropher Seen. Rep. Inst. Freshwater Res. Drottningholm. 30:1-914.

BRUNDIN L., 1983 - Transantarctic relationship and their significance, as evidenced by chironomid midges. With a monograph of the subfamilies Podonominae and Aphroteniinae and austral Heptagyiae. K. Sven. Vetensk. Akad. Handl. 11:1-472.

BRYCE D., HOBART A., 1972 - The biology and identification of the larvae of Chironomidae. - Entomol. Gazzete. 23:175-217.

BUTLER M.G., 1982 - A 7-year life cycle for two Chironomus species in arctic Alaskan tundra ponds (Diptera: Chironomidae). - Can. J. Zoolog. 60:58-70.

BUTLER M.G., 1982 - Production dynamics of some arctic Chironomus larvae. - Limnol. Oceanogr. 27:728-36.

BUTLER M.G., 1980 - Emergence phenologies of some arctic Alaskan Chironomidae. In: MURRAY DA. (Ed.), Proc. $7^{\text {th }}$ Int. Symp. Chironomidae, Dublin, Ireland, August 1979. Chironomidae: Ecology, systematics, cytology, and physiology: 307-314.

BUTLER M.G., 2000 - Tanytarsus aquavolans, spec. nov. and Tanytarsus nearcticus, spec. nov., two surface-swarming midges from arctic tundra ponds (Insecta, Diptera, Chironomidae). - Spixiana 23:211-8.

CALDWELL B.A., HUDSON P.L., LENTA D.R., 1997 - A revised annotated checklist of the Chironomidae (Insecta: Diptera) of the Southeastern United States. - Trans. Am. Entomol. Soc.123:1-53.

CALDWELL B.A., 1996 - Two new Nearctic species of small Orthocladiinae (Diptera: Chironomidae) with notes on ecology. Hydrobiologia 328:1-7.

CALDWELL B.A., 1997 - The American Chaetocladius stamfordi (Johannsen), a synonym of $C$. piger (Goetghebuer) from the Palaearctic (Diptera: Chironomidae). - Aquat. Insect. 19:117-22.

CRANSTON P.S., 1982 - A key to the larvae of the British Orthocladiinae (Chironomidae). Freshwater Biological Association. - Scientific Publication No. 45:152 pp.

CRANSTON P.S., EPLER J.H., 2013 - The larvae of Tanypodinae (Diptera: Chironomidae) of the Holarctic Region-Keys and diagnoses. In: ANDERSEN T., CRANSTON P.S., EPLER J.H., (Eds.), Chironomidae of the Holarctic Region. Keys and diagnoses Larvae. - Insects Syst. Evol. Suppl. 66: 39-136.

DARBY R.E., 1962 - Midges associated with California rice fields, with special refernce to their ecology (Diptera: Chironomidae). Hilgardia 32:1-206.

DETTINGER-KLEMM PMA., 2000 - The metamorphosis of Orthocladius (Symposiocladius) holsatus Goetghebuer, 1937, with the description of Orthocladius (Symposiocladius) lunzensis n. sp. (Diptera: Chironomidae). - Aquat. Insects 23:45-62.

DITTMAR H., 1955- Ein Sauerlandbach. Untersuchungen aneinem Wiesen-Mittelgebirgesbach. - Arch. Hydrobiol. 50: 305-552.

DOUGHMAN J.S., 1983 - A guide to the larvae of the Nearctic Diamesinae (Diptera: Chironomidae). The genera Boreoheptagyia, Protanypus, Diamesa and Pseudokeifferiella. -US Geological Survey Water-Resources Investigations Report. 83-4006.

DRAKE C.M., 1982 - Seasonal dynamics of Chironomidae (Diptera) on the Bulrush Schoenoplectus lacustris in a chalk stream. Freshwater Biol. 12:225-40.

EDWARDS F.W., 1931 - XCII.-0xford University Greenland Expedition, 1928. Diptera Nematocera. - J. Nat. Hist. 8:617-8.

EDWARDS F.W., 1935 - Diptera, Nematocera from East Greenland. - J. Nat. Hist. 15:467-73.

EPLER J.H., EKREM T., CRANSTON P.S., 2013 - The larvae of Chironominae (Diptera: Chironomidae) of the Holarctic RegionKeys and Diagnosis. In: ANDERSEN T., CRANSTON P.S., EPLER J.H., (Eds.), Chironomidae of the Holarctic Region. Keys and diagnoses - Larvae. - Insects Syst. Evol. Suppl. 66: 387-556.

EPLER J.H., 2001 - Identification manual for the larval Chironomidae (Diptera) of North and South Carolina. A guide to the taxonomy of the midges of the southeastern United States including Florida. North Carolina Department of Environment and Natural Resources Division of Water Quality. $530+\mathrm{iv}$ pp.

FERRINGTON L.C., SÆTHER O.A., 2011 - A revision of the genera Pseudosmittia Edwards, 1932, Allocladius Kieffer 1913, and Hydrosmittia gen. n. (Diptera: Chironomidae, Orthocladiinae). Zootaxa 2849:1-314.

FERRINGTON L.C., 2008 - Global diversity of non-biting midges (Chironomidae; Insecta-Diptera) in freshwater. - Hydrobiologia 595:447-55.

FIORENTINO J.F., 2005 - Charles River Watershed 2002 Biological Assessment. - Massachusetts Department of Environmental Protection Division of Watershed Management, Massachusetts: 39 pp.

FU Y., SÆTHER 0.A., 2012 - Corynoneura Winnertz and Thienemanniella Kieffer from Nearctic Region (Diptera: Chironomidae: Orthocladiinae). - Zootaxa 3536:1-61.

GOETGHEBUER M., 1913 - Description de Chironomiden nouveux récoltés en Belgique. - Ann. Biol. Lacustre. 6:148-72. 
GOWIN F., THIENEMANN A., 1942 - Zwei neue Orthocladiinen-Arten aus Lunz (Niederdonau) Chironomiden aus dem Lunzer Seengebiet VII. - Zool Anz. 140:101-9.

HANSEN D.C., COOK E.F., 1976 - The systematics and morphology of the Nearctic species of Diamesa Meigen, 1835 (Diptera: Chironomidae). - Mem. Am. Entomol. Soc. 30: 203 pp.

HARPER P.P., CLOUTIER L., 1979 - Chironomini and Pseudochironomini of a Quebec highland stream (Diptera: Chironomidae). - Entomol. Scand. Suppl. 10:81-94.

HERSHEY A.E., 1985a - Effects of predatory sculpin on the chironomid communities in an arctic lake. - Ecology 66:1131-8.

HERSHEY A.E., 1985b - Littoral chironomid communities in an arctic Alaskan lake. - Ecography 8:39-48.

HESTENSE T.C., SÆTHER 0.A., 2000 - Three new Nearctic Thienemanniella Kieffer species with review of the Nearctic species. In: Hoffrichter 0., (Ed.), Anth. 13 $3^{\text {th }}$ Int. Symp. Chironomidae. Freiburg. 5-9 September 1997. Shaker Verlag GmbH, Germany Aachen, 2000: 103-27.

HEWIT C.G., 1922 - Report of Canadian Arctic expedition 1913-1918. FA Acland, King's printer.

HIRVENOJA M., 1973 - Revision der gattung Cricotopus van der Wulp und ihrer Verwandten (Diptera, Chironomidae). - Ann. Zoolog. Fenn. 10:1-363.

HOFMANN W., 1971 - Zür Taxonomie und Paläokologie subfossiler Chironomiden (Dipt.) in Sesedimenten. - Ergeb. Limnol. 6:1-50.

HUDSON P.L., LENAT D.R., CALDWELL B.A., SMITH D., 1990 Chironomidae of the Southeastern United States: A Checklist of Species and Notes on Biology, Distribution, and Habitat. Fish and wildlife service Ann Arbor Mi Great Lakes Fishery Lab. - FWS-RES7:53 pp.

HUMPHRIES C.F., FROST W.S., 1937 - River Liffey survey. The chironomid fauna of Submerged mosses. - P. Roy. Irish. Acad. B 43:161-81.

JACKSON G.A., 1977 - Nearctic and Palaearctic Paracladopelma Harnisch and Saetheria n. gen. (Dipetera: Chironomidae). - J. Fish. Res. Board Can. 34:1321-59.

KIEFFER J.J., 1926 - Chironomiden der $2^{\text {nd }}$. Fram-Expedition (18981902). - Nor. Entomol. - Tidsskr. 2:78-89.

KOWNACKA M., KOWNACKI A., 1942 - Parametriocnemus boreoalpinus Gowin et Thienemann 1942 (Tendipedidae, Diptera) nowy gatunek dla Tatr Parametriocnemus borealpinus Gowin et Thienemann 1942 (Tendipedidae, Diptera) new species for the Tatra Mts). - Acta Hydrobiol. 9:187-91.

KURECK A., 1966 - Schlüpfrhythmus von Diamesa arctica (Diptera Chironomidae) auf Spitzbergen. - 0ikos 17:276-7.

LANGTON P.H., 1980 - The genus Psectrocladius Kieffer (Diptera: Chironomidae) in Britain. - Entomol. Gazzete. 31:75-88.

LEHMAN J., 1971 - Die Chironomiden der Fulda. Sytematische, ökologische und faunistische Untersuchngen. - Arch. Hydrobiol. Suppl. 37:466-555.

LINDEGAARD-PETERSEN C., 1972 - An ecological investigation of Chironomidae (Diptera) from a Danish lowland stream (Linding A). - Arch. Hydrobiol. 69:465-507.

MAKARCHENKO E.A., MAKARCHENKO M.A., 2000 - Revision of Pagastia Oliver, 1959 (Diptera, Chironomidae) of the Holarctic region. In: Hoffrichter 0., (Ed.), Anth. $13^{\text {th }}$ Int. Symp. Chironomidae. Freiburg. 5-9 September 1997. Shaker Verlag GmbH, Germany Aachen, 2000: 171-176.

MAKARCHENKO E.A., 1985 - Chironomids of far eastern USSR of the subfamilies Podonominae, Diamesinae and Prodiamesinae (Diptera: Chironomidae. DVNC AN SSSR, Vladivostok. 200 pp.

MARZIALI L., ARMANINI D.G., CAZZOLA M., ERBA S., TOPPI E., ROSSARO B., 2010 - Responses of Chironomid larvae (Insecta, Diptera) to ecological quality in Mediterranean river mesohabitats (South Italy). - River Res. Appl. 26:1036-51.
MASCHWITZ D.E., COOK E.F., 2000 - Revision of the Nearctic species of the genus Ploypedillum Kieffer (Diptera: Chironomidae) in the subgenera $P$. (Polypedilum) Kieffer and $P$. (Uresipedilum) Oyewo and Sæther. XII(3)NS: 139 pp.

MOLLER PILLOT H.K.M., 1984 - De larven der Nederlandse Chironomidae (Diptera) (Orthocladiinae sensu lato). Nederlandse Faunistische Mededelingen 1B. Stichting European Survey, Leiden: $175 \mathrm{pp}$.

OLIVER D.R., DILLON M.E., CRANSTON P.S., 1990 - A catalogue of Nearctic Chironomidae. Research Branch Agriculture Canada: 98 pp.

OLIVER D.R., DILLON M.E., 1988 - Review of Cricotopus (Diptera: Chironomidae) of the Nearctic arctic zone with description of two new species. - Can. Entomol. 120:463-96.

OLIVER D.R., DILLON M.E., 1997 - Chironomids (Diptera: Chironomidae) of the Yukon Arctic North Slope and Herschel Island. In: DANKS H.V., DOWNES J.A., (Eds.). - Insects of the Yukon: 615-635.

OLIVER D.R., MCCLYMONT D., ROUSSEL M.E., 1978 - A key to some larvae of Chironomidae (Diptera) from the Mackenzie and Porcupine River watersheds. - Fisheries and Marine Services Technical Report. 791: 73 pp.

OLIVER D.R., 1964 - A limnological investigation of a large arctic lake, Nettilling Lake, Baffin Island. - Arctic 69-83.

OLIVER D.R., 1968 - Adaptations of arctic Chironomidae. - Ann. Zoolog. Fenn. 5:111-8.

OLIVER D.R., 1977 - Bicinctus-group of the genus Cricotopus Van der Wulp (Diptera: Chironomidae) in the Nearctic with a description of a new species. - J. Fish. Res Board Can. 34:98-104.

OLIVER D.R., 1981 - Description of Euryhapsis new genus including three new species (Diptera: Chironomidae). - Can. Entomol. 113: 711-22.

PANKRATOVA V.Y., 1979 - Larvae and pupae of midges of the subfamily Orthocladiinae of the USSR fauna (Diptera, Chironomidae= Tendipedidae). [Lichinki i kukolki komarov podsemeistva Orthocladiinae fauny CCCP (Diptera, Chironomidae= Tendipedidae)]. Opred. Faune SSSR 102: 343 pp.

REYNOLDSON, T.B., LOGAN C., PASCOE T., THOMPSON S.P., 2007 CABIN Canadian Aquatic Biomonitoring Network invertebrate biomonitoring field and laboratory manual. Canada National Water Research Institute, Environment Canada.

ROBACK S.S., 1976 - The Immature Chironomids of the Eastern United States II. Tanypodinae: Tanypodini. - Proc. Nat. Acad. Sci. Philadelphia 128: 55-88.

ROBACK S.S., 1980 - The immature chironomids of the Eastern United States IV. Tanypodinae-Procladiini. - Proc. Acad. Nat. Sci. Philadelphia 132:1-63.

ROBACK S.S., 1981 - The immature chironomids of the Eastern United States V. Pentaneurini-Thienemannimyia group. - Proc. Acad. Nat. Sci. Philadelphia 133:73-128.

ROSENBERG D.M., WIENS A.P., SÆTHER O.A., 1977a - Life histories of Cricotopus (Cricotopus) bicinctus and C. (C.) mackenziensis (Diptera: Chironomidae) in the Fort Simpson Area, Northwest Territories. - J. Fish. Res Board Can.34:247-53.

ROSENBERG D.M., WIENS A.P., S/THER O.A., 1977b - Responses to crude oil contamination by Cricotopus (Cricotopus) bicinctus and $C$. (C.) mackenziensis (Diptera: Chironomidae) in the Fort Simpson area, Northwest Territories. J. Fish. Res Board Can. 34:254-61.

ROSENBERG D.M., WIENS A.P., 1976 - Community and species responses of Chironomidae (Diptera) to contamination of fresh waters by crude oil and petroleum products, with special reference to the Trail River, Northwest Territories. - J. Fish. Res Board Can. 33:1955-63.

ROSSAR0 B., 1991a - Factors that determine Chironomidae species distribution in fresh waters. - B. Zoolog. 58:281-6. 
ROSSARO B., 1991b- Chironomids and water temperature. - Aquat. Insect 13:87-98.

ROSSAR0 B., 2006 - Chironomids from Southern Alpine running waters: ecology, biogeography. - Hydrobiologia 562:231-46.

ROSSARO B., LENCIONI V. 2015a - A key to larvae of species belonging to the genus Diamesa from Alps and Apennines (Italy). - Eur. J. Environ. Sci. 5: 62-79.

ROSSARO B., LENCIONI, V. 2015b - A key to larvae of Diamesa Meigen, 1835 (Diptera, Chironomidae), well known as adult males and pupae from Alps (Europe). - J. Entomol. Acarol. Res. 47:5516.

ROSSAR0 B., MONTAGNA M., LENCIONI V., 2016 - Environmental traits affect chironomid communities in glacial areas of the Southern Alps: evidence from a long-lasting case study. - Insect Conserv. Divers. doi: 10.1111/icad.12157.

SÆTHER 0.A., 1969 - Some Nearctic Podonominae, Diamesinae, and Orthocladiinae (Diptera: Chironomidae). - Bull. Fish. Res. Board Can. 170:1-154.

SÆTHER 0.A., 1975a - Nearctic and Palaearctic Heterotrissocladius (Diptera, Chironomidae). - Bull. Fish. Res. Board Can. 193:1-67.

SÆTHER 0.A., 1975b - Two new species of Heterotanytarsus Spärck, with keys to Nearctic and Palaearctic males and pupae of the genus (Diptera: Chironomidae). - J. Fish. Res Board Can. 32:259-70.

SÆTHER 0.A., 1976 - Revision of Hydrobaenus, Trissocladius, Zalutschia, Paratrissocladius, and some related genera (Diptera: Chironomidae). - Bull. Fish. Res. Board. Can. 195:1-287.

SÆTHER 0.A., 1977a - Female genitalia in Chironomidae and other Nematocera: morphology, phylogenies, keys.- Bull. Fish. Res. Board Can. 197: 1-209.

SÆTHER 0.A., 1977b - Taxonomic studies on Chironomidae: Nanocladius, Pseudochironomus, and the Harnischia complex.Bull. Fish. Res. Board Can. 196: 1-143.

SÆTHER O.A., 1980 - Glossary of chironomid morphology terminology (Chironomidae: Diptera). - Entomol. Scand. Supp. 14: 1-51.

SÆTHER 0.A., 1981 - Doncricotopus bicaudatus n.gen., n.sp. (Diptera: Chironomidae, Orthocladiinae) from Northwest Territories, Canada. - Entomol. Scand. 12:223-9.

SÆTHER O.A., 2005 - A new subgenus and new species of Orthocladius van der Wulp, with a phylogenetic evaluation of the validity of the subgenera of the genus (Diptera: Chironomidae). - Zootaxa 974:1-56.

SÆTHER O.A., ANDERSEN T., 2013 - The larvae of Podonominae (Diptera: Chironomidae) of the Holarctic Region-Keys and diagnoses. In: ANDERSEN T., CRANSTON P.S., EPLER J.H., (Eds.), Chironomidae of the Holarctic Region. Keys and diagnoses Larvae. - Insects Syst. Evol. Suppl. 66: 29-38.

SÆTHER 0.A., SUBLETTE J.E., WILASSEN E., 1984 - Chironomidae (Diptera) from the $2^{\text {nd }}$ Fram Expedition (1898-1902) to Arctic North America described by J.J. Kieffer. - Insect Syst. Evol. 15:249-75.

SÆTHER O.A., WANG X., 1995 - Revision of the genus
Paraphaenocladius Thienemann, 1924 of the World (Diptera: Chironomidae, Orthocladiinae). - Entomol. Scand. Suppl. 48:1-67.

SCHLEE D., 1968 - Vergleichende Mekmalsanalyse zur Morphologie und Phylogenis der Corynoneura-Gruppe (Diptera, Chironomidae) Zugleich eine Allgemeine Morphologie der Chironomiden-Imago . - Stuttg Beitr Zur Naturkunde. 180:1-150.

SCHMID P.E., 1993 - A key to the larval Chironomidae and their instars from Austrian Danube region streams and rivers with particular reference to a numerical taxonomic approach. Part I. Diamesinae, Prodiamesinae and Orthocladiinae. - Wasser Abwasser Suppl. 3:1-5141.

SERRA-TOSIO B., 1971 - Contribution a l'etude taxonomique phylogenetique, biogeograpfique et ecologique des Diamesini (Diptera, Chironomidae) d'Europe. These presente. l' Universite Scientifique et Medicale de Grenoble.

SOPONIS A.R., RUSSEL C.L., 1982 - Identification of instars and species in some larval Polypedilum (Polypedilum) (Diptera: Chironomidae). - Hydrobiologia 94:25-32.

SOPONIS A.R., 1977 - A revision of the Nearctic Species of Orthocladius (Orthocladius) Van der Wulp (Diptera: Chironomidae). - Mem. Entomol. Soc. Can. 102: 1-187.

SOPONIS A.R., 1990 - A revision of Holarctic species of Orthocladius (Euorthocladius) (Diptera: Chironomidae). - Spixiana Suppl. 13:1-56.

STEFFAN A.W., 1965 - Plecopteracoluthus downesi gen. et sp. nov.(Diptera: Chironomidae), a species whose larvae live phoretically on larvae of Plecoptera. - Can. Entomol. 97:1323-44.

SURBER E.W., 1959 - Cricotopus bicinctus, a midgefly resistant to electroplating wastes. - Trans. Amer. Fish. Soc. 88(2):111-6.

THIENEMANN A., 1954 - Chironomus Leben, Verbreitung und wirtschaftliche Bedeutung der Chironomiden. - Binnengewasser. 20:1-834.

THIENEMANN A., KRÜGER F., 1939 - Terrestrische Chironomiden II. Zool. Anz. 127:246-58.

WELCH, H.E., 1973 - Emergence of Chironomidae (Diptera) from Char Lake, Resolute Northwest Territories. - Can. J. Zoolog. 51:1113-23.

WELCH H.E., 1976 - Ecology of Chironomidae (Diptera) in a polar lake. - J. Fish. Board Can. 33:227-47.

WINNER R.W., BOESEL M.W., FARRELL M.P., 1980 - Insect community structure as an index of heavy-metal pollution in lotic ecosystems. - Can. J. Fish. Aquat. Sci. 37:647-55.

WÜLKER W., 1957- Über die Chironomiden der Parakiefferiella-Gruppe (Diptera: Tendipedidae, Orthocladiinae). - Beitr. Zur. Entomol. 7:411-29.

ZAV EL J., 1939 - Chironomidarum larvae et nymphae II. (Genus Eukiefferiella Th.). Morav P rodov decké Spol. XI:1-29.

ZVERVA 0.S., 1950 - Novye formy lichinok Tendipedidae (Diptera) iz rek Peckory i Vychegdy (New forms of Tendipedid larvae from the rivers Pechora and Vychegda). Entomol. Obozr. 31:262-84. 